NASA Technical Paper 3561

\title{
Managing Approach Plate Information Study (MAPLIST): An Information Requirements Analysis of Approach Chart Use
}

Wendell R. Ricks, Jon E. Jonsson, and John S. Barry 



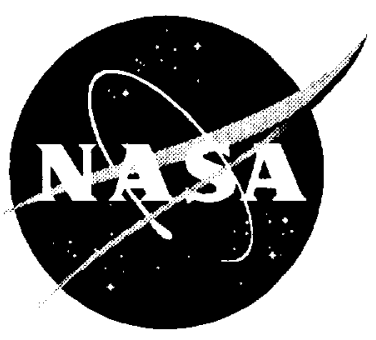

\section{Managing Approach Plate Information Study (MAPLIST): An Information Requirements Analysis of Approach Chart Use}

Wendell R. Ricks

Langley Research Center • Hampton, Virginia

Jon E. Jonsson

McDonnell Douglas Aerospace-West $\bullet$ Long Beach, California

John S. Barry

Lockheed Engineering \& Sciences Company • Hampton, Virginia 


\section{Acknowledgments}

Nichael Cramer, Carl Feehrer, and William Rogers, of Bolt Beranek and Newman, Inc., were instrumental in the development of the software and experiment design used in an exploratory study that was carried out as a precursor to the study described in this paper. Results from this preliminary study contributed to the design of the study described herein. Appreciation is also extended to Ted Thompson and others at Jeppesen Sanderson, Inc., for their advice and other inputs to the experiment reported herein.

Available electronically at the following URL address: http://techreports.larc.nasa.gov/ltrs/ltrs.html

Printed copies available from the following:

NASA Center for AeroSpace Information 800 Elkridge Landing Road

Linthicum Heights, MD 21090-2934

(301) 621-0390
National Technical Information Service (NTIS) 5285 Port Royal Road

Springfield, VA 22161-2171

(703) 487-4650 


\section{Contents}

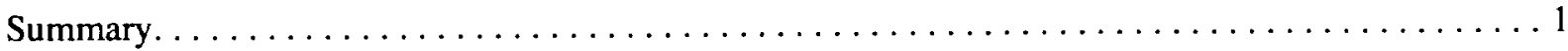

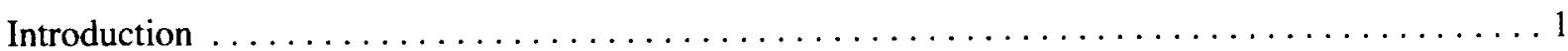

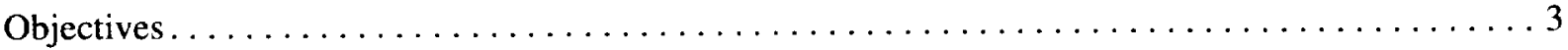

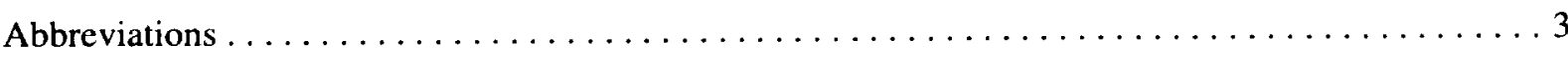

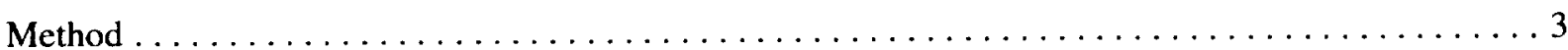

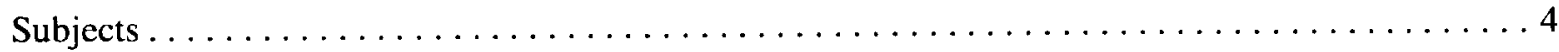

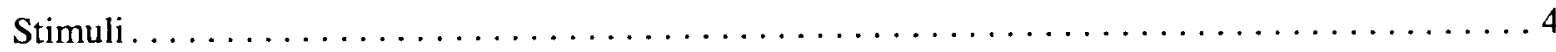

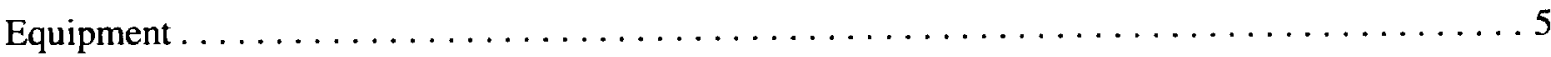

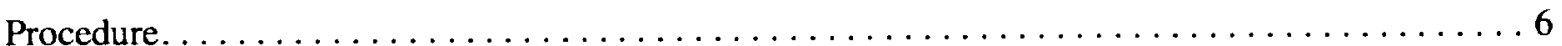

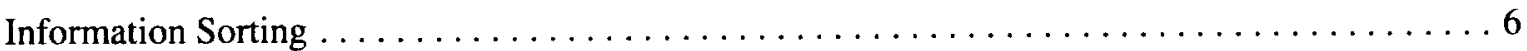

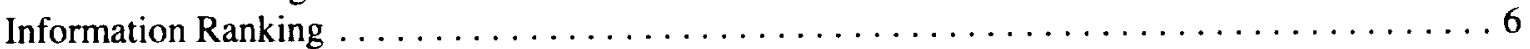

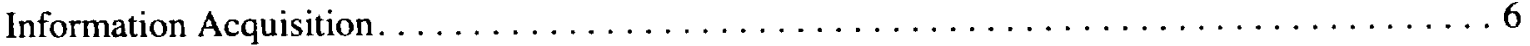

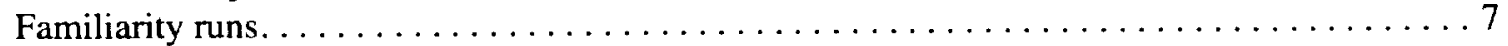

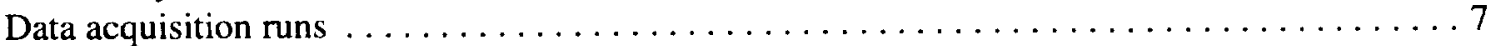

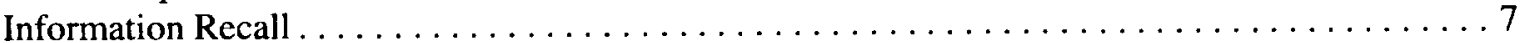

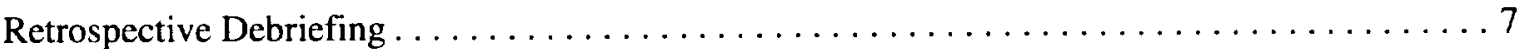

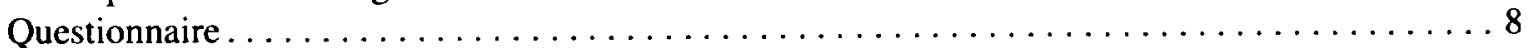

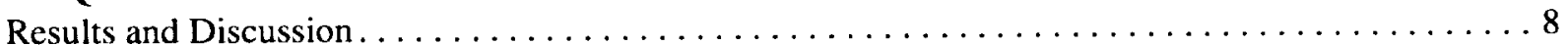

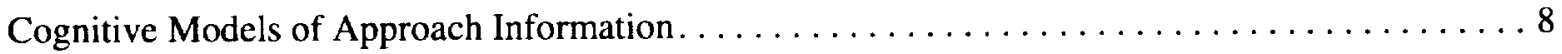

Similarity of Approach Chart Information Elements. $\ldots \ldots \ldots \ldots \ldots \ldots \ldots \ldots \ldots \ldots$

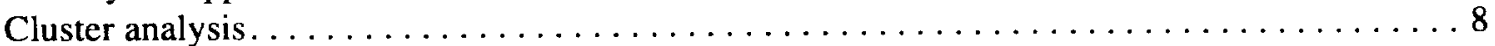

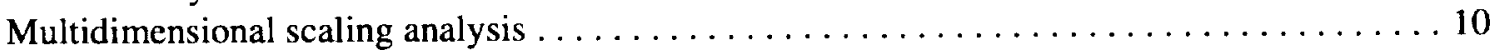

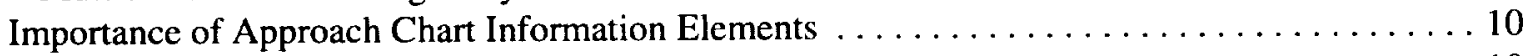

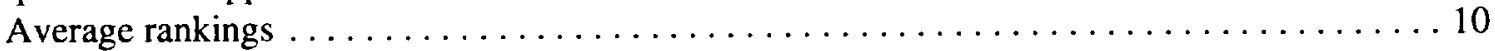

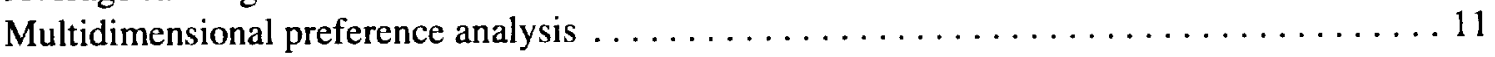

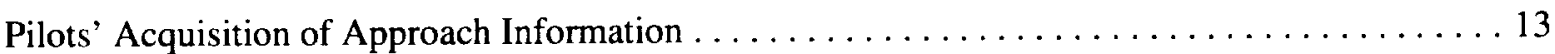

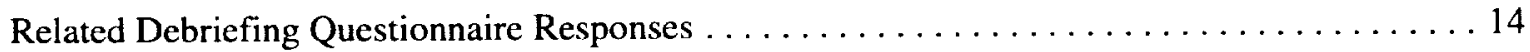

Descriptive Analyses . . . . . . . . . . . . . . . . . . . . . . . . . . . . 14

Effects of Independent Variables on Pilot Acquisition $\ldots \ldots \ldots \ldots \ldots \ldots \ldots \ldots \ldots \ldots \ldots \ldots \ldots \ldots$

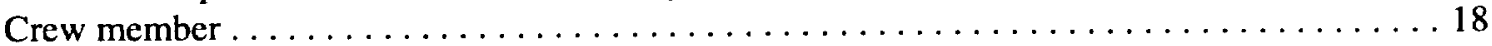

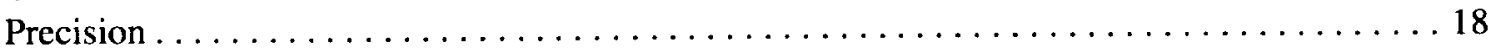

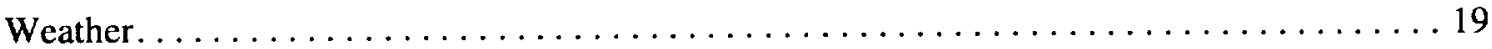

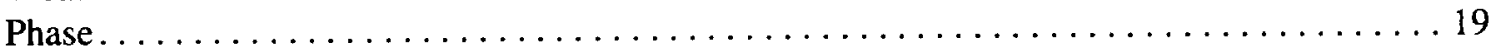

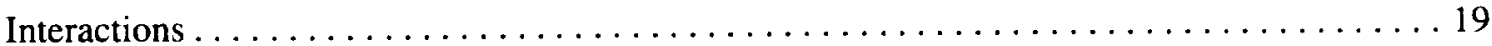

Relationship Between Pilots' Models and Acquisition of Approach Information . . . . . . . . . 19

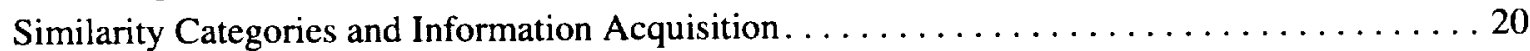

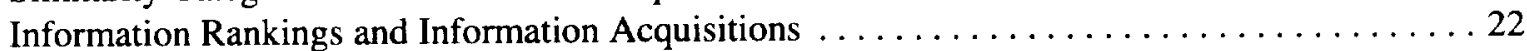

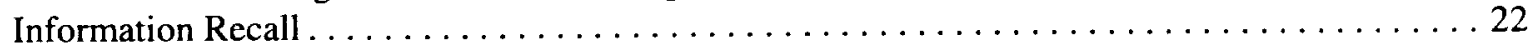

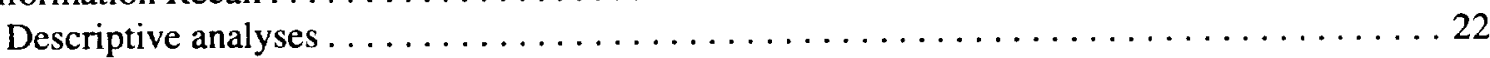

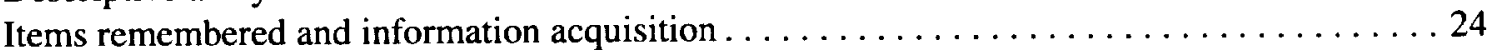

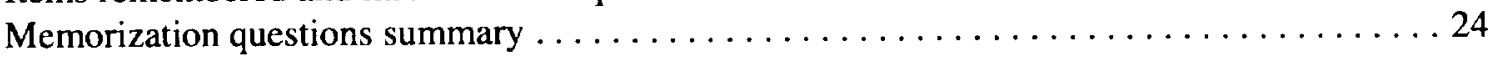

Information Requirements. . . . . . . . . . . . . . . . . . . . . . 24

Categories of Approach Chart Information and Information Requirements . . . . . . . . . 24

Importance of Approach Chart Information and Information Requirements . . . . . . . . . 25

Acquisition of Approach Chart Information and Information Requirements . . . . . . . . 25 


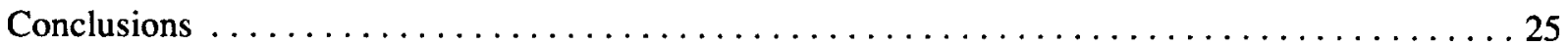

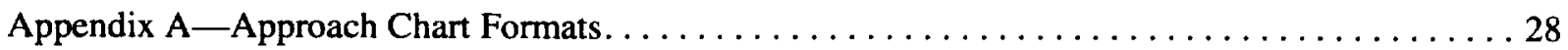

Appendix B-Preapproach and Approach Time Profiles and $z$ Scores . . . . . . . . . . . . 29

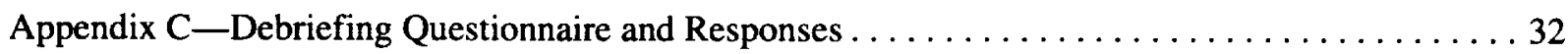

Appendix D-Analysis of Variance (ANOVA) Summary Tables $\ldots \ldots \ldots \ldots \ldots \ldots \ldots \ldots \ldots$

Appendix E-Means and Standard Deviations $\ldots \ldots \ldots \ldots \ldots \ldots \ldots \ldots \ldots \ldots \ldots \ldots \ldots$

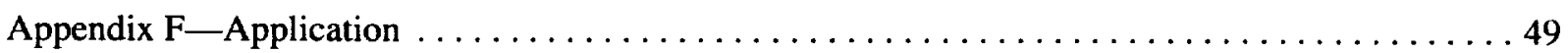

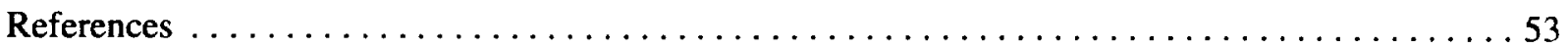

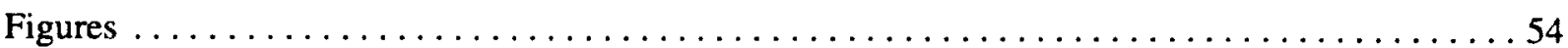




\section{Summary}

A pilot's ability to acquire approach information efficiently is tied closely to the safe, efficient execution of approach and landing procedures. Currently, most of the information that is needed for the preapproach and approach segments is presented on approach charts. The procedures and information requirements of the approach segments are arguably more complex than those that comprise the other flight phases, and being able to adequately present all necessary information presents a challenge for cartographers and flight deck system designers.

Many tasks associated with using approach charts are cognitive (e.g., planning the approach and monitoring its progress). Mental processes that are used to manipulate information in support of higher level cognitive tasks, such as categorization and prioritization, are integral to efficient execution of the higher level tasks. A successful system interface is one that conforms to the user's mental models. Matching the presentation formats of approach information with the mental processes used by the pilots to manipulate the information should improve the pilots' efficiency when they are executing the higher level cognitive tasks. A new methodology was developed for this study to provide designers with data that are necessary to make such design decisions. The methodology used in this study enhances traditional information requirements analyses by combining psychometric scaling techniques with a simulation task to provide quantifiable links between pilots' cognitive representations of approach information and their use of approach information.

The objectives of this study were to determine 1) how pilots categorize and prioritize approach information, 2) how pilots acquire approach information, and 3) the relationship between these cognitive models (i.e., categorization and prioritization) and how pilots use the information. The results indicated that pilots mentally organize approach chart information into 10 primary categories: Communications, Geography, Validation, $\mathrm{Ob}$ structions, Navigation, Missed Approach, Final Items, Other Runways, Visibility Requirement, and Navigation Aids. These similarity categories were found to underlie other mental models and many of the higher level cognitive processes used by pilots to accomplish their tasks. For instance, items within a given category were of similar importance in the average rankings provided by the pilots. Additionally, when pilots were tested on what approach information they could recall from their last approach, the category to which an information element belonged was found to be a good indication of whether or not the information would be remembered, independent of the number of items that comprised the category.

When pilots were flying approaches, acquisitions of information elements were found to be highly related to the categories to which the elements belonged. Certain categories of information were more likely to be selected than others, regardless of the number of items that comprised the category. In general pilots were more likely to select their next information element from the category they were already sampling, rather than change to a new category. Since it is reasonable to assume that pilots will select information that is functionally related to a task, these transition results provided added evidence that the identified categories contain similar information and insight into how the information might be tailored if presented electronically. An analysis of variance (ANOVA) that was conducted on acquisitions from these similarity categories found statistically significant main effects of crew member (pilot flying versus pilot not flying), precision (instrument landing system (ILS) versus very high frequency (VHF) omnidirectional range (VOR)), weather (good versus adverse), and flight phase (preapproach versus approach). Another finding was that the requirements (reflected by the acquisitions) changed as a function of approach segments. This finding suggests that the categories can be used to help define both the presentation formats (e.g., salience and repetition) and the tailoring of information (when presented electronically).

Results of this study augment previous information requirements analyses by identifying what information is acquired, when it is acquired, and which presentation concepts might facilitate its efficient use by better matching the pilots' cognitive model of the information. Since the similarity categories were salient in the pilots' use of approach charts, using these underlying categories of information in designing presentation formats may ease related pilot workload by not requiring the pilot to organize the information to the same extent prior to using it.

\section{Introduction}

An instrument approach chart provides information necessary to descend safely from an en route altitude on a feeder route (usually following a standard arrival procedure) to the landing altitude of a destination runway. The ability of a pilot to acquire approach information proficiently is tied closely to the safe, efficient execution of approach and landing procedures. Most of the 
information that is needed for the approach segments (transition, intermediate, final, and missed) ${ }^{1}$ is presented on the approach chart. The procedures and information requirements of these segments are arguably the most complex, and presenting all the needed information (e.g., frequencies, headings, and altitudes) on a $51 / 2$ in. $\times 81 / 2$ in. approach chart is challenging for the designer. There are currently two primary approach chart formats published today, one by Jeppesen Sanderson, Inc., and one by the National Oceanic and Atmospheric Administration (NOAA) National Ocean Service (NOS) (appendix A).

Both approach chart formats are products of years of evolutionary changes. Appropriate changes were made to the charts as new information and format requirements were identified. Many of these changes were either recommended by pilots or derived from information requirements analyses for the approach and landing phases of flight. Previous information requirements analyses examined information that is necessary for observable descent and landing tasks (Boeing 1991a, 1991b; Hansman and Mykityshyn 1990; Mykityshyn and Hansman 1990, 1991). They did not account explicitly for more unobservable cognitive tasks such as planning and monitoring or for the requirements of the cognitive processes that support these tasks. ${ }^{2}$ For example, how the pilots categorize and prioritize information are two salient cognitive processes (models) that support higher level cognitive tasks and are not explicitly addressed with traditional analyses (Jonsson and Ricks 1995). Such omissions in the design of presentation formats may limit pilot efficiencies since most of the tasks involved with using an approach chart are cognitive.

Cognitive processing refers to mentally representing, organizing, and manipulating information. These mental representations are often referred to as cognitive models. Such models of a person's environment serve several important functions, not the least of which is that they speed the user's rate of comprehension by allowing situations, objects, functions, and relationships to be classified by important or salient features (Cannon-Bowers, Tannenbaum, and Salas 1991). As stated previously,

\footnotetext{
1" A feeder or terminal route may be used to take you from the en route structure to an initial approach fix (IAF). Next, you follow an initial approach segment to an intermediate fix (IF). From here, you follow the intermediate segment to the final approach fix (FAF). The final approach segment ends at the runway, airport, or missed approach point (MAP). Upon reaching the MAP, if you are unable to continue the approach to a landing, you follow the missed approach segment back to the en route structure." (Jeppesen 1993)

${ }^{2}$ Previous studies applied analytical methods to investigate cognitive demands of approach chart use; therefore, they did not provide an empirical (i.e., explicit) connection.
}

these models are integral to the efficient execution of the cognitive tasks associated with approach chart management and are dominant in most tasks that involve information retrieval. For instance, among the information retrieval tasks pilots perform during the approach and landing phases of flight are those used to acquire information to build and validate their mental picture of the approach and landing.

Much of the literature in the area of cognitive models suggests that many performance advantages are realized when information is presented to the users in formats that conform to their cognitive models (Clay 1993). For example, collocating items that the user perceives as similar will improve access time and retention. The converse is also thought to be true: not matching the user's mental model of the information in a presentation format will decrease the efficiency of its use (e.g., adding to the time required to find items). Clay (1993) states that many of the errors associated with presentation formats are a result of discrepancies between the designers' model of the system and the users' mental model of the system.

There is an opportunity to enhance the presentation of approach information by examining the cognitive demands of approach chart use in conjunction with new design efforts. There are currently efforts underway to improve the presentation formats of information on approach charts and to establish more consistency between the two existing formats. There are also research efforts that explore formats for electronically presenting approach information on future flight decks. Given the efficiency advantages of matching the supply of information to the user's expectation, it would be beneficial for designers associated with presenting approach and landing information to design their formats to conform to the pilots' cognitive models.

As mentioned earlier, traditional information requirements analyses are limited because they do not account explicitly for cognitive demands and therefore do not supply the designer with information that is pertinent to the format decisions based on cognitive requirements. Most traditional analyses of the "task decomposition" variety are very good at identifying observable tasks (e.g., descent) while not accounting for cognitive tasks (e.g., planning). Given the advantages associated with matching the presentation of information to the user's mental model of the information, new techniques were developed for this study to enhance traditional information requirements analyses by supplying quantifiable links between the pilots' cognitive models of approach information and their methods of acquiring it.

The premise of the experimental method described in this paper is that traditional information requirements analyses could be enhanced greatly by combining the 
results obtained from psychometric tasks (explicitly designed to examine cognitive processing) with those obtained by using a nonintrusive technique that examines approach chart information acquisitions in a simulator environment. Psychometric scaling tasks are usually done in laboratory environments in which subjects manipulate information on the basis of its significance in the real environment. Scaling this type of data provides quantifiable descriptions of people's cognitive representations (e.g., similarity categories). The new techniques that were developed for this study combined these traditional laboratory tasks with a new domain-specific data acquisition technique in order to provide an empirical link between the cognitive models that result from the psychometric scaling and how the pilots use them.

Central to this experiment was this new domainspecific data acquisition tool that the pilots used when they were flying simulated approaches. The tool recorded what approach chart information the pilots acquired and when they acquired it. This objective was accomplished by providing the flight crew with approach chart information on computer screens that were driven by a program that requires them to acquire the information actively. Data that were obtained with this acquisition tool and the data from the psychometric scaling tasks provided quantifiable links between how the pilots cognitively model approach information and how and when they use it.

\section{Objectives}

There were three primary objectives of the research reported in this paper. The first was to identify how pilots categorize and prioritize approach chart information. The second objective was to determine how pilots acquire the information when they are flying instrument approaches. This objective prompted the design of a new acquisition technique which recorded data on the information that pilots acquired and when they acquired it during each phase of the approach. The third objective was to assess the relationship of the pilots' cognitive models and the manner in which the pilots acquire approach chart information. Issues associated with this objective were 1) determining the correlation between the pilots' categorization models and their acquisition methods, 2) assessing the relationship between the pilots' prioritization models and their acquisition patterns and frequencies, and 3 ) determining the relationship between their recall of information and acquisition practices.

\section{Abbreviations \\ AGL above ground level \\ ANOVA analysis of variance}

$\begin{array}{ll}\text { ATC } & \text { air traffic control } \\ \text { ATIS } & \text { Automatic Terminal Information Service } \\ \text { DC } & \text { Douglas Commercial } \\ \text { DFW } & \text { Dallas-Fort Worth } \\ \text { DME } & \text { distance measuring equipment } \\ \text { ELS } & \text { electronic library system } \\ \text { FAF } & \text { final approach fix } \\ \text { GS } & \text { glideslope } \\ \text { IAF } & \text { initial approach fix } \\ \text { IF } & \text { intermediate fix } \\ \text { ILS } & \text { instrument landing system } \\ \text { MAP } & \text { missed approach point } \\ \text { MAPLIST } & \text { managing approach plate information study } \\ \text { MDPREF } & \text { multidimensional preference } \\ \text { MDS } & \text { multidimensional scaling } \\ \text { MM } & \text { middle marker } \\ \text { MSA } & \text { minimum safe altitude } \\ \text { MSL } & \text { mean sea level } \\ \text { NASA } & \text { National Aeronautics and Space } \\ & \text { Administration } \\ \text { NAV } & \text { navigation display } \\ \text { NDB } & \text { nondirectional beacon } \\ \text { NOAA } & \text { National Oceanic and Atmospheric } \\ \text { NOS } & \text { Administration } \\ \text { ORD } & \text { National Ocean Service } \\ \text { PF } & \text { phicago-O'Hare } \\ \text { PCPREF } & \text { personal computer (multidimensional) } \\ \text { VHI } & \text { preference } \\ \text { PFD } & \text { primary flight display } \\ \text { PNF } & \text { pilot not flying } \\ \text { VDZE } & \text { touchdown zone elevation } \\ \text { very high frequency } \\ \text { VHF omnidirectional range } \\ \text { vertical speed indicator } \\ \text { VOR }\end{array}$

\section{Method}

The following sections describe an experiment entitled Managing Approach Plate Information Study (MAPLIST) that was conducted at Langley Research Center. As a precursor to the experiment that is reported in this paper, an exploratory study was conducted that concentrated primarily on the feasibility of the methodology. Results from this preliminary study were not 
published and will be referred to in this paper as the exploratory study. From findings in the exploratory study, MAPLIST was refined and formally conducted from September 1993 through January 1994 (including piloted checkout sessions). Each crew's testing required approximately $7 \mathrm{hr}$ and was completed in 1 day.

\section{Subjects}

Participants in this study were tested as members of a flight crew. For background training consistency, each flight crew came from the same airline and had a currently active captain and a first officer (i.e., no captains performed the role of first officer or vice versa). All participants were currently flying commercially. Data were collected from 13 DC-9 (aircraft restriction based on simulator used) flight crews who came from American Airlines, Express One International, and USAir. The average age of pilots participating in the study was 41 years. The youngest pilot was 29 and the oldest was 53. Average commercial flying time for each pilot was $8786 \mathrm{hr}$, with a minimum of $3500 \mathrm{hr}$ and a maximum of $20000 \mathrm{hr}$.

\section{Stimuli}

For the psychometric scaling tasks described below, pilots were required to work with the types of information contained on an approach chart. The information element types were compiled in a list (table 1) using the Jeppesen Sanderson, Inc., Instrument Rating Manual (Jeppesen 1993). Added to this list was some information pertaining to runway data (typically found on a separate chart with the Jeppesen format and on the same chart with the NOS format. (See appendix A.)

Included in table 1 are two element types that were inadvertently omitted from the psychometric scaling tasks: middle marker (MM) crossing altitude above ground level (AGL) and MM crossing altitude mean sea level (MSL). These two element types were not part of the list that was used to generate the stimuli but were present on the charts that were used during the simulation portion and are therefore included in table 1. Also included in table 1 are the numbers of corresponding approach chart items (of each type) that were used in this study. ${ }^{3}$

Approach charts were needed for the simulation portion of the experiment. From observations in the exploratory study, difficulty of the approach procedure only affected how often a subject acquired information. More

\footnotetext{
${ }^{3}$ Since the procedure turn was not part of any of the flight profiles used in this study, the procedure turn altitude depicted on the charts (in the profile section) was counted as a step-down altitude and explains the zero item account for procedure turn altitude in table 1 .
}

acquisitions were made during the preapproach segment and fewer were made in the flying segments of difficult approaches. Difficulty as a variable did not affect what information was acquired; therefore, it was decided not to vary the approach difficulty in the study that is reported in this paper.

Four separate approach charts were developed for use in the experimental conditions. To maintain the same level of approach difficulty across the four charts, each chart was a transformation of McCarren International in Las Vegas, Nevada, instrument landing system (ILS) $25 \mathrm{R}$ and VOR $25 \mathrm{~L} / \mathrm{R}$. (The McCarren International procedures chosen for this study were deemed neither difficult nor easy.) The chart transformations involved changes to all names (e.g., fix names and navigation aid names), frequencies, altitudes, and rotations to the basic geography of the airport. These transformations served to eliminate the possible impact of approach familiarization (e.g., memory) on the acquisition of information that might have occurred with the use of an existing chart or the same chart. The four approach charts used for data acquisition in this study can be seen in figures 1 through 4.

For this study, the approaches were divided into two major phases: preapproach and approach. Preapproach refers to the time preceding the flying portion of the experiment. During preapproach, the airplane was suspended on a feeder radial at top of descent (approximately 20000 feet AGL) 50 n.mi. from the initial approach fix (IAF). The approach phase was further divided into four segments: transition, intermediate, final, and missed. In this study transition refers to the segment starting at top of descent and ending at the IAF. Intermediate refers to the segment starting at the IAF and ending at the final approach fix (FAF). Final approach was the segment starting at the FAF and ending at the runway threshold or when initiating missed approach procedures. Missed approach refers to the period at which the missed approach procedures are first initiated.

The Jeppesen format is most representative of the charts used in this study. Given the task in which the pilots used these charts (described below), it was important that the subjects be familiar with where and how information was presented. Since all the major United States commercial airlines and 90 percent of all airlines worldwide use Jeppesen charts (Mykityshyn and Hansman 1991) and because the subjects were active airline pilots, this format best suited the study's objectives. As can be seen in figures 1 through 4, airport information was added to the bottom right corner (i.e., as in the NOS formats), which allowed the presentation of desired airport information without providing the pilots with additional charts. It is important to understand that this 
Table 1. Element Types and Number of Chart Items

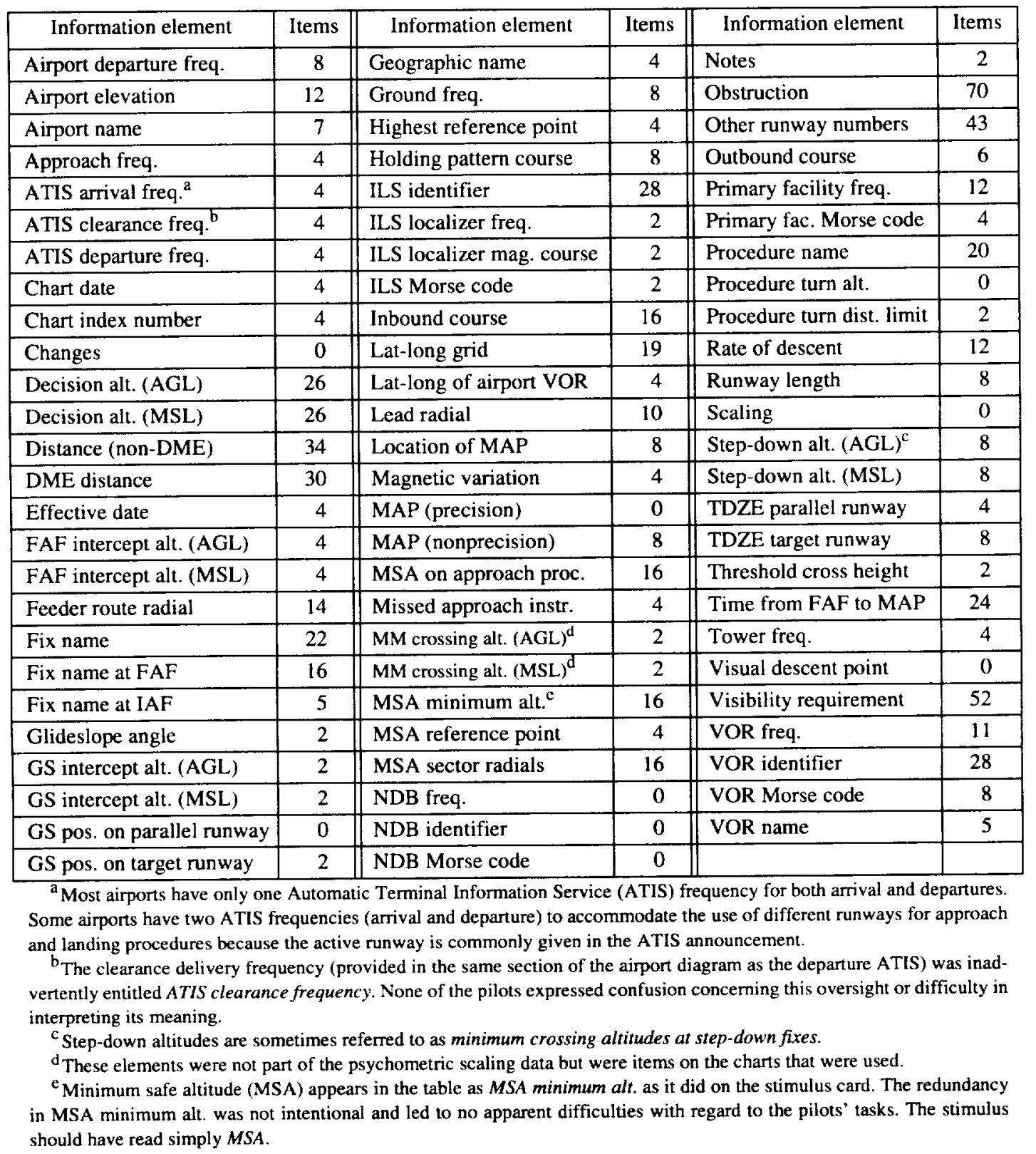

format is not a recommendation or an endorsement of any specific presentation format. This study was concerned exclusively with information requirements analyses, not with presentation concepts.

\section{Equipment}

For the information acquisition portion of the experiment, flight crews flew scenarios in the specially configured Langley DC-9 simulator. The Langley DC-9 simulator was a full workload, fixed-base, series-30 cockpit simulator. Two visual displays provided out-thewindow scenes for each crew member. Full workload studies were supported by this simulator since the capacity existed to simulate all aircraft instruments, annunciators, switches, and alarms. The autopilot was functional for this experiment, and subjects were encouraged to use it as they would when flying for their airline. The configuration of the Langley DC-9 simulator for this experiment can be seen in figure 5 .

Air traffic control (ATC) was simulated at a workstation in a room adjacent to the Langley DC-9 simulator. Three different ATC controllers (only one per session) fulfilled this responsibility. At the controller's station was a computer screen that indicated the aircraft's 
position on the current approach; instrument readings that indicated the altitude, airspeed, and distance from the runway threshold; and scripts for each scenario that indicated key aspects to ensure test consistency. Controllers also were able to view actions within the cockpit by monitoring the videotaping. The primary responsibility of the controllers was to maintain the time profile consistency of each flight crew by issuing realistic ATC instructions (e.g., speed reductions). Figure 6 shows the ATC station for MAPLIST.

The flight crews' computer interfaces to the acquisition task were located outside the simulator windows to the left of the captain and to the right of the first officer (fig. 5). The two computers operated independently, which means that computer interactions by one pilot were not apparent on the screen of the other pilot. For the acquisition task, a grayed-out (i.e., items made illegible) form of the approach chart required for the current scenario was generated on the screen (fig. 7). With the cursor control device, the pilot could point to and select an item by pressing on (i.e., clicking) the cursor control device button.

Once selected, an item would stay legible for $15 \mathrm{sec}-$ onds ${ }^{4}$ before returning to its illegible (i.e., grayed-out) state. An item could be selected as many times as desired, and more than one item could be made legible at one time by simply clicking on multiple items within 15 seconds of one another. Figure 8 shows a grayed-out chart and the same chart with some items selected.

Subjects were given access to each approach chart (on the acquisition device) prior to engaging in the flying portion of each scenario. During this preapproach phase, the pilots were given their initial position, heading, altitude, and ATIS information. Pilots were instructed to become familiar with the approach and the captain was to do a formal preapproach briefing. The captain was always the pilot flying (PF) and the first officer was the pilot not flying (PNF) for all data runs.

Recording of the information selected prior to the flying segment (referred to as preapproach in this study) was marked for differentiation from that selected during the flying portion to assist in post analysis. The information items selected and the time of selection were recorded separately for each pilot. In addition to the number of selections and elapsed time, segments of the approach (i.e., transition, intermediate, final, and missed)

\footnotetext{
${ }^{4}$ Fifteen seconds was a duration derived from feedback and observation during the exploratory study and the checkout portion of the study described in this paper. Fifteen seconds afforded enough time to gather the information and combine it with the presentation of other information and also required the pilots to acquire information explicitly again if they needed it later.
}

were marked in the data. As stated previously, a major function of ATC in this study was to give instructions to the crews that would help maintain consistent times within the flight segments between flight crews.

\section{Procedure}

As mentioned above, MAPLIST combined psychometric scaling tasks with a domain-specific information acquisition task in order to assess how pilots cognitively model approach chart information, how they acquire the information, and how the cognitive models relate to the acquisition of this information. Pilots were first required to complete a background questionnaire regarding their experience and age. They were then given a brief description of the study, their schedules for the day, and the tasks they would be performing. The tasks were completed in 1 day and are described below in the order in which they were administered.

\section{Information Sorting}

The first task that was accomplished by each subject was a card-sorting task. Subjects were given a deck of index cards, each containing 1 of the 75 information elements listed in table 1 . Note that the 75 elements do not include middle marker (MM) crossing altitude (AGL) or MM crossing altitude (MSL). Instructions were given to sort the elements into piles according to similarity. The subjects were instructed to build as many similarity piles of cards as they felt were necessary and were told that the number of cards in each pile could vary. No definition of similarity was supplied to the subjects. After the cards were sorted, the number of groups and the cards within each group were recorded.

\section{Information Ranking}

Following the similarity sorting, each subject was instructed to rank the same 75 information elements from 1 (most important) to 75 (least important) according to the pilot's perception of the information's importance. No context or definition of importance was given to the pilots. After the cards were ordered by the pilot, the positions were recorded. Immediately following this contextfree ranking, the subjects were then instructed to rank the importance of the elements when they were flying an approach where both visibility and cloud bottom are at minimums (called adverse weather condition). The positions of each card were again recorded.

\section{Information Acquisition}

Flight crews participated in an acquisition task which took place in the Langley full-workload DC-9 simulator (described previously). Each crew was given a briefing and training concerning the simulator, its 
equipment, and the acquisition task. Each crew's certification for the DC-9 airplane was current, which minimized the time required for simulator and cockpit equipment familiarization.

Familiarity runs. In order to make the pilots familiar with the simulator, the approach chart display, and the means for acquiring approach chart information, each crew was required to fly two preliminary approaches before starting the set of scheduled data runs. The two approaches used for practice were the same for each crew, and to avoid familiarity with specific approach information they were not used again during the data collection portion. Each approach was preceded with a preapproach phase in which the crew was given the initial position, heading, speed, altitude (always level flight at approximately $20000 \mathrm{ft}$ AGL), and ATIS information. Each approach phase was initiated by ATC instruction (a descend and maintain instruction). Flight crews were provided with paper and writing utensils for recording initial conditions and ATC instructions but were instructed not to record any of the information from the approach chart screen.

Data acquisition runs. To test differences in acquisitions under certain factors, three independent variables were chosen. The independent factors in the simulation portion of the experiment included 1) approach precision (very high frequency omnidirectional range (VOR) versus instrument landing system (ILS)), 2) weather (good versus adverse), ${ }^{5}$ and 3 ) flight phase (preapproach versus approach). The treatment combinations were counterbalanced to control for possible effects caused by order (table 2). As noted above, each crew consisted of a captain, who was always the PF, and a first officer, who was always the PNF. This design was analyzed by using a

\footnotetext{
${ }^{5}$ Good weather was defined as unrestricted visibility and a measured ceiling well above the decision altitude (approximately $2000 \mathrm{ft} \mathrm{AGL}$ ). Bad weather was defined as $3 / 4$ mile visibility (just legal) and a measured ceiling barely above the decision altitude.
}

mixed-model analysis of variance (ANOVA) with PF-PNF (termed crew member) as the between-subject variable, while precision, weather, and flight phase were the within-subject variables.

Again, the difficulty of the approaches was held constant, and to ensure that familiarity was not an issue, four approach charts (figs. 1 through 4) were created for this test design. The approach chart numbers correspond to the condition numbers (the numbers in parentheses) noted in table 2 .

As with the familiarity runs, each data run was preceded with ATIS information, aircraft location, and time for the pilots to become familiar with the approach and to do a preapproach briefing. The time required for each scenario (preapproach plus approach) was approximately $20 \mathrm{~min}$.

\section{Information Recall}

Immediately after completing all scheduled simulation runs, each pilot was given a grayed-out paper copy of the chart that was used during the last approach. The pilots were instructed to do this task individually and to write on the paper copy all the information (e.g., specific courses, altitudes, and frequencies) that they could recall, whether or not they were completely confident regarding its accuracy or completeness. To prevent their changing the manner in which they would have acquired the information (e.g., extra acquisitions to improve retention), pilots were given no advance knowledge that they would be given a memory test.

\section{Retrospective Debriefing}

After the information recall test, each crew participated in a debriefing session. During the debriefing, audio recordings were made of the pilots' explanations for each information item that was selected during their last flights. Crews were questioned together for this task,

Table 2. Simulation Test Design

\begin{tabular}{|c|c|c|c|c|}
\hline Crew condition & Flown first & Flown second & Flown third & Flown fourth \\
\hline $\begin{array}{l}\text { Crew 1, Crew 5, } \\
\text { Crew } 9\end{array}$ & $\begin{array}{l}\text { (1) Nonprecision } \\
\text { adverse weather }\end{array}$ & $\begin{array}{l}\text { (2) Nonprecision } \\
\text { good weather }\end{array}$ & $\begin{array}{l}\text { (3) Precision } \\
\text { adverse weather }\end{array}$ & $\begin{array}{l}\text { (4) Precision } \\
\text { good weather }\end{array}$ \\
\hline $\begin{array}{l}\text { Crew 2, Crew 6, } \\
\text { Crew } 10 \text { and } 10 b^{*}\end{array}$ & $\begin{array}{l}\text { (2) Nonprecision } \\
\text { good weather }\end{array}$ & $\begin{array}{l}\text { (3) Precision } \\
\text { adverse weather }\end{array}$ & $\begin{array}{l}\text { (4) Precision } \\
\text { good weather }\end{array}$ & $\begin{array}{l}\text { (1) Nonprecision } \\
\text { adverse weather }\end{array}$ \\
\hline $\begin{array}{l}\text { Crew 3, Crew 7, } \\
\text { Crew } 11\end{array}$ & $\begin{array}{l}\text { (3) Precision } \\
\text { adverse weather }\end{array}$ & $\begin{array}{l}\text { (4) Precision } \\
\text { good weather }\end{array}$ & $\begin{array}{l}\text { (1) Nonprecision } \\
\text { adverse weather }\end{array}$ & $\begin{array}{l}\text { (2) Nonprecision } \\
\text { good weather }\end{array}$ \\
\hline $\begin{array}{l}\text { Crew 4, Crew 8, } \\
\text { Crew } 12\end{array}$ & $\begin{array}{l}\text { (4) Precision } \\
\text { good weather }\end{array}$ & $\begin{array}{l}\text { (1) Nonprecision } \\
\text { adverse weather }\end{array}$ & $\begin{array}{l}\text { (2) Nonprecision } \\
\text { good weather }\end{array}$ & $\begin{array}{l}\text { (3) Precision } \\
\text { adverse weather }\end{array}$ \\
\hline
\end{tabular}


but the pilots were afforded the opportunity to explain their individual acquisitions. To assist in this reenactment, a paper version of the approach chart and the listing of selected items were used by the experimenter to guide the pilots through the selections they had made. During this exchange pilots were encouraged to elaborate on why they had selected each piece of information.

\section{Questionnaire}

Subjects completed their day of testing by answering a five-part questionnaire. Questions pertained to the simulator's fidelity, use of the acquisition device, approach chart adequacy, strategies when using the information acquisition task, and the experimental conditions.

\section{Results and Discussion}

As stated previously, the objectives of this research were threefold. This section has been organized first by the research objectives and then by the analyses performed in support of them. The first section addresses the cognitive models that pilots have of approach chart information. The second section addresses the pilots' acquisition of information when they are flying instrument approaches. ${ }^{6}$ The third section addresses the last objective: the relationship between the pilots' cognitive models and the way they acquire the information. The final section discusses possible implications of these results on the pilots' information requirements of approach chart use.

\section{Cognitive Models of Approach Information}

Knowing how pilots categorize and prioritize approach information should provide key knowledge for the designers of presentation concepts. Having information presented to people in a way that matches their mental model has been shown to improve the efficiency of their task performance (Clay 1993). The analyses and results described in this first section address two of the more salient cognitive models of approach chart information that pilots have: categorization and prioritization. The data used for these analyses were obtained from the similarity sorting and ranking tests described previously.

\footnotetext{
${ }^{6}$ Crew 10 simulation data were eliminated from the analyses described in the "Results" section because of a procedural error that occurred when scenario 2 was being flown. Another crew, labeled Crew $10 \mathrm{~b}$, was added to replace Crew 10 simulation data. Eliminating Crew 10 data for scenario 2 was based on an unacceptable $z$ score for the total flight time of that scenario. Please refer to the tables in appendix B for time profiles and $z$ scores of all the simulation test runs. Psychometric scaling data were retained from all 26 subjects since the flying portion did not affect these data.
}

\section{Similarity of Approach Chart Information Elements}

Each of the 26 pilots sorted the approach information elements (into piles) based on their similarity. From these sortings, a single $75 \times 75$ matrix (i.e., the proximity matrix) was constructed where the columns and rows corresponded to the stimuli, and the number in each cell corresponded to how many pilots put the two stimuli in the same pile. This matrix was then used in a cluster analysis and in a multidimensional scaling analysis.

Cluster analysis. Recent developments in cognitive research have demonstrated the usefulness of psychometric techniques in representing human knowledge and information processing (Ashby 1992; Nosofsky 1984, 1986; summarized in Nosofsky 1992). One such method, cluster analysis, identifies items that are closely associated with one another, groups them, and provides a hierarchical representation of the stimuli, thereby allowing the investigator to examine the representation for obvious or intuitive categories. Clusters of information tell researchers how pilots define category membership.

A cluster analysis was done on the similarity data with SYSTAT (see Wilkinson, Hill, and Vang 1992) using the average linkage method. The number of clusters selected for interpretation was determined by the clustering solution that exhibited the highest level of stability across the widest range of the Euclidean distance metric (Romesburg 1984). In other words, the cut was made at a point at which moving it within a wide range did not affect the number of clusters.

Three evaluators independently examined the clustering solution for the point (i.e., cut position) where the number of clusters was constant for the greatest distance. There was unanimous agreement that the cut could be made at either the 7- or 10-cluster level. Qualitatively, the evaluators felt that the 10-cluster solution would yield a better interpretation, and it was selected. Figure 9 shows the clustering dendogram and the resulting stability cut.

Since the subjects were instructed to sort the information by how they viewed the information's similarity, the resulting clusters can be thought of as representing the pilots' cognitive categories. These mental classifications of information are used by individuals to reduce the amount of information with which they work (Woods 1985). ${ }^{7}$ Instead of dealing with each item of information

\footnotetext{
${ }^{7}$ As summarized in Clay (1993), page 40, Woods (1985) suggests that information should be organized based on high-level units and that task-meaningful units should be identified for organization. In addition, information that must be processed together should be grouped together.
} 
on the approach chart as an independent element, the pilots can categorize (organize by similarity clusters) the information, manage it through these categories, and then call on the individual item when it is needed. Pilots are then able to work comfortably with the approach chart without being overwhelmed by the amount of information it contains.

Results of the cluster analysis showed that the pilots use 10 primary categories to organize and manage approach chart information. The 10 clusters that emerged (numbered from top to bottom in fig. 9) are shown in figure 10 and have been labeled with category interpretations. Neither the order of the clusters nor the order of elements within clusters has any significance in this figure.

The first cluster includes the ATIS and other frequencies that are used for verbal communications. Consequently, this category has been labeled Communications. While many frequencies exist on the approach chart, only those in this category pertain to radios that are used for verbal communications. It is probably for this reason that pilots mentally separate the frequencies by the higher level tasks they support. As stated above, by categorizing the information, pilots should be able to determine that information is of a certain type (e.g., Communications) without individually addressing each element that comprises the category. Many decisions then can be made based solely on the category, thus lessening the overall task workload. When the occasion arises, pilots are able to access specific information from the categories efficiently.

The second cluster shown in the figure contains elements pertaining to geographic positions and has been labeled Geography. Elements in this cluster pertain to the physical layout of the terrain surrounding the airport and runway. Members of this category were the latitudelongitude grid for the approach chart, the depiction of the airport VOR's latitude-longitude, the magnetic variation, and the map scaling. Major geographic elements (e.g., contour lines) on the chart were not manipulated (i.e., used as stimuli or grayed on the approach chart) in this experiment; however, given this interpretation, they would be members of this cognitive category since they provide the general map of the surrounding terrain.

The next cluster contains elements such as airport name and chart date, which appear to represent elements used in chart Validation. These items are used to assure the pilots that the chart is the correct one, that it is currently valid, and that both pilots are on the same page. An exception to this interpretation might be airport elevation. However, its membership in this cluster may be because many of the crews were from American Airlines, who by using the conversion factor given to them by dispatch to make one altimeter read zero at the airport elevation, subsequently use airport elevation for validation.

The fourth cluster has been labeled Obstructions since all elements in this cluster present either minimum safe altitudes or altitudes of obstructions. Members of this cluster were the highest reference point, minimum safe altitude (MSA) on approach procedure, MSA minimum altitude, MSA reference point, MSA sector radials, and obstructions. These element types differ from other altitude references on the chart (e.g., step-down altitude) by the task they support. Altitudes in the Obstructions category are lower limits (not to be met), whereas the other altitudes on the approach chart are target altitudes.

The fifth and largest cluster contains the primary elements that are used for planning and monitoring the approach descent and direction. While the other elements on the chart can be considered reference information, members of this cluster are the ones used for planning and monitoring the general task of navigation (both horizontal and profile). Large clusters are the most difficult to interpret. Since nine of the elements pertain to those found strictly in the profile section of the chart (vertical navigation) and seven are used for both profile and horizontal navigation, the tendency would be to give this category a name that captures only the profile theme. However, when lower level clustering was studied, it was obvious that the elements pertaining to the horizontal navigation were not arbitrarily being grouped with this information and should not be lost in the interpretation. A subsequent look at the elements making up this cluster led to the more general interpretation of Navigation. While the overall purpose of the approach chart is to provide navigation information, this cluster was most representative of that function. It would have been more convenient had the vertical and horizontal elements remained separate (as they were at lower level clusterings) where the cut was made; however, the elements were grouped at this level because the pilots deemed them more similar to one another than to members of the other clusters. Perhaps this similarity exists because these elements are the primary ones used for planning the approach and monitoring its progress.

The next cluster, labeled Missed Approach, contains elements that are of interest when pilots are executing a missed approach. Members of this cluster were holding-pattern course, location of missed approach point (MAP), MAP (nonprecision), MAP (precision), missed-approach instruction, and time from FAF to MAP.

The seventh cluster contains Final Items that the pilots use or reference, such as the glideslope (GS) angle, rate of descent, threshold crossing height, and the 
touchdown zone elevation (TDZE) of the target runway. Unlike items in the Navigation cluster that are used during the final segment, members of Final Items are used for reference instead of for planning and monitoring.

While the information in cluster 7 deals with final items for the target runway, cluster 8 pertains to final items for other runways and has been labeled Other Runways. With the exception of runway length, these items probably emerged as a separate cluster for the pilots because they do not pertain to their approach. Including runway length in Other Runways may have been an artifact of the linkage method selected for this analysis.

The next cluster contained only one element and was labeled accordingly, Visibility Requirement. This information stands out with pilots and subsequently did not cluster with other stimuli, perhaps because of its perceived importance, use, and frequent acquisition.

The tenth and final cluster contained elements pertaining to navigation radios and has been labeled Navigation Aids. This cluster contains more than just the frequencies for the navigation aids (in contrast to Communications). As the lower level clustering (fig. 9) and the acquisition data (described below) showed, pilots considered the navigation aid frequency, identifier, and Morse code as one "chunk" of information. This consideration was again apparent in the retrospective descriptions that were given by the pilots when they described why they acquired specific items. It is probably for this reason that these elements combined within one cluster.

Multidimensional scaling analysis. In addition to the cluster analysis, the similarity data (i.e., the proximity matrix) were also analyzed using multidimensional scaling (MDS); MDS calculates a spatial representation among stimuli using the subjects' measures of how the stimuli are related to one another. This spatial representation presents the objects in an $n$-dimensional space, with items that are similar to one another lying close together, while dissimilar items lie farther apart in the space. The MDS analyses are used to determine whether the subjects' underlying processes that are used as the basis for their information similarity ratings can be meaningfully represented spatially. For example, if pilots perceived information similarity by determining when an item is used and also by the section of the chart in which it appears, then a two-dimensional solution might result with items on the dimensions arranged according to these interpretations. For a more detailed description of MDS, refer to Kruskal and Wish (1978).

The MAPLIST similarity data were scaled in one, two, and three dimensions using a nonmetric scaling program (Wilkinson, Hill, and Vang 1992). Adequacy of the solutions was based on both the reduction in STRESS values with the addition of each dimension (lower STRESS values indicate that the data fit better) and the interpretability of the obtained solution. For the current data, STRESS values were $0.283,0.148$, and 0.104 for the one-, two-, and three-dimensional solutions, respectively. The reduction in STRESS values appeared to level off at two dimensions, so this solution was retained for analysis.

Because of the large number of stimuli, only a subset (of the stimuli) was used in this two-dimensional plot (for legibility). Since dimensional interpretation is enhanced frequently by examining the stimuli that are lying on the extremes of the dimensions, the stimuli that were plotted constitute the low and high ends of each dimension. In addition, several stimuli lying in the center of the solution were plotted. This spatial solution is shown in figure 11.

Examination of the plot revealed no obvious dimensional interpretation and might suggest that the data are not particularly well fit by a scaling solution. Given the well-defined clusters, this is not particularly surprising. The clustering results show that pilots have wellestablished categories into which they place flight deck information. In such cases spatial representation may be inappropriate for representing the data, thereby leading to a poor spatial fit. As Shepard (1980, p. 397) has noted, "While both clustering and MDS analyses are useful for exploring some sets of data, different models may be more appropriate for different sets of stimuli or types of data." In the present case, the proximity data appear best suited to a nonspatial clustering representation, as presented above. While no interpretation was rendered in this experiment, the results and discussion were included for completeness and to afford the reader an opportunity to interpret the results.

\section{Importance of Approach Chart Information Elements}

As described in the "Methods" section, subjects were asked to rank the 75 information elements by perceived importance. The pilots were first instructed to rank the elements without a given context (context free). Immediately after the context-free ranking, the pilots were asked to rank the elements again, based on the importance of the information pilots use when they are flying approaches in adverse weather. Adverse weather was described as both visibility and cloud bottom at minimums. Average rankings were calculated for the two test conditions, and multidimensional preference analyses were done on these rankings. Descriptions of these analyses and results are presented below.

Average rankings. The average ranking of elements for both the context-free and bad weather context is 
given in table 3 . The subjects assigned low numbers to elements that they perceived to be the most important. This numbering indicates that elements such as ILS localizer magnetic course and visibility requirement are considered to be very important whereas magnetic variation and the TDZE of the parallel runway are of lesser importance. An observation in addition to the relative order of elements within a context is the relative consistency of element rankings between contexts (i.e., context free and adverse weather). This ranking was demonstrated by a correlation coefficient of 0.983 , which indicated that there was a very high level of agreement on the importance of each information element across these two different contexts.

Since the relative order of the stimuli was very close, it is possible that the importance of the information on approach charts is insensitive to context or is somewhat absolute. The results could be explained also by the context in which some pilots defaulted when they were not given a context (i.e., defaulting to adverse weather conditions during the context-free ranking). While neither explanation is definitive, it can be said that the context that was used in this study did not affect the pilots' perception of the importance of this information (as reflected in the data).

In studying the average rankings, it was observed that many of the element types that were identified as highly important come from the similarity categories of Visibility Requirement ("Are we legal to fly this approach?"), and chart Validation ("Do we have the correct and same approach?"). Since these elements represent items checked at the very beginning of the approach, there may have been a temporal factor used when importance was assigned.

That Geography and Other Runways information occupied the "least important" positions is also noteworthy. From this observation it is fairly safe to say that some elements identified as least important were named so because they did not pertain to this flight (i.e., Other Runways). With the exception of the element runway length (which was also an exception to the similarity category), each element in the Other Runways category was deemed unimportant. These elements were the TDZE of the parallel runway, the glideslope position on the parallel runway, and other runway numbers.

Geography was another similarity category in which elements were deemed of lesser importance by the pilots. Each element from the Geography category, even though it was pertinent to the approach, was deemed least important by the pilots when they ranked the elements. As a reminder, these elements were latitude-longitude grid, latitude-longitude of airport VOR, magnetic variation, and scaling.
Multidimensional preference analysis. The element rankings for all subjects were also analyzed by using multidimensional preference (MDPREF) (Carroll 1972); MDPREF is a multidimensional-preference analysis program designed to accommodate ranking data. The MDPREF is a technique that takes ranking stimulus data and provides a joint representation of the data and subject preferences. The analysis presents the stimuli spatially, analogous to MDS (discussed earlier). The MDPREF analysis was conducted using the personal computer (multidimensional) preference (PCPREF) algorithm, a personal computer version of an MDPREF analysis. (For further details on the model, see Carroll 1972.) An MDPREF analysis was performed on both the context-free and adverse weather conditions.

A dimension in an MDPREF solution corresponds to a factor that subjects use to process the information (i.e., determine its importance). Subjects often use multiple factors when making their ratings. For example, pilots may determine the importance of information according to when it is needed in the flight and also by logical dependencies. In such a case a two-dimensional solution would result.

In determining the number of significant factors (i.e., the dimensionality), an examination is made of the proportion of variance that is accounted for by each factor. The larger the variance, the more a given factor is able to reproduce the original data matrix; hence, the factor can be thought of as representing whatever common structure exists, to a greater degree, in the underlying data. Particular attention is paid to relative decreases in variance that could be accounted for as more dimensions are added and that would ease interpretation of the solution.

Proportion of variance values showed that a onedimensional solution of the context-free data accounted for 0.092 of the variance. Adding a second dimension accounted for an additional 0.081 of the variance (total $=0.173$ ). The total proportion of variance when adding a third dimension was 0.249 , and it was 0.321 after adding a fourth dimension. Cumulative proportion of variance declined at a slightly slower rate thereafter (five dimensions added 0.059 and six dimensions added another 0.056).

These values are very low and indicate that the data did not conform well to a spatial solution. This result can be explained by the subjects use of many different factors when they were making their ratings. Since the primary goal of an MDPREF analysis is to reduce the number of factors to a smaller set that accounts for a fairly large proportion of the variance, these results indicate a poor fit. Therefore, for this input, a "good" dimensional solution was not discernible. 
Table 3. Average Rankings

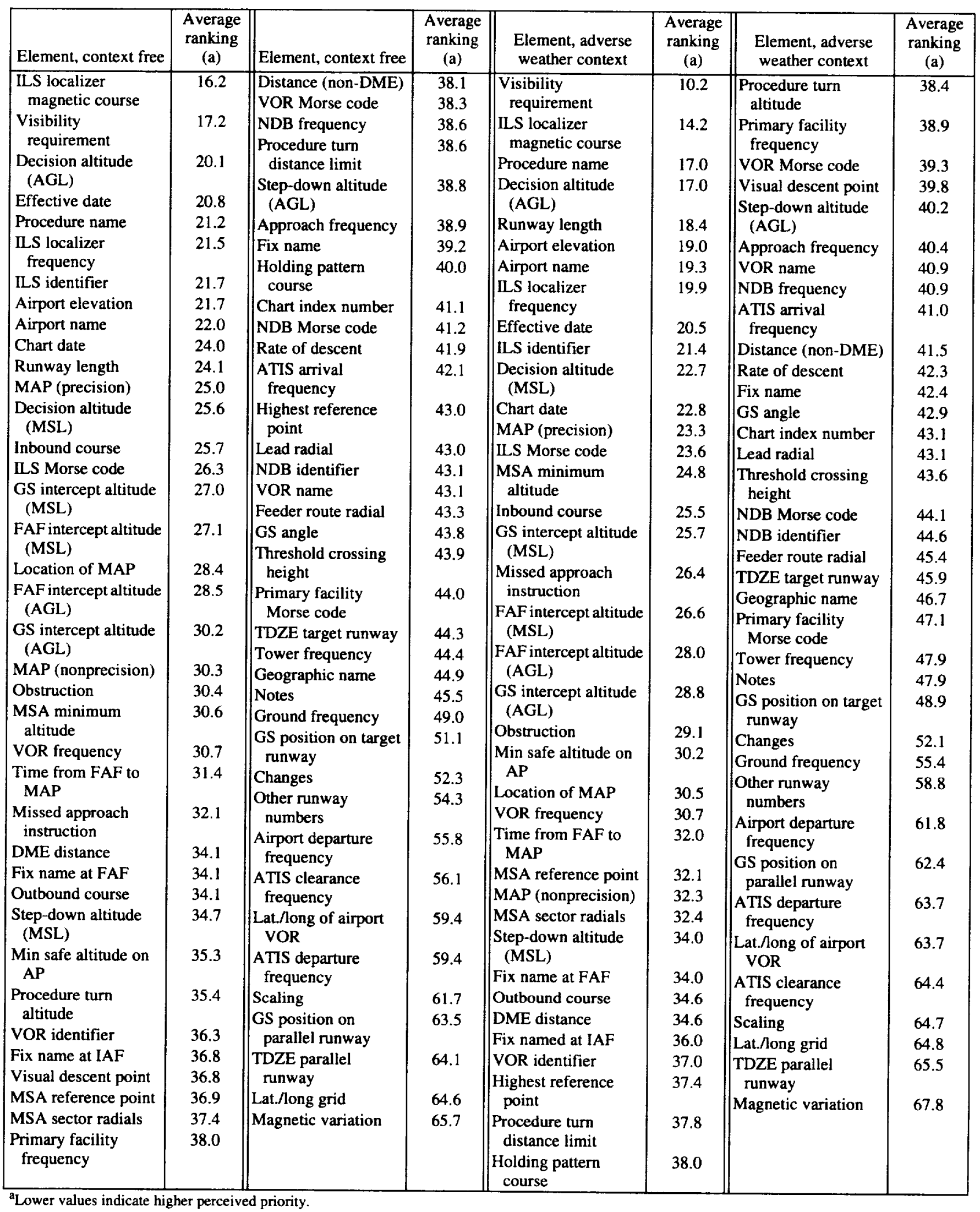


The same was true in the adverse weather condition. As with the context-free condition, proportion-ofvariance values indicated that discriminating among different dimensional solutions was not possible. The onedimensional solution accounted for 0.095 of the variance and adding a second dimension accounted for an additional 0.077 of the variance (total $=0.172$ ). The total proportion of variance when adding a third dimension was 0.246 , and it was 0.315 after adding a fourth dimension. Cumulative proportion of variance declined at a slightly slower rate thereafter (five dimensions added 0.059 , and six dimensions added another 0.056).

Although the above results indicated that these data might not be represented best spatially, an attempt was still made (by examining a few of the spatial plots) to interpret the factors the pilots used when they were making their importance rankings. Since solutions for the context-free and adverse weather rankings were nearly identical, the discussion below will focus only on the context-free condition. To aid in this investigation and for discussion concerning what the pilots may have been using to differentiate between the stimuli during this task, the three-dimensional solution was used and is plotted (fig. 12) using those stimuli that define the dimensional extremes. When looking at the three-dimensional plot, it appeared as though the pilots made their rankings based on their temporal position in the approach. That is, their rankings differed depending on whether or not the pilots envisioned themselves to be in the preapproach, approach transition, intermediate, or final segment.

For the first dimension the ends were defined by Visibility Requirement and decision altitude (MSL) at one end and location of missed approach point (MAP) and glideslope (GS) angle at the other. Elements appear to be ordered along this dimension based on their importance to the preapproach phase of the approach. In the preapproach phase, pilots are more concerned with whether they are legal to fly the approach (i.e., comparing visibility and cloud bottom values given by ATIS to the Visibility Requirement and decision altitude listed for the approach) than they are for elements of interest during the final segment, such as the glideslope angle and the location of the MAP.

The second dimension is defined by elements such as non-DME distances and the MSA reference point at one end and TDZE's of both the target and parallel runways at the other end. The most important elements on this dimension seem to be those of most interest during the transition to intermediate segments of the flight. During these segments pilots are planning, using the mileage presented (nondistance measuring equipment (DME) distances) and the minimum altitudes, as well as constantly monitoring both of these items when they are flying the feeder radials.
The elements that define both extremes of the third dimension seem to be most important, with the distinction being the temporal position within the final segment (i.e., beginning or end of final approach). Glideslope intercept altitude, rate of descent, and runway length are most important to the pilots when they are beginning the final segment of the approach. During this segment, the PNF checks the altitude when intercepting the glideslope against the altitude depicted on the chart. Rate of descent is an element of constant monitoring during this phase, especially when the pilots are flying VOR (i.e., no glideslope signal to provide this information). In the event that either the rate of descent is too slow or the point of intercept of the glideslope is too high, crews must ascertain that there is still enough runway (i.e., runway length) to land or adjust their rate of descent. Items on the other end of this dimension, such as decision altitude (MSL) and Visibility Requirement, are most important toward the end of the final segment when a final decision must be made that concerns continuing the approach or initiating missed approach procedures.

\section{Pilots' Acquisition of Approach Information}

All information items that could be selected on the approach charts by the pilots during the simulation portion of the experiment were identified by their corresponding information element types (table 1) for post analysis. Segments of the approach in which they were selected were identified for further delineation.

The preapproach phase was not a time-controlled segment. Each crew was told to take the time it needed to get familiar with the approach and for the PF to brief the PNF. Average time for the preapproach phase was 315 seconds with crew averages ranging from 211 seconds to 504 seconds. Transition, intermediate, and final were time-controlled segments of the approach (i.e., duration within segments was controlled by ATC). Average time in the transition phase was 626 seconds. Average time in the intermediate phase was 79 seconds, and average time in the final segment was 139 seconds. For more information on the time profiles, please refer to the tables in appendix $B$.

This section begins with a discussion of the possible limiting factors and presents the descriptive results that concern the characteristics of the pilots' retrieval of information during the simulated approaches. Inferential analyses also were done by using the derived clusters (i.e., similarity categories) as dependent measures when the acquisition test matrix that is described in the "Method" section was being analyzed. These results will be described in the "Effects of Independent Variables on Pilot Acquisition" section following the descriptive analyses. 


\section{Related Debriefing Questionnaire Responses}

One question in the debriefing questionnaire pertained to the effect of the pilots' doing the psychometric scaling tasks before their simulation session. The intent of the question was to determine whether the pilots changed the way they did things in the simulator because of their perception of the experiment's objectives. The pilots were asked whether or not their experience in the card tasks changed their information acquisition strategy in the simulation task. Five said that they did change their strategies based on the psychometric scaling tasks and 21 said they did not. Assessment of the five pilots' comments indicated that there was no real impact on the study's objectives. Pilot comments have been included below for completeness.

"I realized that there was some important information that I was overlooking; however, the general flow of information in the acquisition strategy did not change."

"It made me try to be more time-information efficient and to prioritize to a greater degree."

"Possibly there was an impact. The card task heightened awareness of some items that are normally provided or taken for granted (e.g., airport name)."

"I usually forget all about MSA's at ChicagoO'Hare (ORD) and Dallas-Fort Worth (DFW). However, seeing the cards brought it to mind, and I was more aware of it for the sim."

"I focused attention on what I was doing to verify my card task decision."

In addition, the pilots were asked many questions pertaining to the acquisition task and the simulation session in general. Answers to these questions and the pilots' comments were useful in the analyses of these data and provided many insights. A compilation of these questions and comments is included in the discussion provided in appendix $C$.

\section{Descriptive Analyses}

As described above, the subjects' acquisitions of approach chart information were time stamped and logged with corresponding flight segment information. These acquisition counts of the information items were mapped to the element types and graphed against the flight segments. Each row of a graph corresponds to an information element type (ordered alphabetically) and each column is a flight segment. A summary graph of the acquisitions from all the runs was made and is shown in figure 13. Graphs were also generated for acquisitions by the PF (fig. 14) and PNF (fig. 15), as well as for each level of the independent variables: weather and precision. Good weather acquisitions are shown in figure 16; adverse weather acquisitions are presented in figure 17 . For precision, ILS approach acquisitions are shown in figure 18, and VOR approach acquisitions are plotted in figure 19.

In figure 13 it is apparent that most of the acquisitions are made during the preapproach phase of the flight. Sixty percent of all information acquired was selected during this phase in preparation for the approach (i.e., before initial descent). Thirty-one percent of the selections were made during the approach transition phase. Five percent of the selections were made during the intermediate phase. Four percent of the selections were made during the final segment. ${ }^{8}$ These acquisition patterns appear inversely proportional to the number of flying tasks to be performed. As the number of flying tasks increased, the number of approach chart acquisitions decreased. These data may support the theory that the approach chart is primarily used for planning.

Table 4 repeats the data in the last column of figure 13 and orders the elements according to frequency of acquisitions. Elements that were omitted from the table were never acquired. Apparent from this presentation of the data is that the first 9 of the information types that were listed accounted for over 50 percent of the overall acquisitions but that those 9 types represented less than 26 percent of the total number of items that could be selected on the charts. Feeder route radial ( 1.81 percent of total items) was selected 8.28 percent of the time; minimum safe altitude (MSA) on approach procedure (2.07 percent of total items) was selected 7.81 percent of the time; DME distance (3.89 percent of total items) was selected 6.33 percent of the time; VOR identifier (3.63 percent of total items) was selected 6.11 percent of the time; distance (non-DME) (4.40 percent of total items) was acquired 5.88 percent of the time; fix name at FAF (2.07 percent of total items) was acquired 4.40 percent of the time; VOR frequency ( 1.42 percent of total items) was acquired 4.35 percent of the time; ILS identifier ( 3.63 percent of total items) was selected 4.33 percent of the time; and fix name ( 2.85 percent of items) was acquired 3.95 percent of the time.

As stated above, most of the acquisitions were made during the preapproach segment of the simulation run (on average, 61 percent of all acquisitions). Tables 5 through 8 show the acquisition totals for preapproach and each approach segment, except for the missed approach segment, ranked by number of acquisitions. Together these

\footnotetext{
${ }^{8}$ Missed Approach was not an intended segment for this study; however, some crews initiated missed approaches which accounted for a small fraction of the total number of items selected.
} 
Table 4. Total Acquisitions

\begin{tabular}{|c|c|c|c|c|c|}
\hline Information element & Acquisition & Information element & Acquisition & Information element & Acquisition \\
\hline Feeder route radial & 956 & VOR Morse code & 149 & Primary facility Morse code & 38 \\
\hline MSA on approach proc. & $\overline{902}$ & ILS localizer mag. course & 148 & Lat-long grid & 30 \\
\hline DME distance & 731 & FAF intercept alt. (AGL) & 139 & TDZE parallel runway & 30 \\
\hline VOR identifier & 706 & Geographic name & 132 & MSA reference point & 29 \\
\hline Distance (non-DME) & 679 & Airport name & 130 & Procedure turn dist. limit & 29 \\
\hline Fix name at FAF & 508 & Obstruction & 128 & GS intercept alt. (AGL) & 28 \\
\hline VOR freq. & 503 & Chart index number & 116 & Approach freq. & 27 \\
\hline ILS identifier & 500 & Chart date & 110 & MSA sector radials & 25 \\
\hline Fix name & 456 & Holding pattern course & 105 & Ground freq. & 19 \\
\hline Procedure name & 324 & Outbound course & 98 & MM crossing alt. (MSL) ${ }^{\mathrm{a}}$ & 15 \\
\hline Decision alt. (MSL) & 306 & Location of MAP & 97 & Rate of descent & 15 \\
\hline Inbound course & 299 & GS intercept alt. (MSL) & 94 & MM crossing alt. (AGL) ${ }^{\mathrm{a}}$ & 10 \\
\hline FAF intercept alt. (MSL) & 279 & ILS Morse code & 80 & Notes & 10 \\
\hline Missed approach instruction & 239 & Time from FAF to MAP & 80 & GS angle & 8 \\
\hline Visibility requirement & 239 & Runway length & 65 & Lat-long of airport VOR & 8 \\
\hline Fix name at IAF & 233 & Step-down alt. (AGL) & 65 & ATIS arrival freq. & 6 \\
\hline VOR name & 199 & Other runway numbers & 58 & GS position on target rwy & 6 \\
\hline Airport elevation & 194 & TDZE target runway & 50 & Airport departure freq. & 2 \\
\hline MSA minimum alt. & 190 & MAP (nonprecision) & 47 & ATIS departure freq. & 2 \\
\hline Decision alt. (AGL) & 189 & Highest reference point & 45 & ATIS clearance freq. & 1 \\
\hline Step-down alt. (MSL) & 178 & Lead radial & 45 & Magnetic variation & 1 \\
\hline ILS localizer freq. & 175 & Tower freq. & 45 & Threshold cross height & 1 \\
\hline Primary facility freq. & 161 & Effective date & 38 & & \\
\hline
\end{tabular}

${ }^{\mathrm{a}}$ Element was not part of the psychometric scaling stimuli.

Table 5. Preapproach Acquisitions

\begin{tabular}{|l|c||l|c||l|c|}
\hline \multicolumn{1}{|c|}{ Information element } & Acquisition & Information element & Acquisition & \multicolumn{1}{|c|}{ Information element } & Acquisition \\
\hline Feeder route radial & 464 & Geographic name & 128 & ILS Morse code & 37 \\
\hline VOR identifier & 437 & Airport name & 124 & TDZE target runway & 37 \\
\hline MSA on approach proc. & 398 & MSA minimum alt. & 118 & MAP (nonprecision) & 36 \\
\hline DME distance & 350 & Chart index number & 115 & Lead radial & 32 \\
\hline VOR freq. & 347 & Chart date & 110 & Primary facility Morse code & 29 \\
\hline ILS identifier & 291 & Step-down alt. (MSL) & 107 & Highest reference point & 25 \\
\hline Procedure name & 290 & VOR Morse code & 106 & MSA reference point & 23 \\
\hline Distance (non-DME) & 282 & Holding pattern course & 95 & TDZE parallel runway & 21 \\
\hline Fix name at FAF & 280 & FAF intercept alt. (AGL) & 91 & GS intercept alt. (AGL) & 19 \\
\hline Visibility requirement & 220 & ILS localizer freq. & 75 & MM crossing alt. (MSL) & 13 \\
\hline Fix name & 216 & ILS localizer mag. course & 69 & MSA sector radials & 13 \\
\hline Fix name at IAF & 181 & Runway length & 62 & Procedure turn dist. limit & 13 \\
\hline Decision alt. (MSL) & 179 & Location of MAP & 60 & Lat-long grid & 12 \\
\hline Missed approach instruction & 157 & Obstruction & 59 & Rate of descent & 9 \\
\hline Decision alt. (AGL) & 151 & Time from FAF to MAP & 58 & MM crossing alt. (AGL) & \\
\hline FAF intercept alt. (MSL) & 150 & GS intercept alt. (MSL) & 53 & Notes & 8 \\
\hline Inbound course & 148 & Outbound course & 48 & Lat-long of airport VOR & $\mathbf{8}$ \\
\hline Primary facility freq. & 147 & Other runway numbers & 42 & GS angle & 6 \\
\hline VOR name & 143 & Step-down alt. (AGL) & 38 & GS pos. on target runway & 4 \\
\hline Airport elevation & 136 & Effective date & 37 & & 5 \\
\hline
\end{tabular}

${ }^{\mathrm{a}}$ Element was not part of the psychometric scaling stimuli. 
Table 6. Transition Phase Acquisitions

\begin{tabular}{|c|c|c|c|c|c|}
\hline Information element & Acquisition & Information element & Acquisition & Information element & Acquisition \\
\hline Feeder route radial & 487 & Outbound course & 32 & Visibility requirement & 10 \\
\hline MSA on approach proc. & 485 & Procedure name & 26 & Primary facility Morse code & 8 \\
\hline Distance (non-DME) & 381 & Step-down alt. (AGL) & 24 & MAP (nonprecision) & 6 \\
\hline DME distance & 248 & Tower freq. & 22 & MSA reference point & 6 \\
\hline Fix name & 217 & Approach freq. & 21 & Rate of descent & 6 \\
\hline VOR identifier & 179 & GS intercept alt. (MSL) & 21 & Airport name & 5 \\
\hline ILS identifier & 148 & Highest reference point & 20 & TDZE target runway & 4 \\
\hline VOR freq. & 139 & FAF intercept alt. (AGL) & 19 & ATIS arrival freq. & 3 \\
\hline Fix name at FAF & 128 & Lat-long grid & 18 & GS angle & 3 \\
\hline Inbound course & 117 & Time from FAF to MAP & 18 & GS intercept alt. (AGL) & 3 \\
\hline ILS localizer freq. & 89 & Ground freq. & 17 & Geographic name & 3 \\
\hline ILS localizer mag. course & 74 & Missed approach instruction & 16 & Runway length & 3 \\
\hline MSA minimum alt. & 72 & Proc. turn distance limit & 16 & TDZE parallel runway & 3 \\
\hline Obstruction & 67 & Other runway numbers & 15 & Airport departure freq. & 2 \\
\hline Step-down alt. (MSL) & 65 & Decision alt. (MSL) & 14 & GS pos. on target runway & 2 \\
\hline VOR name & 52 & Location of MAP & 14 & MM crossing alt. (AGL) ${ }^{\mathrm{a}}$ & 2 \\
\hline Fix name at IAF & 47 & Primary facility freq. & 13 & MM crossing alt. (MSL) ${ }^{2}$ & 2 \\
\hline FAF intercept alt. (MSL) & 45 & Lead radial & 12 & Notes & 2 \\
\hline lLS Morse code & 40 & MSA sector radials & 12 & Chart index number & 1 \\
\hline VOR Morse code & 40 & Decision alt. (AGL) & 11 & Effective date & 1 \\
\hline Airport elevation & 38 & Holding pattern course & 10 & Lat-long of airport VOR & 1 \\
\hline
\end{tabular}

Table 7. Intermediate Phase Acquisitions

\begin{tabular}{|l|c||l|c||l|c|}
\hline \multicolumn{1}{|c|}{ Information element } & Acquisition & \multicolumn{1}{|c|}{ Information element } & Acquisition & \multicolumn{1}{|c|}{ Information element } & Acquisition \\
\hline DME distance & 110 & Missed approach instruction & 10 & Step-down alt. (AGL) & 3 \\
\hline Fix name at FAF & $\mathbf{8 0}$ & Distance (non-DME) & 9 & VOR name & 3 \\
\hline FAF intercept alt. (MSL) & $\mathbf{6 4}$ & ILS localizer freq. & 9 & Fix name at IAF & 1 \\
\hline VOR identifier & 52 & VOR freq. & 9 & ILS Morse code & 1 \\
\hline ILS identifier & 40 & Step-down alt. (MSL) & 6 & Lat-long of airport VOR & 1 \\
\hline Inbound course & 31 & Decision alt. (AGL) & 5 & Location of MAP & 1 \\
\hline Decision alt. (MSL) & 26 & Airport elevation & 4 & Magnetic variation & 1 \\
\hline Fix name & 22 & Approach freq. & 4 & Primary facility freq. & 1 \\
\hline FAF intercept alt. (AGL) & 20 & GS intercept alt. (AGL) & 4 & Procedure name & 1 \\
\hline GS intercept alt. (MSL) & 17 & ILS localizer mag. course & 4 & TDZE parallel runway & 1 \\
\hline Tower freq. & 17 & Visibility requirement & 4 & TDZE target runway & 1 \\
\hline MSA on approach proc. & 13 & Feeder route radial & 3 & VOR Morse code & 1 \\
\hline Outbound course & 13 & & & & \\
\hline
\end{tabular}

indicate that different information elements are accessed most during different segments of flight. Elements that were omitted from the tables were those that were not acquired during the respective phase.

In the preapproach phase, 52 percent of the acquisitions were of items commonly used for validating and planning the approach. These 11 element types repre- sented only 35 percent of the items that could have been selected. Since most of the acquisitions were done in the preapproach segment, these acquisitions dominated the summary data presented above. In addition to the 9 dominant elements listed in the above summary table, the preapproach segment had procedure name and visibility requirement in the top 50 percent of acquisitions. 
Table 8. Final Phase Acquisitions

\begin{tabular}{|l|c||l|l||l|c|}
\hline \multicolumn{1}{|c|}{ Information element } & Acquisition & Information element & Acquisition & \multicolumn{1}{|c|}{ Information element } & Acquisition \\
\hline Decision alt. (MSL) & 87 & DME distance & 7 & GS intercept alt. (AGL) & 2 \\
\hline Missed approach instruction & 52 & Procedure name & 7 & ILS localizer freq. & 2 \\
\hline VOR identifier & 38 & MSA on approach proc. & 6 & ILS Morse code & 2 \\
\hline Distance (non-DME) & 23 & MAP (nonprecision) & 5 & Obstruction & 2 \\
\hline Decision alt. (AGL) & 22 & Outbound course & 5 & VOR Morse code & 2 \\
\hline Location of MAP & 22 & TDZE parallel runway & 5 & Airport name & 1 \\
\hline ILS identifier & 21 & Tower freq. & 5 & ATIS departure freq. & 1 \\
\hline FAF intercept alt. (MSL) & 20 & Visibility requirement & 5 & Fix name & 1 \\
\hline Fix name at FAF & 20 & Fix name at IAF & 4 & ILS localizer mag. course & 1 \\
\hline Airport elevation & 16 & Time from FAF to MAP & 4 & Lead radial & 1 \\
\hline FAF intercept alt. (AGL) & 9 & GS intercept alt. (MSL) & 3 & Other runway numbers & 1 \\
\hline TDZE target runway & 8 & Inbound course & 3 & Primary facility freq. & 1 \\
\hline VOR freq. & 8 & Feeder route radial & 2 & VOR name & 1 \\
\hline
\end{tabular}

In the transition segment of the approach, 5 element types were acquired over 50 percent of the time, but they represented only 15 percent of the total number of items that could be selected. Feeder route radial ( 1.81 percent of total items) was selected 13.51 percent of the time; minimum safe altitude on approach procedure (2.07 percent of total items) was selected 13.45 percent of the time; distance (non-DME) (4.40 percent of total items) was selected 10.57 percent of the time; DME distance (3.89 percent of total items) was selected 6.88 percent of the time; and fix name ( 2.85 percent of total items) was selected 6.02 percent of the time. There were many common items with those dominating the preapproach-phase acquisitions that may suggest that the transition phase is used primarily as a continuation of the planning process.

Acquisitions in the intermediate phase were dominated by four information element types. Over 50 percent of the intermediate phase acquisitions were of elements that represented only 10.11 percent of all selection items. The DME distance (3.89 percent of total items) was acquired 18.58 percent of the time; fix name at FAF (2.07 percent of total items) was acquired 13.51 percent of the time; FAF intercept altitude (MSL) (0.52 percent of total items) was selected 10.81 percent of the time; and VOR identifier (3.63 percent of total items) was selected 8.78 percent of the time. The tasks that these items support might suggest a transition during this segment to monitoring progress of the approach (versus planning).

Acquisition counts were dominated during the final segment by missed approach and distance information. While on final, 5 of the information element types were selected more than 52 percent of the time, but they only represented 15 percent of the total number of selection items. Decision altitude (MSL) (3.37 percent of total items) was selected 20.57 percent of the time; missed approach instruction ( 0.52 percent of total items) was selected 12.29 percent of the time; VOR identifier (3.63 percent of total items) was selected 8.98 percent of the time; distance (non-DME) (4.40 percent of total items) was selected 5.44 percent of the time; and decision altitude (AGL) (3.37 percent of total items) was selected 5.20 percent of the time. Not part of the 52 percent of acquisitions during this phase, but of an equal number of acquisitions as decision altitude (AGL), was location of MAP (1.04 percent of total items), which was selected 5.20 percent of the time. These items again appear to support the pilots' monitoring task, except for the Missed Approach information.

Figures 13 and 14 chart the acquisitions made by all PF's and by all PNF's. The PNF's made more acquisitions in each segment of flight than did the PF. The difference between the two was more pronounced during the flying segments. Overall, the PNF accounted for 65 percent of all the information items that were acquired. During the preapproach segment the PNF's acquisitions totaled 56 percent, and during the flying segments they accounted for 78 percent of the total number of information item acquisitions.

The PF was expected to have fewer acquisitions overall than the PNF because the PF's primary attention would be the flying tasks, while the PNF would handle the retrieval of approach chart information to support both the PF's and the PNF's planning and monitoring tasks. Two facts support this hypothesis: The PF got most of his information during the preapproach phase and the PNF retrieved more information during the flying phase. Responses to questions during the debriefing confirmed that this acquisition pattern is common in actual airline flying. 
Figures 18 and 19 show graphs of acquisition counts that were logged during the precision (ILS) and nonprecision (VOR) scenarios. In each flight segment, crews made more acquisitions in the nonprecision scenarios than they made in the precision scenarios (when counts pertaining solely to precision approaches are excepted). There were notably more acquisitions in the VOR totals for information elements: fix name at FAF, inbound course, minimum safe altitude on approach, distance (non-DME), and time from FAF to MAP. The ILS scenarios produced considerably more acquisitions of the element fix name than did the VOR scenarios. Since much of the descent guidance is calculated automatically (e.g., glideslope) during the precision approaches and manually during the nonprecision approaches, it was expected that the number of acquisitions would be greater for the latter. The specific items that were accessed most during the nonprecision approaches supported that expectation.

The hypothesis that more acquisitions would be made during approaches in adverse weather than in good weather was valid. In adverse weather, the pilots are more concerned with such things as whether they are legal to fly the approach and distance to decision points. Figures 16 and 17 show the acquisition frequency graphs of the good and adverse weather scenarios. In all flight segments the subjects made more acquisitions in the adverse weather scenarios. The most notable differences were in the distance (non-DME) and the Visibility Requirement counts.

\section{Effects of Independent Variables on Pilot Acquisition}

In addition to the descriptive analyses discussed above, inferential analyses that used the derived similarity categories as dependent variables were done for the experiment design described in table 2 of the "Method" section. Acquisition of the information that comprises each category was sorted into their respective treatment combination. Since each subject participated in all combinations of the treatments of precision (ILS and VOR), weather (good and adverse), and flight phase (preapproach and approach), there were eight treatment combinations.

A computer program was written to sort the number of information elements from the given category for each of 8 treatment combinations and for each of the 10 categories. This sorting procedure allowed analyses of variance (ANOVA) to be done for each of the 10 information categories, thereby rendering inferential statistical tests to observe the effects of the treatment conditions on the pilots' acquisition behavior. Some of the statistically significant results from these analyses will be presented in terms of the respective main effects (crew member, precision, weather, and flight phase) in conjunction with statistically significant interactions where they are appropriate. In addition to this selective reporting of the ANOVA results, the complete ANOVA summary tables are presented in appendix D. Means and standard deviations for the respective ANOVA's are shown in appendix E.

Crew member. As expected from the descriptive results presented earlier, the PNF acquired more information from the approach chart than did the PF for all 10 information categories. This result was statistically significant at the 5-percent level for the Navigation, Navigation Aids, Obstructions, and Missed Approach categories. As discussed above, the PF's primary interaction with the approach chart was during the preapproach phase, and at this point the PF and PNF both acquired about the same amount of information from the charts. However, when the flight ensues, the PF depends on the PNF to obtain the information from the approach chart. Several of the other information categories contained interactions that involve the crew member with another factor. These will be discussed in further detail in the appropriate section below.

Precision. Statistically significant main effects for precision (VOR versus ILS) were observed for several of the information categories. More Navigation category information was obtained in the VOR condition than in the ILS condition, $F(1,22)=14.2$; probability $(p)<0.01$. This was probably due to the necessity of the pilots to manually calculate and monitor their descent. The same pattern was observed also for Obstructions information, $F(1,22)=12.15, p<0.01$, Missed Approach information, $F(1,22)=29.96, p<0.01$, and for Visibility Requirement, $F(1,22)=9.52, p<0.01$. This pattern is attributable to the task differentiation between precision and nonprecision approaches. With VOR approaches, the pilots manually calculate and monitor the descent. Furthermore, their concern for Obstructions, Missed Approach information, and Visibility Requirements heightens when they are not given the automated guidance that is afforded in ILS approaches.

Significant main effects for Geography, $F(1,22)=$ $4.83, p<0.04$, and for Final Items, $F(1,22)=6.13$, $p<0.05$ were also found, but in these cases more information was obtained in the ILS condition than in the VOR condition. A primary reason for this result might be that some elements in the category are only pertinent to ILS approaches (e.g., glideslope) or that flying an ILS approach afforded the crew more free time to look at this information (e.g., out-the-window validation of obstructions). 
Weather. Statistically significant main effects for weather (adverse versus good) were observed for several of the information types. For Visibility Requirement, Missed Approach, Navigation, and Final Items, significantly more information of each type was gathered during adverse weather conditions than during good weather conditions. In addition to the simple need for more information when they are planning flights in adverse weather, pilots need to increase their monitoring of the fixes and target altitudes (Navigation) in adverse weather conditions to determine whether they are legal (Visibility Requirement), and if not, to identify the alternative (Missed Approach).

More Obstructions information was gathered during good weather conditions than during adverse conditions, $F(1,22)=5.04, p<0.05$. This main effect was opposite of what was expected but may be attributable to the transfer of related tasks to ATC. Many pilots noted in their debriefings that obstruction avoidance became ATC's primary responsibility in adverse weather conditions.

Phase. As pointed out in the descriptive section above, the greatest amount of information was collected during the preapproach phase of flight. When analyzed statistically for each category, the above result was confirmed. For all similarity categories, except for Navigation, Obstructions, Visibility Requirement, and Geography significantly more information was acquired during the preapproach phase of flight. While no significant differences were found for the four information categories listed above, only Obstructions and Geography demonstrated a pattern in which more information was collected during the approach phase than during the preapproach phase. Again, this difference appears to be explained by the planning versus monitoring paradigm, in which Obstruction and Geography acquisitions increase during the approach while the progress of the approach is being monitored.

Interactions. In addition to the main effects discussed above, there were some statistically significant interactions of interest. While phase was not statistically significant for Navigation category acquisitions, a statistically significant crew-member-by-phase interaction emerged. While the PF's acquisitions of Navigation information decreased from preapproach to approach, the PNF's acquisition increased. Since the number of PF flying tasks increases during the approach, the PF is accustomed to obtaining needed Navigation information from the PNF. This task allocation also confirms the planning and monitoring model of the approach and the interpretation of the Navigation category. While both pilots are involved with planning during the preapproach, it is the
PNF's primary responsibility to monitor progress during the approach (and also to be a memory aid for the PF).

For Navigation Aids information, a significant precision-by-weather interaction emerged. When pilots are flying a VOR approach in bad weather, the number of Navigation Aids acquisitions increases, whereas the number of acquisitions decreases while they are flying ILS in adverse weather. This pattern of acquisitions may be attributed to the use of items contained in this category for validation during approaches. The need to validate the current state increases in adverse weather because of the inability to make visual checks. One form of validation is to check that the radios are properly tuned to ascertain the correctness of the current flight profile. The possible reason that these checks decreased in bad weather for ILS while increasing for VOR is that positive glideslope and localizer signals on the flight deck help ascertain that the Navigation Aids are properly tuned when flying ILS, whereas checking the VOR signal can only be done against what is printed on the chart.

A statistically significant interaction of phase by crew member emerged for Obstructions items. This interaction showed that the PNF acquired more information about Obstructions during the approach versus the preapproach, whereas the PF acquired more of this information during the preapproach. This explanation again seems to lie in the difference in task allocation among the crew members. The PF uses Obstructions information primarily for planning, whereas the PNF's primary use of Obstructions information is in monitoring flight progress.

The interaction between precision and weather when acquiring Missed Approach information is also of interest. While acquisitions of this information in good weather were somewhat constant for both VOR and ILS approaches, there were significantly more acquisitions of Missed Approach information when flying VOR approaches in adverse weather than when flying ILS approaches in adverse weather. An explanation might be that the crews had more trust in the avionics provided during ILS approaches to help them obtain a position that would prevent a missed approach.

\section{Relationship Between Pilots' Models and Acquisition of Approach Information}

One of the primary goals of this study was to assess relationships between the pilots' cognitive models and how pilots acquire information. Relationships between similarity categories and acquisitions were evident in the ANOVA results described above. If further results show that pilots acquire information relative to their cognitive models, empirically substantiated guidelines can be developed that use these models. This section addresses 
Table 9. Preapproach Clustered Acquisitions

\begin{tabular}{|l|c|c|c|c|c|c|c|c|}
\hline \multicolumn{1}{|c|}{ Category } & $\begin{array}{c}\text { Average } \\
\text { items chart }\end{array}$ & $\begin{array}{c}\text { Selection } \\
\text { probability }\end{array}$ & $\begin{array}{c}\text { Expected } \\
\text { acquisition }\end{array}$ & $\begin{array}{c}\text { Actual } \\
\text { acquisition }\end{array}$ & $\begin{array}{c}\text { Category } \\
\text { selection } \\
\text { probability }\end{array}$ & $\begin{array}{c}\text { Expected } \\
\text { category } \\
\text { acquisition }\end{array}$ & $\begin{array}{c}\text { Actual } \\
\text { category } \\
\text { acquisition }\end{array}$ & $\begin{array}{c}\text { Between } \\
\text { category } \\
\text { acquisition }\end{array}$ \\
\hline Navigation aids & 25.00 & 0.130 & 901 & 1612 & 0.017 & 117 & 740 & 511 \\
\hline Visibility requirement & 13.00 & 0.068 & 469 & 220 & 0.005 & 32 & 106 & 55 \\
\hline Other runway & 13.75 & 0.072 & 496 & 125 & 0.005 & 36 & 47 & 50 \\
\hline Final items & 6.50 & 0.034 & 234 & 56 & 0.001 & 8 & 4 & 48 \\
\hline Missed approach & 13.00 & 0.068 & 469 & 406 & 0.005 & 32 & 141 & 189 \\
\hline Navigation & 59.25 & 0.309 & 2136 & 2892 & 0.095 & 660 & 1718 & 461 \\
\hline Obstructions & 31.50 & 0.164 & 1136 & 636 & 0.027 & 186 & 207 & 321 \\
\hline Validation & 14.25 & 0.074 & 514 & 948 & 0.006 & 38 & 594 & 150 \\
\hline Geography & 6.75 & 0.035 & 243 & 18 & 0.001 & 9 & 6 & 9 \\
\hline Communications & 9.00 & 0.047 & 325 & 10 & 0.002 & 15 & 5 & 3 \\
\hline Total & 192.00 & 1.000 & 6923 & 6923 & 0.163 & 1132 & 3569 & 1797 \\
\hline
\end{tabular}

Table 10. Approach Clustered Acquisitions

\begin{tabular}{|l|c|c|c|c|c|c|c|c|}
\hline \multicolumn{1}{|c|}{ Category } & $\begin{array}{c}\text { Average } \\
\text { items chart }\end{array}$ & $\begin{array}{c}\text { Selection } \\
\text { probability }\end{array}$ & $\begin{array}{c}\text { Expected } \\
\text { acquisition }\end{array}$ & $\begin{array}{c}\text { Actual } \\
\text { acquisition }\end{array}$ & $\begin{array}{c}\text { Category } \\
\text { selection } \\
\text { probability }\end{array}$ & $\begin{array}{c}\text { Expected } \\
\text { category } \\
\text { acquisition }\end{array}$ & $\begin{array}{c}\text { Actual } \\
\text { category } \\
\text { acquisition }\end{array}$ & $\begin{array}{c}\text { Between } \\
\text { category } \\
\text { acquisition }\end{array}$ \\
\hline Navigation aids & 25.00 & 0.130 & 602 & 899 & 0.017 & 78 & 333 & 378 \\
\hline Visibility requirement & 13.00 & 0.068 & 313 & 19 & 0.005 & 21 & 9 & 4 \\
\hline Other runway & 13.75 & 0.072 & 331 & 28 & 0.005 & 24 & 4 & 20 \\
\hline Final items & 6.50 & 0.034 & 157 & 24 & 0.001 & 5 & 6 & 15 \\
\hline Missed approach & 13.00 & 0.068 & 313 & 162 & 0.005 & 21 & 33 & 102 \\
\hline Navigation & 59.25 & 0.309 & 1428 & 2593 & 0.095 & 441 & 1597 & 372 \\
\hline Obstructions & 31.50 & 0.164 & 759 & 683 & 0.027 & 125 & 198 & 377 \\
\hline Validation & 14.25 & 0.074 & 343 & 106 & 0.006 & 25 & 21 & 70 \\
\hline Geography & 6.75 & 0.035 & 163 & 21 & 0.001 & 6 & 7 & 8 \\
\hline Communications & 9.00 & 0.047 & 217 & 92 & 0.002 & 10 & 30 & 39 \\
\hline Total & 192.00 & 1.000 & 4627 & 4627 & 0.163 & 756 & 2238 & 1385 \\
\hline
\end{tabular}

the further relationships between similarity categories and information acquisitions, information rankings and information acquisitions, and items recalled with information acquisitions, as well as with both the categorization and prioritization models.

\section{Similarity Categories and Information Acquisition}

One hypothesis of interest in this study was whether the pilots' cognitive model of approach chart information similarity influences their acquisition of information from the approach chart. For instance, if tasks are supported by similar items of information, then a disproportionate number of acquisitions should be seen for some categories (i.e., those supporting the dominant tasks). A counterhypothesis would be that items on the approach chart are all equally likely to be selected and that the categories that are composed of the most items will be selected most often.
To test whether the categories are reflective of the information acquisitions, data were first compiled that concern the average number of chart items for each of the 10 similarity categories, the probability of selection based on the number of items in a category, expected acquisitions (probability multiplied by total acquisitions), and the actual acquisitions from a category. These data are shown in table 9 for the preapproach phase and in table 10 for the approach phase.

For the preapproach phase, a chi-square $\left(\chi^{2}\right)$ test was performed to compare the expected versus the actual number of acquisitions from each of the 10 categories. A chi-square test is used to measure agreement or disagreement. If the observed values differ appreciably from the expected, then the chi-square value will be large. When the chi-square value is large, the hypothesis of independence is rejected. For the expected versus the actual number of acquisitions of the 10 categories, $\chi^{2}(9)=2482.4, p<0.001$, which indicates that pilots 
Table 11. Transitions Between Categories During Preapproach

\begin{tabular}{|c|c|c|c|c|c|c|c|c|c|c|}
\hline & $\begin{array}{l}\text { Navigation } \\
\text { aids }\end{array}$ & $\begin{array}{c}\text { Visibility } \\
\text { requirement }\end{array}$ & $\begin{array}{l}\text { Other } \\
\text { runway }\end{array}$ & $\begin{array}{l}\text { Final } \\
\text { items }\end{array}$ & $\begin{array}{c}\text { Missed } \\
\text { approach }\end{array}$ & Navigation & Obstrs. & Validation & Geog. & Comm. \\
\hline Navigation aids & 0.46 & 0.00 & 0.00 & 0.00 & 0.05 & 0.38 & 0.04 & 0.07 & 0.00 & 0.00 \\
\hline Visibility requirement & 0.02 & 0.48 & 0.00 & 0.01 & 0.20 & 0.19 & 0.01 & 0.08 & 0.00 & 0.00 \\
\hline Other runway & 0.05 & 0.01 & 0.41 & 0.12 & 0.08 & 0.05 & 0.01 & 0.27 & 0.01 & 0.00 \\
\hline Final items & 0.13 & 0.00 & 0.24 & 0.07 & 0.22 & 0.13 & 0.00 & 0.17 & 0.04 & 0.00 \\
\hline Missed approach & 0.21 & 0.03 & 0.05 & 0.04 & 0.36 & 0.22 & 0.04 & 0.06 & 0.01 & 0.00 \\
\hline Navigation & 0.19 & 0.03 & 0.00 & 0.00 & 0.04 & 0.60 & 0.10 & 0.03 & 0.00 & 0.00 \\
\hline Obstructions & 0.07 & 0.00 & 0.00 & 0.00 & 0.01 & $\mathbf{0 . 5 2}$ & 0.33 & 0.05 & 0.00 & 0.00 \\
\hline Validation & 0.16 & 0.01 & 0.03 & 0.01 & 0.01 & 0.09 & 0.06 & 0.63 & 0.00 & 0.00 \\
\hline Geography & 0.11 & 0.06 & 0.06 & 0.00 & 0.00 & 0.11 & 0.11 & 0.22 & 0.33 & 0.00 \\
\hline Communications & 0.10 & 0.00 & 0.00 & 0.00 & 0.00 & 0.20 & 0.10 & 0.10 & 0.00 & 0.50 \\
\hline
\end{tabular}

Table 12. Transitions Between Categories During Approach

\begin{tabular}{|c|c|c|c|c|c|c|c|c|c|c|}
\hline & $\begin{array}{l}\text { Navigation } \\
\text { aids }\end{array}$ & $\begin{array}{c}\text { Visibility } \\
\text { requirement }\end{array}$ & $\begin{array}{l}\text { Other } \\
\text { runway }\end{array}$ & $\begin{array}{l}\text { Final } \\
\text { items }\end{array}$ & $\begin{array}{c}\text { Missed } \\
\text { approach }\end{array}$ & Navigation & Obstrs. & Validation & Geog. & Comm. \\
\hline Navigation aids & 0.37 & 0.00 & 0.00 & 0.00 & 0.05 & 0.49 & 0.06 & 0.02 & 0.00 & 0.01 \\
\hline Visibility requirement & 0.00 & 0.47 & 0.00 & 0.00 & 0.16 & 0.32 & 0.00 & 0.05 & 0.00 & 0.00 \\
\hline Other runway & 0.07 & 0.00 & 0.14 & 0.11 & 0.11 & 0.11 & 0.04 & 0.04 & 0.00 & 0.39 \\
\hline Final items & 0.04 & 0.00 & 0.17 & 0.26 & 0.17 & 0.04 & 0.04 & 0.17 & 0.00 & 0.09 \\
\hline Missed approach & 0.19 & 0.01 & 0.02 & 0.02 & 0.27 & 0.36 & 0.08 & 0.04 & 0.00 & 0.02 \\
\hline Navigation & 0.17 & 0.00 & 0.00 & 0.00 & 0.03 & 0.63 & 0.15 & 0.01 & 0.00 & 0.01 \\
\hline Obstructions & 0.09 & 0.00 & 0.00 & 0.00 & 0.01 & 0.58 & 0.29 & 0.02 & 0.00 & 0.01 \\
\hline Validation & 0.21 & 0.02 & 0.01 & 0.05 & 0.04 & 0.34 & 0.11 & 0.21 & 0.00 & 0.02 \\
\hline Geography & 0.10 & 0.00 & 0.00 & 0.05 & 0.05 & 0.10 & 0.24 & 0.10 & 0.33 & 0.05 \\
\hline Communications & 0.12 & 0.00 & 0.13 & 0.00 & 0.02 & 0.30 & 0.08 & 0.02 & 0.00 & 0.33 \\
\hline
\end{tabular}

were not equally likely to select from each of the derived categories. Since the data showed that the pilots were not randomly selecting from the categories, there is support for the notion that each category contains related elements (i.e., supporting common tasks).

Probabilities were also calculated and compared to actual values for the flying portion of the approach. These values are given in table 10. As in the preapproach analysis, a chi-square test was performed on the expected versus the actual number of acquisitions from each of the 10 categories. This test yielded a $\chi^{2}(9)=2203.2$, $p<0.005$, again demonstrating that pilots were not choosing equally from among all 10 categories.

Also shown in tables 9 and 10 are the category selection probabilities, which indicate the probability that there are two or more successive selections from a given category. These probabilities were again based on the number of items that comprise a category and therefore on the hypothesis that all items were equally likely to be selected. The probability of two succeeding selections within the same category would be the probability that the category would be selected multiplied by the proba- bility of its being selected. For example, the probability of Navigation Aids being selected is 0.130 (i.e., 25/192), and the probability of two Navigation Aids selections being made in succession is 0.017 (i.e., $0.130 \times 0.130$ ). With these probability data, it was then possible to calculate an expected number of clustered acquisitions (i.e., two or more acquisitions in succession from a category) and compare the expected number to actual clustered acquisitions. As tables 9 and 10 show for both the preapproach and approach segments, the number of items in a category was a poor indicator of clustered acquisition; that is, acquisitions were determined more by similarity category than by expectation as determined by chance selection.

Tables 11 and 12 show the transition frequencies between categories for the preapproach and approach segments, respectively. The largest frequencies for each row are in bold print. For example, in the preapproach the pilots looked at Navigation Aids in succession 46 percent of the time and went from Navigation Aids to navigation information 38 percent of the time. For the preapproach segment, only Final Items and Obstructions had a higher between-category transition rate than 
within-category transition rate. The within-category transitions were second highest for Obstructions.

For the flying portion of the approach, five categories showed higher between-category transitions than within-category transitions (table 12). However, in all five cases (Navigation Aids to Navigation, Missed Approach to Navigation, Validation to Navigation, Other Runway to Communications, and Obstructions to Navigation) the within-category transitions were second in rank. The remaining five transitions were highest for the within-category.

These transition statistics provide additional evidence that the identified categories contain functionally related information. The presence of functionally related information is evident because the highest, or second highest transition probabilities occur along the diagonals. This transition pattern indicates that it is more likely that a subject's next information request will be from within the same category than from another category. The above result is consistent with the notion that the 10 categories contain similar information. Once a task is initiated, a pilot will probably continue selecting similar information to achieve that task's goal. It is also plausible that the items required for completion of the task will come from the same general information category. The current results are consistent with and suggest this notion. Contrast this result with a situation in which each category contains unrelated information. When there is unrelated information, the transition matrix would show all cells being of equal frequency.

\section{Information Rankings and Information Acquisitions}

Recall that each subject was asked to rank the approach chart information elements in terms of their perceived importance. Ranking was done under two conditions. The first was without regard to any particular situation (context free) while the second was in the context of adverse weather (e.g., reduced minimums). The relationship between these orderings and the pilot's acquisition of information from the approach chart was of interest. To examine this relationship the rankings for each of the two conditions were averaged across all subjects. These average rankings were then correlated with the total number of acquisitions provided in table 4 . When the rankings were correlated with acquisition behavior, the correlations were quite low. The correlation between acquisitions and the context-free ranking was 0.274 , and the correlation between acquisitions and the adverse weather ranking was 0.259 . At first these results may seem surprising, yet there is at least one potential explanation for the low correlations. If certain forms of information are extremely important, it is likely that the pilot will memorize them, write them down, or in the case of frequencies, enter them immediately after requesting them. Thus, the assumption that higher importance requires more acquisitions may be incorrect (as suggested by these data).

\section{Information Recall}

The information recall section pertains to the recall test that the subjects took concerning the information items on the approach chart of their last simulation flight. Statistics that concern the recalled information, how that information relates to other cognitive processes, and how it relates to acquisitions are discussed.

Descriptive analyses. After the simulation portion of the study, subjects completed a "recall" quiz. On a paper copy of the grayed (illegible) chart for the last approach that was flown, each subject wrote all the information that he could recall. Table 13 gives a summary of the pilots' statistics for this test. On average, subjects filled in 25.62 items, which accounted for 13.31 percent of the total number of items on the chart. The subjects correctly recalled 81.35 percent of the 13.31 percent of the items that they filled in.

Table 14 lists only the elements correctly recalled by the subjects. The elements are arranged in the table according to the recall frequency. For instance, procedure name was most often recalled, followed by Visibility Requirement, and fix name at FAF. Elements that are absent from the table never were recalled correctly by any of the subjects.

The data in table 15 have been ordered by the number of items in a similarity category (defined above) which were correctly recalled (from the most to the least). For instance, the Navigation category had the most items recalled (220) and the Other Runways category had the least (7). To test whether these numbers were just an artifact of the number of chart items that comprise a category, an expected value (i.e., expected recall) was calculated for each category by multiplying the ratio of average chart items in a category by the average total items on a chart by the total number of items recalled. The last column presents the difference between the actual and expected recall.

A chi-square test was performed to compare expected and actual recall of items. The value for table 15 data, $\chi^{2}(9)=180.17$, is significant at the 1-percent level and indicates that the pilots are not recalling information from within each of the categories with equal frequency. These data may suggest that the information that is contained within some of the categories is more critical to memorize, thereby leading to the increased recall. An equally possible explanation may be 
Table 13. Information Recall Statistics

\begin{tabular}{|c|c|c|c||c|c|c|c|}
\hline Pilot & No. tried & Percent tried & Percent correct & Pilot & No. tried & Percent tried & Percent correct \\
\hline 1 & 25 & 12.32 & 76.00 & 14 & 17 & 9.29 & 82.35 \\
\hline 2 & 38 & 18.72 & 76.32 & 15 & 31 & 15.27 & 70.97 \\
\hline 3 & 41 & 22.28 & 85.37 & 16 & 16 & 7.88 & 93.75 \\
\hline 4 & 29 & 15.76 & 79.31 & 17 & 30 & 14.78 & 83.33 \\
\hline 5 & 41 & 22.40 & 85.37 & 18 & 30 & 14.78 & 80.00 \\
\hline 6 & 18 & 9.84 & 72.22 & 19 & 19 & 10.33 & 68.42 \\
\hline 7 & 41 & 20.20 & 85.37 & 20 & 21 & 11.41 & 80.95 \\
\hline 8 & 24 & 11.82 & 91.67 & 21 & 28 & 15.30 & 89.29 \\
\hline 9 & 19 & 9.36 & 84.21 & 22 & 21 & 11.48 & 85.71 \\
\hline 10 & 18 & 8.87 & 61.11 & 23 & 22 & 10.84 & 68.18 \\
\hline 11 & 9 & 4.89 & 77.78 & 24 & 28 & 13.79 & 82.14 \\
\hline 12 & 18 & 9.78 & 94.44 & 25 & 15 & 8.15 & 86.67 \\
\hline 13 & 15 & 8.20 & 80.00 & 26 & 52 & 28.26 & 94.23 \\
\hline Average & 25.62 & 13.31 & 81.35 & & & & \\
\hline
\end{tabular}

Table 14. Frequency of Elements Correctly Recalled

\begin{tabular}{|l|c||l|c||l|c|}
\hline \multicolumn{1}{|c|}{ Information element } & Recalled & Information element & Recalled & \multicolumn{1}{|c|}{ Information element } & Recalled \\
\hline Procedure name & 54 & Chart index number & 10 & Glideslope angle & 3 \\
\hline Visibility requirement & 37 & FAF intercept alt. (MSL) & 10 & GS intercept alt. (MSL) & 3 \\
\hline Fix name at FAF & 27 & ILS identifier & 10 & Proc. turn dist. limit & 3 \\
\hline Inbound course & 25 & Location of MAP & 10 & Tower freq. & 3 \\
\hline Decision altitude (AGL) & 23 & Time from FAF to MAP & 10 & Airport name & 2 \\
\hline Feeder route radial & 23 & VOR name & 10 & FAF intercept alt. (AGL) & 2 \\
\hline Fix name & 22 & Fix name at IAF & 9 & MSA minimum alt. & 2 \\
\hline Distance (non-DME) & 20 & ILS loc. magnetic course & 9 & MSA ref. point & 2 \\
\hline VOR identifier & 20 & Outbound course & 9 & Rate of descent & 2 \\
\hline Airport elevation & 19 & Decision altitude (MSL) & 7 & TDZE parallel runway & 2 \\
\hline Missed approach proc. & 19 & Primary fac-freq. & 7 & ATIS arrival freq. & 1 \\
\hline Min. safe alt. on AP & 18 & Approach freq. & 5 & Latitude-longitude grid & 1 \\
\hline DME distance & 15 & Effective date & 5 & Lead radial & 1 \\
\hline VOR freq. & 15 & ILS localizer freq. & 5 & Magnetic variation & 1 \\
\hline Geographic name & 14 & Holding pattern course & 4 & Runway length & 1 \\
\hline Obstruction & 12 & MAP (nonprecision) & 4 & Step-down alt. (AGL) & 1 \\
\hline Step-down alt. (MSL) & 11 & Other runway numbers & 4 & Threshold cross height & 1 \\
\hline Chart date & 10 & TDZE target runway & 4 & & \\
\hline
\end{tabular}

Table 15. Categories and Information Recall Statistics

\begin{tabular}{|l|c|c|c|c|c|}
\hline \multicolumn{1}{|c|}{ Category } & Types in category & Average chart items & Items recalled & Expected recall & Difference \\
\hline Navigation & 21 & 59.25 & 220 & 169 & 51 \\
\hline Validation & 9 & 14.25 & 100 & 41 & 59 \\
\hline Navigation aids & 12 & 25.00 & 67 & 71 & -4 \\
\hline Missed approach & 6 & 13.00 & 47 & 37 & 10 \\
\hline Visibility requirement & 1 & 13.00 & 37 & 37 & 0 \\
\hline Obstructions & 6 & 31.50 & 34 & 90 & -56 \\
\hline Geography & 4 & 6.75 & 16 & 19 & -3 \\
\hline Final items & 5 & 6.50 & 10 & 19 & -9 \\
\hline Communications & 7 & 9.00 & 9 & 26 & -17 \\
\hline Other runway & 4 & 13.75 & 7 & 39 & -32 \\
\hline Total & 75 & 192.00 & 547 & 547 & \\
\hline
\end{tabular}


that some items just do not promote or require memorization, such as Communications, which are annunciated by tuning the instruments and therefore are not memorized. Overall, values indicate that the number of items represented in a category was not a good indicator of how often items in a category would be recalled and that the category memberships themselves might influence which items are memorized.

The perceived importance of approach information was a poor predictor of which items pilots memorize. The correlation between element types that were correctly recalled versus their average importance rankings was 0.440 , indicating that importance played a very small role in determining which items pilots commit to memory. When the number of acquisitions was normalized by the number of chart items of that type, this correlation dropped to 0.382 .

Items remembered and information acquisition. This section addresses whether a relationship exists between the number of information acquisitions and the subjects' recall of those items. Since the selected information disappeared from the screen after $15 \mathrm{sec}$, it was often necessary for subjects to repeatedly acquire the information. It would seem logical to assume that the more times the information was acquired the more likely it would be for the pilot to recall it later. To examine the likelihood of recalling often repeated information, the number of times each piece of information from the approach chart was acquired was paired with the number of times that information was correctly recalled. A correlation coefficient was calculated between these variables, yielding $r=0.618$ ( $r$ is the correlation coefficient). This correlation demonstrates that the recalled items were selected more often than those that were not recalled.

It would also seem logical that the more recently an item was acquired (i.e., nearer the end of the flight) the more likely it would be for the pilot to recall it. Thus, the average time of each item's last access (in percentage of overall time) was compared to whether or not it was correctly recalled. This analysis showed that items that were correctly recalled were accessed more recently than items that were not recalled.

Memorization questions summary. After the subjects took the recall test, they completed two questions concerning the memorization of approach chart information. The first question asked whether, under actual flying conditions, pilots make a conscious effort to memorize approach chart information during the preapproach briefing so that they will not have to acquire it again during descent and approach. Eleven said that they did try to memorize items but 14 did not. (One subject did not answer these two questions.) The second question was whether pilots made a conscious effort during the simulation flights to memorize approach chart information during the predescent briefing so that they did not have to acquire it again during descent and approach. Fourteen said that they did make a conscious effort to memorize and 11 said they did not. Subjects also supplied a list of elements that they felt they memorized. The correlation ( 0.330$)$ of the elements the pilots thought they memorized to what was correctly recalled indicated that the pilots have a poor understanding of what they actually commit to memory. ${ }^{9}$ A possible explanation for this difference might be that pilots felt that important elements are memorized, but an earlier analysis showed that an item's perceived importance was not directly related to its likelihood of being recalled.

\section{Information Requirements}

Past information requirements analyses (Boeing 1991a, 1991b; Hansman and Mykityshyn 1990; Mykityshyn and Hansman 1990, 1991) of approach chart use help identify the information that is necessary for safe descent from an en route altitude to the landing altitude of a destination runway. These studies concentrated primarily on observable tasks (e.g., descent) and not on the cognitive tasks (e.g., planning), which are highly represented when managing approach information. Given the dominance of cognitive tasks when one is managing information, the study described in this paper further investigated the information requirements of approach chart use and emphasized cognitive task and actual use. Results of this study are intended to augment previous studies that identified the information that is required by identifying what information is acquired, when it is acquired, and what presentation concepts might facilitate its efficient use by better matching the pilots' mental model of the information with its presentation.

\section{Categories of Approach Chart Information and Information Requirements}

Knowing how pilots mentally organize approach chart information provides cartographers and flight-deck system designers with knowledge that is useful in their endeavors for efficient interfaces. Having information formatted in a way that matches the users' mental models improves the users' efficiency when they are working with that information (Clay 1993; Woods 1985). This study indicated that pilots use 10 primary categories to organize approach chart information: Communications, Geography, Validation, Obstructions, Navigation,

\footnotetext{
The inability of individuals to articulate how they do things mentally spans all domains. This inability is one reason why cognitive models are explored using techniques other than just interviews.
} 
Missed Approach, Final Items, Other Runways, Visibility Requirement, and Navigation Aids. These similarity categories appear to underlie many of the cognitive tasks that are invoked by pilots and were highly reflective in their acquisition of approach information. Presenting information according to these classifications should facilitate pilots' use of approach chart information by not requiring them to expend additional cognitive effort organizing the information prior to cataloging and using it. If information is presented according to the categories that are identified in this study, pilots should be able to extract and use the information easily by recognizing it in the contexts that support the higher level cognitive tasks. Please refer to appendix $F$ for a brief elaboration on how these categories might be used to organize approach charts and the electronic presentation of approach information.

\section{Importance of Approach Chart Information and Information Requirements}

A review of the pilots' perception of the importance of approach chart information indicated that there was stability across the contexts used in this study. Stability across contexts is critical if design guidelines are to be derived from these data. When combined with the actual use of information, perceived importance of information can help determine which information to highlight or duplicate in its presentation concept. These guidelines can be derived by the average ranking of the individual element types (e.g., ILS localizer magnetic course) or by the relative order of similarity categories in the average rankings. By examining the relative order of similarity categories, it was observed that many of the element types that are identified as highly important come from the similarity categories of Visibility Requirement ("Are we legal to fly this approach?") and chart Validation ("Do we have the correct and same approach?"). Also note-worthy was that Geography and Other Runways information occupied the "least important" positions.

\section{Acquisition of Approach Chart Information and Information Requirements}

Many design guidelines can be derived from observing the actual acquisition of information. Two primary findings that concern the acquisition of approach chart information were that similarity categories were highly represented in the acquisitions and that the requirements (reflected by the acquisitions) changed as a function of flight phase. These findings suggest that the categories can be used to help define both the presentation formats and the tailoring of information (when the information is presented electronically).
Figure 20 presents the data that were discussed earlier in a slightly different way. In figure 20 the acquisitions from the similarity categories are plotted as a function of flight phase. As can be seen, all the categories of information are used primarily during the preapproach phase. As discussed earlier, this result supports the theory that the primary use of the approach charts is for planning (versus monitoring). Acquisitions from the different categories then vary somewhat for the remaining phases of the approach. These data on category usage can directly affect design guidelines, or emphasis can be placed on the acquisition of individual items instead of on the categories, as discussed earlier.

Additional analyses showed that some categories were more likely to be accessed than others, independent of the number of elements that comprise the category (refer to tables 9 and 10). This likelihood again can affect both guidelines that concern the presentation formats (e.g., salience) and the tailoring of information. The transition frequencies shown in tables 11 and 12 are another finding that would affect the dynamic tailoring of information. The transitions show that when a pilot acquires information from a given category, the next acquisition (i.e., the transition) is probably another element within the same category.

Usually, the perceived importance of information dictates its presentation format for arranging choices such as the salience or repetition of information. However, a primary reason for making a specific piece of information more salient or for repeating it is to make it easier to acquire. Analyses in this study showed that there was a very low correlation between importance and frequency of acquisition. This result suggests that neither frequency nor importance should be used by itself to dictate guidelines that concern the salience of information presentation formats.

\section{Conclusions}

Many tasks that are associated with using approach charts are cognitive, such as planning and monitoring. Clay found that pilots were required to do more tasks during the approach segments of flight and that because of this increase in cognitive workload, there is increased importance associated with the abilities of the pilot to obtain information quickly and accurately to support these tasks and remember the information long enough to apply it. To aid the pilot during this phase of flight, design efforts associated with the presentation of approach information should consider the pilots' cognitive demands. The study reported in this paper, managing approach plate information study (MAPLIST), combined psychometric scaling techniques with a simulation task to provide cartographers and flight-deck system 
designers with such information. This study provides quantifiable links between pilots' cognitive representations of approach information and their use of approach information.

Categorization is a dominant cognitive process that supports cognitive tasks in all domains that involve information management. Categories of information are used by people to reduce the amount of information with which they work. For instance, pilots do not treat each item of information on the approach chart as a completely independent element (an impossible task given the amount of information). Instead, pilots categorize (i.e., organize by similarity) the information, manage it through mental manipulations of the category, and then use the mental classification to access the individual item when it is needed. Through this process pilots are able to comfortably work with the approach chart by not being overwhelmed by the amount of information it contains.

A primary finding in this study was that pilots appear to mentally organize approach chart information into 10 primary categories: Communications, Geography, Validation, Obstructions, Navigation, Missed Approach, Final Items, Other Runways, Visibility Requirement, and Navigation Aids. These similarity categories were found to underlie many of the cognitive tasks invoked by pilots and were highly reflected in their acquisition of approach information. Given these findings, it is reasonable to believe that the use of these categories in chart design may facilitate pilots' use of approach charts. Incorporating the categories in the presentation formats could relieve the pilot of the additional cognitive effort that is associated with organizing the information prior to cataloging and using it. When information is presented using the categories found here, pilots should be able to extract the information more easily by recognizing it in a context that supports their higher level cognitive tasks. Categorization is already being done by the pilots to prevent overload when they are dealing with a large amount of information (such as that on an approach chart). Having the presentation coincide with this process should improve efficiency and decrease errors that are associated with its use. Appendix F provides a brief elaboration on possible applications of these categories to approach chart organization and electronic presentation concepts.

As stated previously, the similarity categories appeared significant in many of the analyses, thus giving more support for their use in presentation formats. For the average importance rankings of the information obtained from the pilots, information elements from within the same categories appear close together in the ranking data. For instance, elements that comprise Validation and Visibility Requirement were given high importance rankings, while members of the Geography and Other Runways categories were given low priority ratings. A strong relation with categories allows the designer to use the relative order of either the similarity categories or individual elements within similarity categories to decide presentation-format issues that concern priority (e.g., salience or repetition).

It was also suggested that adverse weather did not affect the pilots' perception of the importance of information. However, the temporal position within the approach did seem to affect the perceived importance of the information. That is, the importance of an information type seemed to depend on approach segment (i.e., preapproach, approach transition, intermediate, or final segment). This change in importance may be a reflection of the information requirements of the individual segments and again provides design insight for dynamic tailoring of information presentations.

The acquisition data provide many insights for presentation formats and for dynamically tailoring information. Results showed that a greater amount of information was collected during the preapproach phase of flight. Acquisition counts showed that the information types that were acquired varied most with the approach segments (i.e., transition, intermediate, final, and missed). When they were analyzed statistically for each category, five categories were acquired significantly more in preapproach. For the remaining five categories, only Obstructions and Geography demonstrated a pattern in which more information was collected during the approach phase than during the preapproach phase. These findings were just a few of many that supported the planning versus monitoring task allocation paradigm that is associated with approach chart use.

Additional analysis of variance (ANOVA) results (with the similarity categories as dependent measures) showed that the pilot not flying (PNF) acquired more information than the pilot flying (PF) for five of the categories. The main effect of precision indicated that more Navigation, Obstructions, and Missed Approach information was obtained when pilots were flying very high frequency (VHF) omnidirectional range (VOR), while more information was acquired from the Geography and Final Items categories when they were flying instrument landing system (ILS). More information was also acquired during adverse weather scenarios of VOR approaches than of ILS approaches. While it was not immediately obvious, a significant main effect of weather showed that Obstructions information was acquired more in good weather. More intuitive were the significant increases in acquisitions from Visibility Requirement, Missed Approach, Navigation, and Final Items for adverse weather. 
Further investigation into the relationship of similarity categories and the acquisition of approach information showed that category membership provided a good indication of selection probability. Certain categories of information were selected more often than others, independent of the number of items that comprise the category. Analyses also showed high within-category transitions for each of the categories. These transition relationships provide additional evidence that the identified categories contain functionally related information, since similar items are probably necessary to support a task. The transition relations also provide additional insight into how information might be tailored if presented electronically.

When testing subjects for information that was recalled from the last approach, the category membership of an information item was a good indication of whether it would be remembered. This finding was independent of the number of items that comprise the category. Both Validation and Navigation information were recalled well whereas members of Obstructions, Communications and Other Runways were not recalled well. The correlation of an element's recall frequency with its average importance ranking showed that importance was not a strong indicator of which information would be recalled. However, more exposure to an item increased the likelihood of its recall. A fairly high correlation of acquisition frequency to recall frequency showed that the items that were remembered had been accessed more than those items that were not remembered. Another finding was that items that were recalled correctly were on average accessed more recently than those that were not recalled or that were recalled incorrectly.

Results of this study are intended to augment previous work that identified what information was required by identifying what information is acquired, when it is acquired, and the mental models that pilots have of this information. Augmentation of this type should help cartographers and flight-deck system designers devise presentation concepts that facilitate efficient use by better matching the pilots' cognitive models and use of the information with its presentation. For instance, the similarity categories were salient in the pilots' use of approach charts. Therefore, using these underlying categories of information in designing presentation formats might ease related pilot workload by not requiring the pilot to organize the information to the same extent prior to using it.

NASA Langley Research Center

Hampton, VA 23681-0001

October 27, 1995 


\section{Appendix A}

\section{Approach Chart Formats}

Instrument approach charts are currently published by Jeppesen Sanderson, Inc., (hereafter referred to as Jeppesen) and the National Oceanic and Atmospheric Administration (NOAA) National Ocean Service (hereafter referred to as NOS). Both Jeppesen and NOS charts provide the pilot with all the information that is needed for a given runway. While both charts share more commonalties than differences, there are differences in the positioning of some of the information and symbols that are used. (See fig. A1, taken in most part from Jeppesen Sanderson, 1993, pp. 3-6.)

Both formats have a heading section, plan view, profile view, landing minimums, missed approach instruction, and a missed approach point (MAP) table. The NOS charts also have two additional sections: one has notes and cautions (that are placed in either the plan view or profile view of Jeppesen charts), and the other shows the airport diagram (separate chart with Jeppesen format).

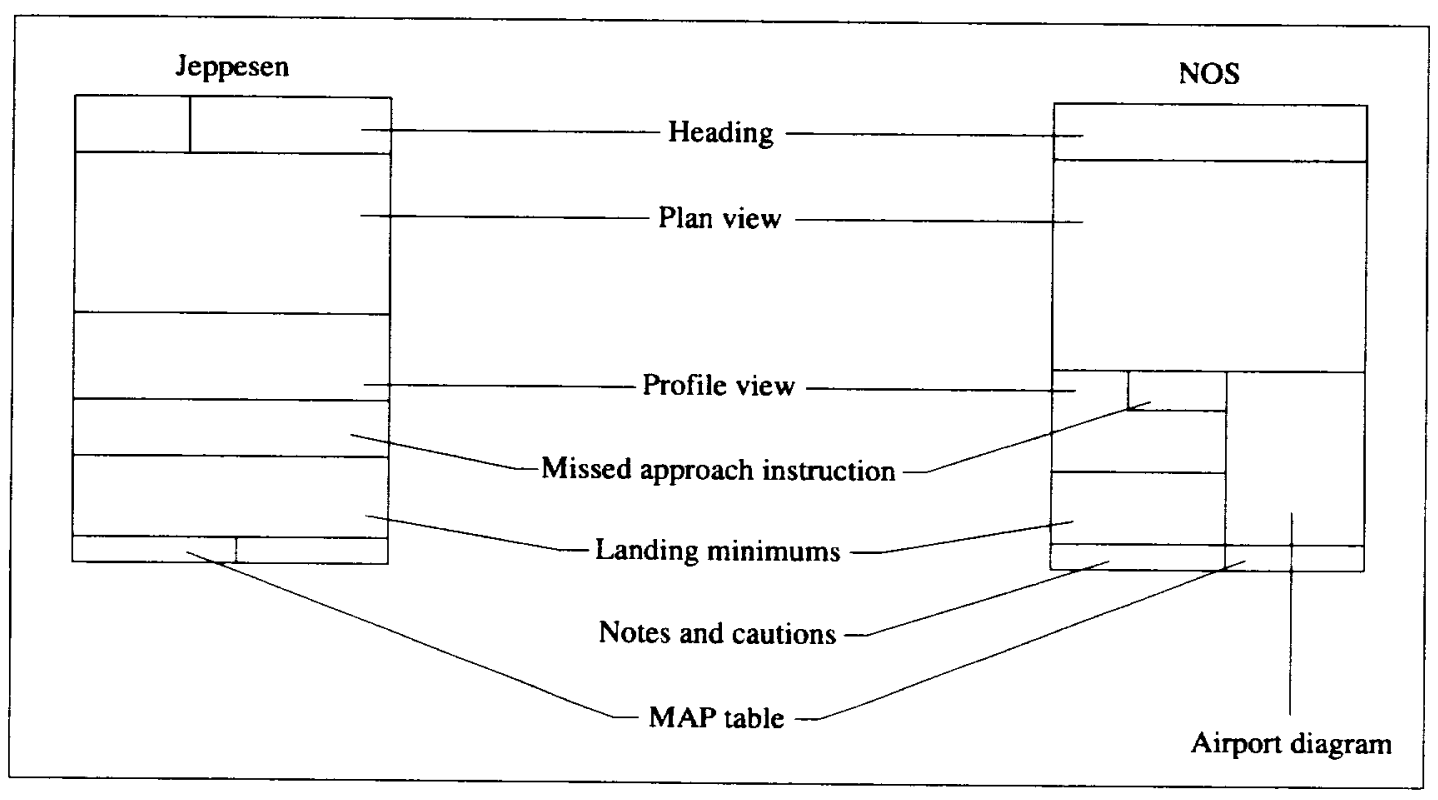

Figure A1. Approach chart layouts. 


\section{Appendix B}

\section{Preapproach and Approach Time Profiles and} $z$ Scores

The $z$ score is the number of standard deviations that a given data point is above or below the mean. A positive $z$ score represents an above-the-mean score, and a negative $z$ score represents a finding that is below the mean. Because of a procedural error during scenario 2 for crew 10 , the subsequent $z$ score for their total time was 3.443 , which was well outside the range that is acceptable for this study ( -2 to 2 ). All other $z$ scores were within the range -1.953 through 1.864 and were retained for analysis.

In tables B1 through B5, phase 0 refers to the approach transition segment. Phase 1 refers to the intermediate segment. Phase 2 refers to the final approach segment. Phase 3 is the missed approach segment.

Table B1. Scenario 1 Simulation Statistics

\begin{tabular}{|c|c|c|c|c|c|c|c|c|c|c|}
\hline \multirow[b]{2}{*}{ Crew } & \multicolumn{5}{|c|}{ Time, sec } & \multicolumn{5}{|c|}{$z$ score } \\
\hline & Phase 0 & Phase 1 & Phase 2 & Phase 3 & Total & Phase 0 & Phase 1 & Phase 2 & Phase 3 & Total \\
\hline 1 & 578.500 & 102.400 & 158.700 & & 839.600 & -0.6182 & 0.0449 & 0.2206 & & -0.4060 \\
\hline 2 & 578.500 & 87.100 & 148.500 & & 814.100 & -0.6182 & -0.8659 & -0.2199 & & -1.1763 \\
\hline 3 & 604.100 & 87.100 & 158.700 & & 849.900 & 0.5293 & -0.8659 & 0.2206 & & -0.0948 \\
\hline 4 & 640.000 & 97.300 & 168.900 & & 906.200 & 2.1385 & -0.2587 & 0.6610 & & 1.6060 \\
\hline 5 & 604.100 & 87.100 & 163.800 & & 855.000 & 0.5293 & -0.8659 & 0.4408 & & 0.0593 \\
\hline 6 & 563.200 & 87.000 & 102.400 & 35.800 & 788.400 & -1.3041 & -0.8718 & -2.2106 & & -1.9527 \\
\hline 7 & 552.900 & 138.300 & 158.700 & & 849.900 & -1.7658 & 2.1819 & 0.2206 & & -0.0948 \\
\hline 8 & 599.000 & 87.100 & 158.700 & & 844.800 & 0.3007 & -0.8659 & 0.2206 & & -0.2489 \\
\hline 9 & 609.200 & 102.400 & 174.100 & & 885.700 & 0.7579 & 0.0449 & 0.8856 & & 0.9867 \\
\hline 10 & 578.500 & 112.700 & 174.100 & & 865.300 & -0.6182 & 0.6580 & 0.8856 & & 0.3704 \\
\hline 11 & 604.100 & 133.200 & 174.100 & & 911.400 & 0.5293 & 1.8783 & 0.8856 & & 1.7631 \\
\hline 12 & 578.500 & 107.600 & 102.400 & 35.800 & 824.300 & -0.6182 & 0.3544 & -2.2106 & & -0.8682 \\
\hline $10 \mathrm{~b}$ & 609.200 & 92.100 & 153.600 & & 854.900 & 0.7579 & -0.5682 & 0.0003 & & 0.0562 \\
\hline Average $^{\mathbf{a}}$ & 592.292 & 101.646 & 153.592 & & 853.038 & & & & & \\
\hline Avg. dev. ${ }^{b}$ & 19.024 & 13.342 & 16.535 & & 24.657 & & & & & \\
\hline Stdevp $^{c}$ & 22.309 & 16.799 & 23.158 & & 33.102 & & & & & \\
\hline
\end{tabular}

${ }^{\mathrm{a}}$ Mean

${ }^{b}$ Average of absolute deviations from the mean

${ }^{c}$ Standard deviation from the mean 
Table B2. Scenario 2 Simulation Statistics

\begin{tabular}{|c|c|c|c|c|c|c|c|c|c|c|}
\hline \multirow[b]{2}{*}{ Crew } & \multicolumn{5}{|c|}{ Time, sec } & \multicolumn{5}{|c|}{$z$ score } \\
\hline & Phase 0 & Phase 1 & Phase 2 & Phase 3 & Total & Phase 0 & Phase 1 & Phase 2 & Phase 3 & Total \\
\hline 1 & 578.500 & 82.000 & 163.800 & & 824.300 & -0.5627 & -0.3576 & -0.1393 & & -0.3821 \\
\hline 2 & 599.000 & 87.100 & 153.600 & & 839.700 & 0.1688 & -0.3368 & $-0 . \overline{4645}$ & & -0.3275 \\
\hline 3 & 599.000 & 87.100 & 158.700 & & 844.800 & 0.1688 & -0.3368 & -0.3019 & & -0.3094 \\
\hline 4 & 640.000 & 97.300 & 168.900 & & 906.200 & 1.6319 & -0.2952 & 0.0233 & & -0.0918 \\
\hline 5 & 619.500 & 92.200 & 158.700 & & 870.400 & 0.9003 & -0.3160 & -0.3019 & & -0.2187 \\
\hline 6 & 558.000 & 92.100 & 138.300 & & 788.400 & -1.2942 & -0.3164 & -0.9523 & & -0.5093 \\
\hline 7 & 558.000 & 128.000 & 158.700 & & 844.700 & -1.2942 & -0.1700 & -0.3019 & & -0.3098 \\
\hline 8 & 614.400 & 92.100 & 153.600 & & 860.100 & 0.7184 & -0.3164 & -0.4645 & & -0.2552 \\
\hline 9 & 634.800 & 102.400 & 168.900 & & 906.100 & 1.4463 & -0.2744 & 0.0233 & & -0.0922 \\
\hline 10 & 614.400 & 1017.800 & 271.400 & & 1903.600 & 0.7184 & 3.4598 & 3.2912 & & 3.4432 \\
\hline 11 & 568.300 & 102.400 & 179.200 & & 849.900 & -0.9267 & -0.2744 & 0.3517 & & -0.2914 \\
\hline 12 & 583.600 & 112.600 & 163.900 & & 860.100 & -0.3807 & -0.2328 & -0.1361 & & -0.2552 \\
\hline $10 \mathrm{~b}$ & 558.000 & 112.600 & 148.500 & & 819.100 & -1.2942 & -0.2328 & -0.6271 & & -0.4005 \\
\hline Average $^{\mathrm{a}}$ & 594.269 & 169.669 & 168.169 & & 932.108 & & & & & \\
\hline Avg. dev. ${ }^{b}$ & 24.802 & 130.482 & 17.804 & & 149.460 & & & & & \\
\hline Stdevp $^{c}$ & 28.024 & 245.140 & 31.365 & & 282.152 & & & & & \\
\hline
\end{tabular}

${ }^{b}$ Average of absolute deviations from the mean

cStandard deviation from the mean

Table B3. Scenario 2 Simulation Statistics Without Crew 10

\begin{tabular}{|c|c|c|c|c|c|c|c|c|c|c|}
\hline \multirow[b]{2}{*}{ Crew } & \multicolumn{5}{|c|}{ Time, sec } & \multicolumn{5}{|c|}{$z$ score } \\
\hline & Phase 0 & Phase 1 & Phase 2 & Phase 3 & Total & Phase 0 & Phase 1 & Phase 2 & Phase 3 & Total \\
\hline 1 & 578.500 & 82.000 & 163.800 & & 824.300 & -0.5627 & -0.3576 & -0.1393 & & -0.3821 \\
\hline 2 & 599.000 & 87.100 & 153.600 & & 839.700 & 0.1688 & -0.3368 & -0.4645 & & -0.3275 \\
\hline 3 & 599.000 & 87.100 & 158.700 & & 844.800 & 0.1688 & -0.3368 & -0.3019 & & -0.3094 \\
\hline 4 & 640.000 & 97.300 & 168.900 & & 906.200 & 1.6319 & -0.2952 & 0.0233 & & -0.0918 \\
\hline 5 & 619.500 & 92.200 & 158.700 & & 870.400 & 0.9003 & -0.3160 & -0.3019 & & -0.2187 \\
\hline 6 & 558.000 & 92.100 & 138.300 & & 788.400 & -1.2942 & -0.3164 & -0.9523 & & -0.5093 \\
\hline 7 & 558.000 & 12.800 & 158.700 & & 844.700 & -1.2942 & -0.1700 & -0.3019 & & -0.3098 \\
\hline 8 & 614.400 & 92.100 & 153.600 & & 860.100 & 0.7184 & -0.3164 & -0.4645 & & -0.2552 \\
\hline 9 & 634.800 & 102.400 & 168.900 & & 906.100 & 1.4463 & -0.2744 & 0.0233 & & -0.0922 \\
\hline 10 & 568.300 & 102.400 & 179.200 & & 849.900 & -0.9267 & -0.2744 & 0.3517 & & -0.2914 \\
\hline 11 & 583.600 & 112.600 & 163.900 & & 860.100 & -0.3807 & -0.2328 & -0.1361 & & -0.2552 \\
\hline 12 & 558.000 & 112.600 & 148.500 & & 819.100 & -1.2942 & -0.2328 & -0.6271 & & -0.4005 \\
\hline Average $^{\mathrm{a}}$ & 592.592 & 98.992 & 159.567 & & 851.150 & & & & & \\
\hline Avg. dev. & 25.192 & 10.507 & 7.811 & & 24.525 & & & & & \\
\hline Stdevp $^{c}$ & 28.534 & 12.750 & 10.184 & & 32.250 & & & & & \\
\hline
\end{tabular}

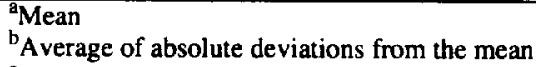

${ }^{\mathrm{c}} \mathrm{Standard}$ deviation from the mean 
Table B4. Scenario 3 Simulation Statistics

\begin{tabular}{|c|c|c|c|c|c|c|c|c|c|c|}
\hline \multirow[b]{2}{*}{ Crew } & \multicolumn{5}{|c|}{ Time, sec } & \multicolumn{5}{|c|}{$z$ score } \\
\hline & Phase 0 & Phase 1 & Phase 2 & Phase 3 & Total & Phase 0 & Phase 1 & Phase 2 & Phase 3 & Total \\
\hline 1 & 650.200 & 51.200 & 128.000 & & 829.400 & -0.4474 & -1.9251 & 0.6481 & & -0.4950 \\
\hline 2 & 675.800 & 61.500 & 107.500 & & 844.800 & 0.7640 & 0.0101 & -0.9555 & & 0.1502 \\
\hline 3 & 645.100 & 56.300 & 112.700 & & 814.100 & -0.6887 & -0.9669 & -0.5488 & & -1.1360 \\
\hline 4 & 650.200 & 56.300 & 122.800 & & 829.300 & -0.4474 & -0.9669 & 0.2413 & & -0.4992 \\
\hline 5 & 650.200 & 61.500 & 133.100 & & 844.800 & -0.4474 & 0.0101 & 1.0470 & & 0.1502 \\
\hline 6 & 650.200 & 61.500 & 128.000 & & 839.700 & -0.4474 & 0.0101 & 0.6481 & & -0.0635 \\
\hline 7 & 650.200 & 66.600 & 81.900 & 5.200 & 803.900 & -0.4474 & 0.9683 & -2.9581 & & -1.5633 \\
\hline 8 & 670.700 & 61.400 & 122.800 & & 854.900 & 0.5227 & -0.0087 & 0.2413 & & 0.5733 \\
\hline 9 & 655.300 & 71.700 & 128.000 & & 855.000 & -0.2060 & 1.9266 & 0.6481 & & 0.5775 \\
\hline 10 & 701.400 & 56.300 & 128.000 & & 885.700 & 1.9754 & -0.9669 & 0.6481 & & 1.8636 \\
\hline 11 & 686.000 & 61.400 & 122.900 & & 870.300 & 1.2467 & -0.0087 & 0.2491 & & 1.2185 \\
\hline 12 & 675.800 & 66.600 & 117.800 & & 860.200 & 0.7640 & 0.9683 & -0.1498 & & 0.7953 \\
\hline $10 \mathrm{~b}$ & 614.400 & 66.500 & 122.800 & & 803.700 & -2.1414 & 0.9496 & 0.2413 & & -1.5716 \\
\hline Average $^{\mathrm{a}}$ & 659.654 & 61.446 & 119.715 & & 841.215 & & & & & \\
\hline Avg. dev. ${ }^{b}$ & 17.143 & 3.966 & 9.071 & & 19.568 & & & & & \\
\hline Stdevp $^{c}$ & 21.133 & 5.322 & 12.784 & & 23.870 & & & & & \\
\hline
\end{tabular}

${ }^{2}$ Mean

${ }^{b}$ Average of absolute deviations from the mean

${ }^{\mathrm{c}}$ Standard deviation from the mean

Table B5. Scenario 4 Simulation Statistics

\begin{tabular}{|c|c|c|c|c|c|c|c|c|c|c|}
\hline \multirow[b]{2}{*}{ Crew } & \multicolumn{5}{|c|}{ Time, sec } & \multicolumn{5}{|c|}{$z$ score } \\
\hline & Phase 0 & Phase 1 & Phase 2 & Phase 3 & Total & Phase 0 & Phase 1 & Phase 2 & Phase 3 & Total \\
\hline 1 & 593.900 & 56.300 & 117.800 & & 768.000 & -1.7580 & 0.0278 & -0.4132 & & -1.6397 \\
\hline 2 & 640.000 & 66.500 & 87.000 & & 793.500 & -0.5214 & 0.7647 & -2.4555 & & -1.0540 \\
\hline 3 & 734.400 & 40.800 & 117.300 & & 892.500 & 2.0108 & -1.0921 & -0.4463 & & 1.2201 \\
\hline 4 & 670.700 & 66.600 & 122.900 & & 860.200 & 0.3021 & 0.7719 & -0.0750 & & 0.4781 \\
\hline 5 & 650.200 & 76.800 & 133.200 & & 860.200 & -0.2478 & 1.5089 & 0.6080 & & 0.4781 \\
\hline 6 & 619.500 & 66.600 & 122.900 & & 809.000 & -1.0713 & 0.7719 & -0.0750 & & -0.6979 \\
\hline 7 & 655.300 & 35.900 & 143.400 & & 834.600 & -0.1110 & -1.4461 & 1.2844 & & -0.1099 \\
\hline 8 & 660.400 & 56.300 & 112.600 & & 829.300 & 0.0258 & 0.0278 & -0.7580 & & -0.2316 \\
\hline 9 & 665.600 & 66.500 & 122.800 & & 854.900 & 0.1653 & 0.7647 & -0.0816 & & 0.3564 \\
\hline 10 & 701.400 & 51.200 & 128.000 & & 880.600 & 1.1256 & -0.3407 & 0.2632 & & 0.9467 \\
\hline 11 & 675.800 & 61.500 & 122.900 & & 860.200 & 0.4389 & 0.4035 & -0.0750 & & 0.4781 \\
\hline 12 & 609.200 & 25.600 & 128.000 & & 762.800 & -1.3476 & -2.1902 & 0.2632 & & -1.7591 \\
\hline $10 \mathrm{~b}$ & 696.300 & 56.300 & 153.600 & & 906.200 & 0.9888 & 0.0278 & 1.9607 & & 1.5347 \\
\hline Average $^{\mathrm{a}}$ & 659.438 & 55.915 & 124.031 & & 839.385 & & & & & \\
\hline Avg. dev. ${ }^{b}$ & 29.005 & 10.794 & 10.161 & & 36.786 & & & & & \\
\hline $\operatorname{Stdevp}^{c}$ & 37.279 & 13.841 & 15.081 & & 43.535 & & & & & \\
\hline
\end{tabular}

${ }^{a}$ Mean

${ }^{b}$ Average of absolute deviations from the mean

${ }^{\mathrm{S}} \mathrm{Standard}$ deviation from the mean 


\section{Appendix C}

\section{Debriefing Questionnaire and Responses}

Debriefing questions and summaries of responses are provided in this appendix. Comments have been edited; those that were not pertinent were deleted, and those that pertained specifically to differences between the MD80 and the DC-9 series 30 were deleted. Since all American Airline pilots made adjustments because of their use of above ground level (AGL) altitudes instead of mean sea level (MSL) altitudes, all related comments were also removed.

The first question was how similar the simulator response and other general handling characteristics were to the aircraft that pilots were accustomed to. One pilot felt the response and other general handling characteristics were very similar, while 17 judged them similar and 8 said they were not similar. Specific comments concerning this question have been paraphrased below:

- Pitch and roll rates don't feel similar, and fuel flow was not close.

- The simulator was more sensitive (i.e., move the nose slightly and the vertical speed indicator and the (VSI) really jumped).

- The simulator was more sensitive than aircraft in all phases of pitch, roll, and yaw.

- The simulator was overly sensitive in pitch and roll.

- The simulator was too sensitive in pitch with gear down.

- The simulator was too sensitive to rudder inputs on landing rollout.

The second question was how similar the onboard equipment-systems were to what the pilots are accustomed to. Three pilots judged them very similar, 18 said they were similar, and 5 said they were dissimilar. Comments specific to this question are presented below:

- There are differences in flight director controls.

- The altitude selector is different and in a different location.

The next question asked whether pilots needed to change their normal strategies in order to accomplish their tasks. In response to this question 9 pilots said they did change their normal strategies while 17 said they did not. Comments offered to this question were as follows:

- There were different checklist procedures.

- Approach chart information retrieval was more time consuming, thus reducing the amount of attention spent on flying the aircraft.

- I memorized more to avoid using the mouse during a critical phase of flight.

- I used only heading select and vertical speed due to different autopilot.

The next series of questions that the pilots answered pertained to the acquisition device used in the simulator. The first question asked whether the position of the approach chart display generally satisfied pilots' needs. In response to this question, 23 pilots said the position was generally satisfactory, whereas 2 said it was not (1 pilot did not answer this question). Comments specific to this question are listed below:

- I prefer up and down eye movement instead of left to right head movement.

- Excessive head movement could induce vertigo.

- One must look $30 \mathrm{deg}$ away from the instruments to see the monitor.

The next question asked whether the positioning and operation of the cursor-control device was generally satisfactory to meet pilots' needs. Twenty-five subjects answered yes (again, one pilot did not answer this question).

The next series of questions addressed the approach information that was used in the simulator. The first one asked whether the information on the screen was easy to read. Twenty-one pilots said that it was easy to read and 4 said it was not. Comments that are specific to the presentation of the approach information in the simulator are compiled below:

- The resolution could have been better.

- Some areas, such as distance between fixes, were difficult to read.

- Runway information was very small.

- Some items were difficult to click on.

- Some of the smaller crowded information was difficult to read.

When asked whether the acquired information remained on the display long enough, 8 pilots said that display time was usually too short; 17 said it was usually just right; none said that it was too long (1 pilot did not answer). Additional comments indicated that there were times when items faded sooner than the pilots would have liked.

Concerning the acquisition device, the pilots were asked whether they experienced difficulties using the cursor-control device to acquire information from the 
display. In response to this question, 2 pilots said that they often experienced difficulties, 20 said that they rarely experienced difficulties, and 4 said that they never experienced difficulties. Specific comments are listed below:

- Sometimes I couldn't get information on screen because I was hurrying-tried to get 6 or 7 items displayed at once and that caused me to make an error in point-shoot technique.

- There was a learning curve.

- I did have numerous miss clicks of information displayed in a group (i.e., the frequency box).

When asked whether they had difficulties seeing the cursor on the screen, no pilots answered always or occasionally. Eleven pilots said that they rarely had difficulties, and 15 said that they never had problems.

The pilots were also asked whether they recalled any instances in which they decided not to acquire information that they wanted because they were busy with the airplane. Ten said that they did recall such instances, whereas 16 said they did not. Comments pertaining to this question are listed below:

- On final I finally learned to pre-position the cursor to the decision height position for quick access.

- I often recall instances when I was too busy to acquire information because the time element was critical (i.e., course change, altitude change, or approach minimums).

- Once in a while I was too busy during aircraft reconfiguration or altitude transition; I went back to it later.

- Nearing an event like altitude capture or course capture, I deferred accessing information until after the event.

- I just asked the pilot not flying to supply needed information.

- Had I been able to simply look to acquire information, I would have.

- During a critical period such as a turn and descent or intercept, I was too busy.

- I was too busy on final approach.

- I was too busy two or three times: during busiest parts of approach (turns, descents).

- I generally asked the PNF for any information I needed.

Pilots were also asked whether the acquisition task changed the frequency with which they normally obtained information from an approach chart. Fifteen said that it did, whereas 11 said that it did not. The comments listed below give a good indication of how the task changed the frequency of acquisitions.

- I started asking the PNF to retrieve and repeat information.

- Since it took longer, I didn't cross-check as frequently.

- I had to memorize more information.

- I tried to plan ahead more.

- Information is generally gathered in a more all encompassing way (i.e., when checking for lead-in information, I would always note the radial, altitude, and distance when I looked for the radial).

Pilots were also asked whether the different approaches appeared to be approximately equal in difficulty. Twenty-four of the pilots said they did appear equal in difficulty, and two said they did not. Comments pertaining to this question are listed below:

- Short feeder routes made descent altitude more time-critical.

- The task was complicated by large angle turns.

- There were normal differences between precision and nonprecision.

- Two of the approaches were mirror images and some of my selections were to verify that instead of gathering information.

The pilots were asked to exclude the acquisition task and tell how similar the tasks that they performed in the simulator cockpit were to those they would normally perform as captain or first officer. Fifteen pilots said the tasks were very similar and 11 said they were similar. None said that the tasks were dissimilar. Specific comments are listed below:

- You may warn the pilots to bring their normal checklists with them, as opposed to using the Northwest 1989 checklist.

- Except for the outdated other airline checklist they were similar.

The next question asked how adequate the information was that was provided to them by air traffic control (ATC). Fourteen said it was very adequate and 12 said it was adequate. None said that ATC support was inadequate. Specific comments for this question are listed below:

- The controller was very good.

- If this was Hayes, Kansas, the level of support was about right, but for busier airports we 
almost always receive vectors to the final approach course.

Pilots were also asked whether the way approaches were flown in the experiment changed the way they used the approach chart from the way they would normally use it when flying the line. Five said it did change things, whereas 21 said it did not. Specific comments concerning this question are listed below:

- Flying domestic routes in the U.S., I rarely fly an entire approach procedure from a feeder route.
- Normally we are vectored to final.

- I don't memorize as much information.

- Very seldom in line flying would you fly the whole approach.

- We are almost always vectored to final.

- Flying the whole approach with transitions meant that I used more information from the chart than I would normally use. 


\section{Appendix D}

\section{Analysis of Variance (ANOVA) Summary Tables}

The following tables represent the analyses of variance that were done on each of the dependent variables. For each treatment effect or interaction in the tables, the sum of squares (SS), degrees of freedom (df), mean square (MS), $F$ ratio, and significance level $(p)$ are reported.

Table D1. Communications Category ANOVA Summary Table

\begin{tabular}{|c|c|c|c|c|c|}
\hline Source & df & SS & MS & $F$ & $p$ \\
\hline \multicolumn{6}{|c|}{ Between subjects } \\
\hline $\begin{array}{l}\text { Crew member }(\mathrm{CM}) \\
\text { Error } \\
\end{array}$ & $\begin{array}{r}1 \\
22\end{array}$ & $\begin{array}{r}18.13 \\
107.45 \\
\end{array}$ & $\begin{array}{r}18.13 \\
4.89 \\
\end{array}$ & 3.71 & 0.07 \\
\hline \multicolumn{6}{|c|}{ Within subjects } \\
\hline $\begin{array}{l}\text { Precision }(\mathrm{T}) \\
\mathrm{CM} \times \mathrm{T} \\
\quad \text { Error } \\
\end{array}$ & $\begin{array}{r}1 \\
1 \\
22 \\
\end{array}$ & $\begin{array}{r}0.13 \\
0.13 \\
19.37 \\
\end{array}$ & $\begin{array}{l}0.13 \\
0.13 \\
0.88 \\
\end{array}$ & $\begin{array}{l}0.15 \\
0.15\end{array}$ & $\begin{array}{l}0.71 \\
0.71\end{array}$ \\
\hline $\begin{array}{l}\text { Weather (WX) } \\
\mathrm{CM} \times \mathrm{WX} \\
\text { Error }\end{array}$ & $\begin{array}{r}1 \\
1 \\
22 \\
\end{array}$ & $\begin{array}{r}0.01 \\
0.63 \\
18.49 \\
\end{array}$ & $\begin{array}{l}0.01 \\
0.63 \\
0.84 \\
\end{array}$ & $\begin{array}{l}0.01 \\
0.75\end{array}$ & $\begin{array}{l}0.94 \\
0.40\end{array}$ \\
\hline $\begin{array}{l}\text { Phase }(\mathrm{P}) \\
\mathrm{CM} \times \mathrm{P} \\
\text { Error } \\
\end{array}$ & $\begin{array}{r}1 \\
1 \\
22 \\
\end{array}$ & $\begin{array}{r}32.51 \\
26.26 \\
101.87 \\
\end{array}$ & $\begin{array}{r}32.51 \\
26.26 \\
4.63 \\
\end{array}$ & $\begin{array}{l}7.02 \\
5.67\end{array}$ & $\begin{array}{l}0.02 \\
0.03\end{array}$ \\
\hline $\begin{array}{l}\mathrm{T} \times \mathrm{WX} \\
\mathrm{CM} \times[\mathrm{T} \times \mathrm{WX}] \\
\quad \text { Error } \\
\end{array}$ & $\begin{array}{r}1 \\
1 \\
22 \\
\end{array}$ & $\begin{array}{r}1.51 \\
2.30 \\
10.32 \\
\end{array}$ & $\begin{array}{l}1.51 \\
2.30 \\
0.47 \\
\end{array}$ & $\begin{array}{l}3.21 \\
4.90\end{array}$ & $\begin{array}{l}0.09 \\
0.04\end{array}$ \\
\hline $\begin{array}{l}\mathrm{T} \times \mathrm{P} \\
\mathrm{CM} \times[\mathrm{T} \times \mathrm{P}] \\
\quad \text { Error } \\
\end{array}$ & $\begin{array}{r}1 \\
1 \\
22 \\
\end{array}$ & $\begin{array}{r}0.01 \\
0.42 \\
16.20 \\
\end{array}$ & $\begin{array}{l}0.01 \\
0.42 \\
0.74 \\
\end{array}$ & $\begin{array}{l}0.01 \\
0.57\end{array}$ & $\begin{array}{l}0.94 \\
0.46\end{array}$ \\
\hline $\begin{array}{l}\mathrm{WX} \times \mathrm{P} \\
\mathrm{CM} \times[\mathrm{WX} \times \mathrm{P}] \\
\quad \text { Error } \\
\end{array}$ & $\begin{array}{r}1 \\
1 \\
22 \\
\end{array}$ & $\begin{array}{r}1.17 \\
0.13 \\
19.82 \\
\end{array}$ & $\begin{array}{l}1.17 \\
0.13 \\
0.90 \\
\end{array}$ & $\begin{array}{l}1.30 \\
0.14\end{array}$ & $\begin{array}{l}0.27 \\
0.71\end{array}$ \\
\hline $\begin{array}{l}\mathrm{T} \times \mathrm{WX} \times \mathrm{P} \\
\mathrm{CM} \times[\mathrm{T} \times \mathrm{WX} \times \mathrm{P}] \\
\quad \text { Error }\end{array}$ & $\begin{array}{r}1 \\
1 \\
22\end{array}$ & $\begin{array}{r}1.51 \\
0.88 \\
12.74 \\
\end{array}$ & $\begin{array}{l}1.51 \\
0.88 \\
0.58 \\
\end{array}$ & $\begin{array}{l}2.60 \\
1.52\end{array}$ & $\begin{array}{l}0.13 \\
0.24\end{array}$ \\
\hline
\end{tabular}

*Bold $F$ values are statistically significant at the $p$ ratio shown in the table. 
Table D2. Final Items Category ANOVA Summary Table

\begin{tabular}{|c|c|c|c|c|c|}
\hline Source & $\mathrm{df}$ & SS & MS & $F$ & $p$ \\
\hline \multicolumn{6}{|c|}{ Between subjects } \\
\hline $\begin{array}{l}\text { Crew member }(\mathrm{CM}) \\
\text { Error }\end{array}$ & $\begin{array}{r}1 \\
22 \\
\end{array}$ & $\begin{array}{r}4.08 \\
57.23 \\
\end{array}$ & $\begin{array}{l}4.08 \\
2.60 \\
\end{array}$ & 1.57 & 0.23 \\
\hline \multicolumn{6}{|c|}{ Within subjects } \\
\hline $\begin{array}{l}\text { Precision (T) } \\
\mathrm{CM} \times \mathrm{T} \\
\quad \text { Error } \\
\end{array}$ & $\begin{array}{r}1 \\
1 \\
22 \\
\end{array}$ & $\begin{array}{r}4.69 \\
0.00 \\
16.81 \\
\end{array}$ & $\begin{array}{l}4.69 \\
0.00 \\
0.76\end{array}$ & $\begin{array}{l}6.13 \\
0.00\end{array}$ & $\begin{array}{l}0.03 \\
1.000\end{array}$ \\
\hline $\begin{array}{l}\text { Weather }(W X) \\
C M \times W X \\
\text { Error } \\
\end{array}$ & $\begin{array}{r}1 \\
1 \\
22 \\
\end{array}$ & $\begin{array}{l}2.08 \\
0.02 \\
5.40 \\
\end{array}$ & $\begin{array}{l}2.08 \\
0.02 \\
0.25\end{array}$ & $\begin{array}{l}8.49 \\
0.08\end{array}$ & $\begin{array}{l}0.0080 \\
0.78\end{array}$ \\
\hline $\begin{array}{c}\text { Phase }(\mathrm{P}) \\
\mathrm{CM} \times \mathrm{P} \\
\text { Error }\end{array}$ & $\begin{array}{r}1 \\
1 \\
22\end{array}$ & $\begin{array}{r}4.69 \\
0.33 \\
16.98 \\
\end{array}$ & $\begin{array}{l}4.69 \\
0.33 \\
0.77\end{array}$ & $\begin{array}{l}6.07 \\
0.43\end{array}$ & $\begin{array}{l}0.03 \\
0.52\end{array}$ \\
\hline $\begin{array}{l}\mathrm{T} \times \mathrm{WX} \\
\mathrm{CM} \times[\mathrm{T} \times \mathrm{WX}] \\
\text { Error }\end{array}$ & $\begin{array}{r}1 \\
1 \\
22\end{array}$ & $\begin{array}{l}0.33 \\
0.52 \\
4.15 \\
\end{array}$ & $\begin{array}{l}0.33 \\
0.52 \\
0.19 \\
\end{array}$ & $\begin{array}{l}1.77 \\
2.76\end{array}$ & $\begin{array}{l}0.20 \\
0.12\end{array}$ \\
\hline $\begin{array}{l}\mathrm{T} \times \mathrm{P} \\
\mathrm{CM} \times[\mathrm{T} \times \mathrm{P}] \\
\quad \text { Error }\end{array}$ & $\begin{array}{r}1 \\
1 \\
22 \\
\end{array}$ & $\begin{array}{r}0.19 \\
0.75 \\
13.56 \\
\end{array}$ & $\begin{array}{l}0.19 \\
0.75 \\
0.62 \\
\end{array}$ & $\begin{array}{l}0.30 \\
1.22\end{array}$ & $\begin{array}{l}0.59 \\
0.29\end{array}$ \\
\hline $\begin{array}{l}\mathrm{WX} \times \mathrm{P} \\
\mathrm{CM} \times[\mathrm{WX} \times \mathrm{P}] \\
\quad \text { Error }\end{array}$ & $\begin{array}{r}1 \\
1 \\
22\end{array}$ & $\begin{array}{r}0.08 \\
0.02 \\
10.40 \\
\end{array}$ & $\begin{array}{l}0.08 \\
0.02 \\
0.47\end{array}$ & $\begin{array}{l}0.18 \\
0.04\end{array}$ & $\begin{array}{l}0.68 \\
0.84\end{array}$ \\
\hline $\begin{array}{l}\mathrm{T} \times \mathrm{WX} \times \mathrm{P} \\
\mathrm{CM} \times[\mathrm{T} \times \mathrm{WX} \times \mathrm{P}] \\
\quad \text { Error }\end{array}$ & $\begin{array}{r}1 \\
1 \\
22\end{array}$ & $\begin{array}{r}1.33 \\
0.02 \\
10.65\end{array}$ & $\begin{array}{l}1.33 \\
0.02 \\
0.48\end{array}$ & $\begin{array}{l}2.76 \\
0.04\end{array}$ & $\begin{array}{l}0.12 \\
0.84\end{array}$ \\
\hline
\end{tabular}


Table D3. Geography Category ANOVA Summary Table

\begin{tabular}{|c|c|c|c|c|c|}
\hline Source & $\mathrm{df}$ & SS & MS & $F$ & $p$ \\
\hline \multicolumn{6}{|c|}{ Between subjects } \\
\hline $\begin{array}{l}\text { Crew member (CM) } \\
\text { Error }\end{array}$ & $\begin{array}{r}1 \\
22 \\
\end{array}$ & $\begin{array}{r}0.26 \\
19.20 \\
\end{array}$ & $\begin{array}{l}0.26 \\
0.87 \\
\end{array}$ & 0.29 & 0.60 \\
\hline \multicolumn{6}{|c|}{ Within subjects } \\
\hline $\begin{array}{l}\text { Precision }(\mathrm{T}) \\
\mathrm{CM} \times \mathrm{T} \\
\quad \text { Error } \\
\end{array}$ & $\begin{array}{r}1 \\
1 \\
22 \\
\end{array}$ & $\begin{array}{r}4.38 \\
0.05 \\
19.95 \\
\end{array}$ & $\begin{array}{l}4.38 \\
0.05 \\
0.91 \\
\end{array}$ & $\begin{array}{l}\mathbf{4 . 8 3} \\
0.05\end{array}$ & $\begin{array}{l}0.04 \\
0.83\end{array}$ \\
\hline $\begin{array}{l}\text { Weather }(\mathrm{WX}) \\
\mathrm{CM} \times \mathrm{WX} \\
\text { Error }\end{array}$ & $\begin{array}{r}1 \\
1 \\
22 \\
\end{array}$ & $\begin{array}{r}0.42 \\
1.17 \\
13.78 \\
\end{array}$ & $\begin{array}{l}0.42 \\
1.17 \\
0.63 \\
\end{array}$ & $\begin{array}{l}0.67 \\
1.87\end{array}$ & $\begin{array}{l}0.43 \\
0.19\end{array}$ \\
\hline $\begin{array}{l}\text { Phase }(\mathrm{P}) \\
\mathrm{CM} \times \mathrm{P} \\
\text { Error } \\
\end{array}$ & $\begin{array}{r}1 \\
1 \\
22 \\
\end{array}$ & $\begin{array}{r}0.05 \\
0.63 \\
11.70 \\
\end{array}$ & $\begin{array}{l}0.05 \\
0.63 \\
0.53 \\
\end{array}$ & $\begin{array}{l}0.09 \\
1.19\end{array}$ & $\begin{array}{l}0.77 \\
0.29\end{array}$ \\
\hline $\begin{array}{l}\mathrm{T} \times \mathrm{WX} \\
\mathrm{CM} \times[\mathrm{T} \times \mathrm{WX}] \\
\quad \text { Error }\end{array}$ & $\begin{array}{r}1 \\
1 \\
22 \\
\end{array}$ & $\begin{array}{r}1.88 \\
0.13 \\
10.37 \\
\end{array}$ & $\begin{array}{l}1.88 \\
0.13 \\
0.47 \\
\end{array}$ & $\begin{array}{l}3.99 \\
0.28\end{array}$ & $\begin{array}{l}0.06 \\
0.61\end{array}$ \\
\hline $\begin{array}{l}\mathrm{T} \times \mathrm{P} \\
\mathrm{CM} \times[\mathrm{T} \times \mathrm{P}] \\
\quad \text { Error } \\
\end{array}$ & $\begin{array}{r}1 \\
1 \\
22 \\
\end{array}$ & $\begin{array}{r}0.01 \\
0.42 \\
11.95 \\
\end{array}$ & $\begin{array}{l}0.01 \\
0.42 \\
0.54 \\
\end{array}$ & $\begin{array}{l}0.01 \\
0.78\end{array}$ & $\begin{array}{l}0.93 \\
0.39\end{array}$ \\
\hline $\begin{array}{l}\mathrm{WX} \times \mathrm{P} \\
\mathrm{CM} \times[\mathrm{WX} \times \mathrm{P}] \\
\quad \text { Error } \\
\end{array}$ & $\begin{array}{r}1 \\
1 \\
22 \\
\end{array}$ & $\begin{array}{l}0.01 \\
0.01 \\
6.37 \\
\end{array}$ & $\begin{array}{l}0.01 \\
0.01 \\
0.29 \\
\end{array}$ & $\begin{array}{l}0.02 \\
0.02\end{array}$ & $\begin{array}{l}0.90 \\
0.90\end{array}$ \\
\hline $\begin{array}{l}\mathrm{T} \times \mathrm{WX} \times \mathrm{P} \\
\mathrm{CM} \times[\mathrm{T} \times \mathrm{WX} \times \mathrm{P}] \\
\quad \text { Error }\end{array}$ & $\begin{array}{r}1 \\
1 \\
22 \\
\end{array}$ & $\begin{array}{l}0.05 \\
0.05 \\
6.28 \\
\end{array}$ & $\begin{array}{l}0.05 \\
0.05 \\
0.29 \\
\end{array}$ & $\begin{array}{l}0.16 \\
0.16\end{array}$ & $\begin{array}{l}0.69 \\
0.69\end{array}$ \\
\hline
\end{tabular}

${ }^{*}$ Bold $F$ value is statistically significant at the $p$ ratio shown in the table. 
Table D4. Missed Approach Category ANOVA Summary Table

\begin{tabular}{|c|c|c|c|c|c|}
\hline Source & df & SS & MS & $F$ & $p$ \\
\hline \multicolumn{6}{|c|}{ Between subjects } \\
\hline $\begin{array}{l}\text { Crew member (CM) } \\
\text { Error }\end{array}$ & $\begin{array}{r}1 \\
22\end{array}$ & $\begin{array}{r}60.75 \\
197.00 \\
\end{array}$ & $\begin{array}{r}60.75 \\
8.96\end{array}$ & 6.78 & 0.02 \\
\hline \multicolumn{6}{|c|}{ Within subjects } \\
\hline $\begin{array}{l}\text { Precision }(\mathrm{T}) \\
\mathrm{CM} \times \mathrm{T} \\
\quad \text { Error }\end{array}$ & $\begin{array}{r}1 \\
1 \\
22\end{array}$ & $\begin{array}{r}123.52 \\
7.52 \\
90.71 \\
\end{array}$ & $\begin{array}{r}123.52 \\
7.52 \\
4.12 \\
\end{array}$ & $\begin{array}{r}29.96 \\
1.82\end{array}$ & $\begin{array}{l}0.01 \\
0.20\end{array}$ \\
\hline $\begin{array}{l}\text { Weather }(\mathrm{WX}) \\
\mathrm{CM} \times \mathrm{WX} \\
\text { Error }\end{array}$ & $\begin{array}{r}1 \\
1 \\
22\end{array}$ & $\begin{array}{r}12.00 \\
0.75 \\
54.50\end{array}$ & $\begin{array}{r}12.00 \\
0.75 \\
2.48\end{array}$ & $\begin{array}{l}\mathbf{4 . 8 4} \\
0.30\end{array}$ & $\begin{array}{l}0.04 \\
0.59\end{array}$ \\
\hline $\begin{array}{l}\text { Phase }(\mathrm{P}) \\
\mathrm{CM} \times \mathrm{P} \\
\text { Error }\end{array}$ & $\begin{array}{r}1 \\
1 \\
22 \\
\end{array}$ & $\begin{array}{r}261.33 \\
36.75 \\
209.17 \\
\end{array}$ & $\begin{array}{r}261.33 \\
36.75 \\
9.51 \\
\end{array}$ & $\begin{array}{r}27.49 \\
3.87\end{array}$ & $\begin{array}{l}0.01 \\
0.07\end{array}$ \\
\hline $\begin{array}{l}\mathrm{T} \times \mathbf{W X} \\
\mathrm{CM} \times[\mathrm{T} \times \mathrm{WX}] \\
\text { Error }\end{array}$ & $\begin{array}{r}1 \\
1 \\
22 \\
\end{array}$ & $\begin{array}{r}50.02 \\
9.19 \\
35.04 \\
\end{array}$ & $\begin{array}{r}50.02 \\
9.19 \\
1.59\end{array}$ & $\begin{array}{r}31.40 \\
5.77\end{array}$ & $\begin{array}{l}0.01 \\
0.03\end{array}$ \\
\hline $\begin{array}{l}\mathrm{T} \times \mathrm{P} \\
\mathrm{CM} \times[\mathrm{T} \times \mathrm{P}] \\
\quad \text { Error } \\
\end{array}$ & $\begin{array}{r}1 \\
1 \\
22\end{array}$ & $\begin{array}{r}22.69 \\
6.02 \\
105.54 \\
\end{array}$ & $\begin{array}{r}22.69 \\
6.02 \\
4.80\end{array}$ & $\begin{array}{l}\mathbf{4 . 7 3} \\
1.26\end{array}$ & $\begin{array}{l}0.05 \\
0.28\end{array}$ \\
\hline $\begin{array}{l}\mathrm{WX} \times \mathrm{P} \\
\mathrm{CM} \times[\mathrm{WX} \times \mathrm{P}] \\
\quad \text { Error }\end{array}$ & $\begin{array}{r}1 \\
1 \\
22\end{array}$ & $\begin{array}{r}2.08 \\
0.33 \\
79.33 \\
\end{array}$ & $\begin{array}{l}2.08 \\
0.33 \\
3.61\end{array}$ & $\begin{array}{l}0.58 \\
0.09\end{array}$ & $\begin{array}{l}0.46 \\
0.77\end{array}$ \\
\hline $\begin{array}{l}\mathrm{T} \times \mathrm{WX} \times \mathrm{P} \\
\mathrm{CM} \times[\mathrm{T} \times \mathrm{WX} \times \mathrm{P}] \\
\quad \text { Error }\end{array}$ & $\begin{array}{r}1 \\
1 \\
22\end{array}$ & $\begin{array}{r}46.02 \\
2.52 \\
85.21\end{array}$ & $\begin{array}{r}46.02 \\
2.52 \\
3.87\end{array}$ & $\begin{array}{r}11.88 \\
0.65\end{array}$ & $\begin{array}{l}0.01 \\
0.43\end{array}$ \\
\hline
\end{tabular}

*Bold $F$ values are statistically significant at the $p$ ratio shown in the table. 
Table D5. Navigation Category ANOVA Summary Table

\begin{tabular}{|c|c|c|c|c|c|}
\hline Source & $\mathrm{df}$ & SS & MS & $F$ & $p$ \\
\hline \multicolumn{6}{|c|}{ Between subjects } \\
\hline $\begin{array}{l}\text { Crew member (CM) } \\
\text { Error } \\
\end{array}$ & $\begin{array}{r}1 \\
22 \\
\end{array}$ & $\begin{array}{l}10890.19 \\
24360.88 \\
\end{array}$ & $\begin{array}{r}10890.19 \\
1107.31 \\
\end{array}$ & 9.83 & 0.01 \\
\hline \multicolumn{6}{|c|}{ Within subjects } \\
\hline $\begin{array}{l}\text { Precision }(\mathrm{T}) \\
\mathrm{CM} \times \mathrm{T} \\
\quad \text { Error } \\
\end{array}$ & $\begin{array}{r}1 \\
1 \\
22 \\
\end{array}$ & $\begin{array}{r}1064.08 \\
234.08 \\
1648.08 \\
\end{array}$ & $\begin{array}{r}1064.08 \\
234.08 \\
74.91 \\
\end{array}$ & $\begin{array}{r}14.20 \\
3.12\end{array}$ & $\begin{array}{l}0.01 \\
0.10\end{array}$ \\
\hline $\begin{array}{c}\text { Weather }(\mathrm{WX}) \\
\mathrm{CM} \times \mathrm{WX} \\
\text { Error }\end{array}$ & $\begin{array}{r}1 \\
1 \\
22\end{array}$ & $\begin{array}{r}808.52 \\
42.19 \\
1821.54 \\
\end{array}$ & $\begin{array}{r}808.52 \\
42.19 \\
82.80 \\
\end{array}$ & $\begin{array}{l}9.77 \\
0.51\end{array}$ & $\begin{array}{l}0.01 \\
0.49\end{array}$ \\
\hline $\begin{array}{c}\text { Phase }(\mathrm{P}) \\
\mathrm{CM} \times \mathrm{P} \\
\quad \text { Error } \\
\end{array}$ & $\begin{array}{r}1 \\
1 \\
22 \\
\end{array}$ & $\begin{array}{r}623.52 \\
4740.19 \\
14657.54 \\
\end{array}$ & $\begin{array}{r}623.52 \\
4740.19 \\
666.25 \\
\end{array}$ & $\begin{array}{l}0.94 \\
7.11\end{array}$ & $\begin{array}{l}0.35 \\
0.02\end{array}$ \\
\hline $\begin{array}{l}\mathrm{T} \times \mathrm{WX} \\
\mathrm{CM} \times[\mathrm{T} \times \mathrm{WX}] \\
\text { Error } \\
\end{array}$ & $\begin{array}{r}1 \\
1 \\
22 \\
\end{array}$ & $\begin{array}{r}0.75 \\
0.33 \\
2053.17 \\
\end{array}$ & $\begin{array}{r}0.75 \\
0.33 \\
93.33 \\
\end{array}$ & $\begin{array}{l}0.01 \\
0.00\end{array}$ & \\
\hline $\begin{array}{l}\mathrm{T} \times \mathrm{P} \\
\mathrm{CM} \times[\mathrm{T} \times \mathrm{P}] \\
\text { Error } \\
\end{array}$ & $\begin{array}{r}1 \\
1 \\
22\end{array}$ & $\begin{array}{r}14.08 \\
36.75 \\
1908.42 \\
\end{array}$ & $\begin{array}{l}14.08 \\
36.75 \\
86.75 \\
\end{array}$ & $\begin{array}{l}0.16 \\
0.42\end{array}$ & $\begin{array}{l}0.70 \\
0.53\end{array}$ \\
\hline $\begin{array}{l}\mathrm{WX} \times \mathrm{P} \\
\mathrm{CM} \times[\mathrm{WX} \times \mathrm{P}] \\
\quad \text { Error }\end{array}$ & $\begin{array}{r}1 \\
1 \\
22 \\
\end{array}$ & $\begin{array}{r}2.52 \\
315.19 \\
1524.54 \\
\end{array}$ & $\begin{array}{r}2.52 \\
315.19 \\
69.30 \\
\end{array}$ & $\begin{array}{l}0.04 \\
4.55\end{array}$ & $\begin{array}{l}0.86 \\
0.05\end{array}$ \\
\hline $\begin{array}{l}\mathrm{T} \times \mathrm{WX} \times \mathrm{P} \\
\mathrm{CM} \times[\mathrm{T} \times \mathrm{WX} \times \mathrm{P}] \\
\quad \text { Error }\end{array}$ & $\begin{array}{r}1 \\
1 \\
22 \\
\end{array}$ & $\begin{array}{r}10.08 \\
1.33 \\
4987.83 \\
\end{array}$ & $\begin{array}{r}10.08 \\
1.33 \\
226.72 \\
\end{array}$ & $\begin{array}{l}0.04 \\
0.01\end{array}$ & $\begin{array}{l}0.84 \\
0.94\end{array}$ \\
\hline
\end{tabular}

*Bold $F$ values are statistically significant at the $p$ ratio shown in the table. 
Table D6. Navigation Aids Category ANOVA Summary Table

\begin{tabular}{|c|c|c|c|c|c|}
\hline Source & df & SS & MS & $F$ & $p$ \\
\hline \multicolumn{6}{|c|}{ Between subjects } \\
\hline $\begin{array}{l}\text { Crew member (CM) } \\
\text { Error }\end{array}$ & $\begin{array}{r}1 \\
22 \\
\end{array}$ & $\begin{array}{l}3906.02 \\
5635.79 \\
\end{array}$ & $\begin{array}{r}3906.02 \\
256.17 \\
\end{array}$ & 15.25 & 0.01 \\
\hline \multicolumn{6}{|c|}{ Within subjects } \\
\hline $\begin{array}{l}\text { Precision }(\mathrm{T}) \\
\mathrm{CM} \times \mathrm{T} \\
\quad \text { ErTor } \\
\end{array}$ & $\begin{array}{r}1 \\
1 \\
22\end{array}$ & $\begin{array}{r}12.00 \\
0.08 \\
358.92 \\
\end{array}$ & $\begin{array}{r}12.00 \\
0.08 \\
16.31 \\
\end{array}$ & $\begin{array}{l}0.74 \\
0.01\end{array}$ & $\begin{array}{l}0.41 \\
0.95\end{array}$ \\
\hline $\begin{array}{l}\text { Weather }(\mathrm{WX}) \\
\mathrm{CM} \times \mathrm{WX} \\
\text { Error }\end{array}$ & $\begin{array}{r}1 \\
1 \\
22 \\
\end{array}$ & $\begin{array}{r}4.69 \\
46.02 \\
1000.29 \\
\end{array}$ & $\begin{array}{r}4.69 \\
46.02 \\
45.47 \\
\end{array}$ & $\begin{array}{l}0.10 \\
1.01\end{array}$ & $\begin{array}{l}0.76 \\
0.33\end{array}$ \\
\hline $\begin{array}{l}\text { Phase }(P) \\
C M \times P \\
\text { Error } \\
\end{array}$ & $\begin{array}{r}1 \\
1 \\
22 \\
\end{array}$ & $\begin{array}{r}2715.02 \\
247.52\end{array}$ & $\begin{array}{r}2715.02 \\
247.52\end{array}$ & $\begin{array}{r}26.52 \\
2.42\end{array}$ & $\begin{array}{l}0.01 \\
0.14\end{array}$ \\
\hline $\begin{array}{l}\mathrm{T} \times \mathrm{WX} \\
\mathrm{CM} \times[\mathrm{T} \times \mathrm{WX}] \\
\text { Error }\end{array}$ & $\begin{array}{r}1 \\
1 \\
22 \\
\end{array}$ & $\begin{array}{r}114.08 \\
44.08 \\
325.83 \\
\end{array}$ & $\begin{array}{r}114.08 \\
44.08 \\
14.81 \\
\end{array}$ & $\begin{array}{l}7.70 \\
2.98\end{array}$ & $\begin{array}{l}0.02 \\
0.10\end{array}$ \\
\hline $\begin{array}{l}\mathrm{T} \times \mathrm{P} \\
\mathrm{CM} \times[\mathrm{T} \times \mathrm{P}] \\
\quad \text { Error } \\
\end{array}$ & $\begin{array}{r}1 \\
1 \\
22 \\
\end{array}$ & $\begin{array}{r}0.75 \\
3.00 \\
652.75 \\
\end{array}$ & $\begin{array}{r}0.75 \\
3.00 \\
29.67 \\
\end{array}$ & $\begin{array}{l}0.03 \\
0.10\end{array}$ & $\begin{array}{l}0.88 \\
0.76\end{array}$ \\
\hline $\begin{array}{l}\mathrm{WX} \times \mathbf{P} \\
\mathrm{CM} \times[\mathbf{W X} \times \mathrm{P}] \\
\quad \text { Error }\end{array}$ & $\begin{array}{r}1 \\
1 \\
22 \\
\end{array}$ & $\begin{array}{r}15.19 \\
4.69 \\
535.63 \\
\end{array}$ & $\begin{array}{r}15.19 \\
4.69 \\
24.35 \\
\end{array}$ & $\begin{array}{l}0.62 \\
0.19\end{array}$ & $\begin{array}{l}0.44 \\
0.67\end{array}$ \\
\hline $\begin{array}{l}\mathrm{T} \times \mathrm{WX} \times \mathrm{P} \\
\mathrm{CM} \times[\mathrm{T} \times \mathrm{WX} \times \mathrm{P}] \\
\quad \text { Error }\end{array}$ & $\begin{array}{r}1 \\
1 \\
22\end{array}$ & $\begin{array}{r}40.33 \\
8.33 \\
564.83 \\
\end{array}$ & $\begin{array}{r}40.33 \\
8.33 \\
25.67\end{array}$ & $\begin{array}{l}1.57 \\
0.32\end{array}$ & $\begin{array}{l}0.23 \\
0.58\end{array}$ \\
\hline
\end{tabular}


Table D7. Obstructions Category ANOVA Summary Table

\begin{tabular}{|c|c|c|c|c|c|}
\hline Source & df & SS & MS & $F$ & $p$ \\
\hline \multicolumn{6}{|c|}{ Between subjects } \\
\hline $\begin{array}{l}\text { Crew member (CM) } \\
\text { Error }\end{array}$ & $\begin{array}{r}1 \\
22 \\
\end{array}$ & $\begin{array}{r}627.13 \\
1761.24 \\
\end{array}$ & $\begin{array}{r}627.13 \\
80.06 \\
\end{array}$ & 7.83 & 0.02 \\
\hline \multicolumn{6}{|c|}{ Within subjects } \\
\hline $\begin{array}{l}\text { Precision }(\mathrm{T}) \\
\mathrm{CM} \times \mathrm{T} \\
\quad \text { Error } \\
\end{array}$ & $\begin{array}{r}1 \\
1 \\
22 \\
\end{array}$ & $\begin{array}{l}236.30 \\
198.05 \\
428.03 \\
\end{array}$ & $\begin{array}{r}236.30 \\
198.05 \\
19.46 \\
\end{array}$ & $\begin{array}{l}12.15 \\
10.18\end{array}$ & $\begin{array}{l}0.01 \\
0.01\end{array}$ \\
\hline $\begin{array}{l}\text { Weather }(\mathrm{WX}) \\
\mathrm{CM} \times \mathrm{WX} \\
\text { Error }\end{array}$ & $\begin{array}{r}1 \\
1 \\
22 \\
\end{array}$ & $\begin{array}{r}49.01 \\
8.76 \\
214.12 \\
\end{array}$ & $\begin{array}{r}49.01 \\
8.76 \\
9.73 \\
\end{array}$ & $\begin{array}{l}\mathbf{5 . 0 4} \\
0.90\end{array}$ & $\begin{array}{l}0.04 \\
0.36\end{array}$ \\
\hline $\begin{array}{l}\text { Phase }(\mathrm{P}) \\
\mathrm{CM} \times \mathrm{P} \\
\text { Error } \\
\end{array}$ & $\begin{array}{r}1 \\
1 \\
22 \\
\end{array}$ & $\begin{array}{r}7.92 \\
227.51 \\
925.45 \\
\end{array}$ & $\begin{array}{r}7.92 \\
227.51 \\
42.07 \\
\end{array}$ & $\begin{array}{l}0.19 \\
5.41\end{array}$ & $\begin{array}{l}0.67 \\
0.03\end{array}$ \\
\hline $\begin{array}{l}\mathrm{T} \times \mathrm{WX} \\
\mathrm{CM} \times[\mathrm{T} \times \mathrm{WX}] \\
\text { Error }\end{array}$ & $\begin{array}{r}1 \\
1 \\
22 \\
\end{array}$ & $\begin{array}{r}2.30 \\
15.76 \\
342.82 \\
\end{array}$ & $\begin{array}{r}2.30 \\
15.76 \\
15.58 \\
\end{array}$ & $\begin{array}{l}0.15 \\
1.01\end{array}$ & $\begin{array}{l}0.71 \\
0.33\end{array}$ \\
\hline $\begin{array}{l}\mathrm{T} \times \mathrm{P} \\
\mathrm{CM} \times[\mathrm{T} \times \mathrm{P}] \\
\text { Error }\end{array}$ & $\begin{array}{r}1 \\
1 \\
22 \\
\end{array}$ & $\begin{array}{r}49.01 \\
3.80 \\
321.07 \\
\end{array}$ & $\begin{array}{r}49.01 \\
3.80 \\
14.59 \\
\end{array}$ & $\begin{array}{l}3.36 \\
0.26\end{array}$ & $\begin{array}{l}0.09 \\
0.62\end{array}$ \\
\hline $\begin{array}{l}\mathrm{WX} \times \mathrm{P} \\
\mathrm{CM} \times[\mathrm{WX} \times \mathrm{P}] \\
\quad \text { Error }\end{array}$ & $\begin{array}{r}1 \\
1 \\
22 \\
\end{array}$ & $\begin{array}{r}97.76 \\
138.38 \\
283.24 \\
\end{array}$ & $\begin{array}{r}97.76 \\
138.38 \\
12.88 \\
\end{array}$ & $\begin{array}{r}7.59 \\
10.75\end{array}$ & $\begin{array}{l}0.02 \\
0.01\end{array}$ \\
\hline $\begin{array}{l}\mathrm{T} \times \mathrm{WX} \times \mathrm{P} \\
\mathrm{CM} \times[\mathrm{T} \times \mathrm{WX} \times \mathrm{P}] \\
\quad \text { Error }\end{array}$ & $\begin{array}{r}1 \\
1 \\
22\end{array}$ & $\begin{array}{r}22.01 \\
15.76 \\
210.61 \\
\end{array}$ & $\begin{array}{r}22.01 \\
15.76 \\
9.57 \\
\end{array}$ & $\begin{array}{l}2.30 \\
1.65\end{array}$ & $\begin{array}{l}0.15 \\
0.22\end{array}$ \\
\hline
\end{tabular}

*Bold $F$ values are statistically significant at the $p$ ratio shown in the table. 
Table D8. Other Runway Category ANOVA Summary Table

\begin{tabular}{|c|c|c|c|c|c|}
\hline Source & df & SS & MS & $F$ & $p$ \\
\hline \multicolumn{6}{|c|}{ Between subjects } \\
\hline $\begin{array}{l}\text { Crew member (CM) } \\
\text { Error }\end{array}$ & $\begin{array}{r}1 \\
22 \\
\end{array}$ & $\begin{array}{r}8.76 \\
126.12 \\
\end{array}$ & $\begin{array}{l}8.76 \\
5.73 \\
\end{array}$ & 1.53 & 0.23 \\
\hline \multicolumn{6}{|c|}{ Within subjects } \\
\hline $\begin{array}{l}\text { Precision }(\mathrm{T}) \\
\mathrm{CM} \times \mathrm{T} \\
\quad \text { Error } \\
\end{array}$ & $\begin{array}{r}1 \\
1 \\
22 \\
\end{array}$ & $\begin{array}{r}0.05 \\
0.26 \\
20.32 \\
\end{array}$ & $\begin{array}{l}0.05 \\
0.26 \\
0.92 \\
\end{array}$ & $\begin{array}{l}0.05 \\
0.28\end{array}$ & $\begin{array}{l}0.83 \\
0.61\end{array}$ \\
\hline $\begin{array}{c}\text { Weather }(\mathrm{WX}) \\
\mathrm{CM} \times \mathrm{WX} \\
\text { Error }\end{array}$ & $\begin{array}{r}1 \\
1 \\
22 \\
\end{array}$ & $\begin{array}{r}0.42 \\
0.63 \\
33.57 \\
\end{array}$ & $\begin{array}{l}0.42 \\
0.63 \\
1.53 \\
\end{array}$ & $\begin{array}{l}0.28 \\
0.41\end{array}$ & $\begin{array}{l}0.61 \\
0.53\end{array}$ \\
\hline $\begin{array}{c}\text { Phase }(\mathrm{P}) \\
\mathrm{CM} \times \mathrm{P} \\
\text { Error }\end{array}$ & $\begin{array}{r}1 \\
1 \\
22 \\
\end{array}$ & $\begin{array}{r}47.01 \\
0.01 \\
43.12 \\
\end{array}$ & $\begin{array}{r}47.01 \\
0.01 \\
1.96 \\
\end{array}$ & $\begin{array}{r}23.99 \\
0.00\end{array}$ & $\begin{array}{l}0.01 \\
0.96\end{array}$ \\
\hline $\begin{array}{l}\mathrm{T} \times \mathrm{WX} \\
\mathrm{CM} \times[\mathrm{T} \times \mathrm{WX}] \\
\text { Error } \\
\end{array}$ & $\begin{array}{r}1 \\
1 \\
22 \\
\end{array}$ & $\begin{array}{r}1.17 \\
0.42 \\
31.03 \\
\end{array}$ & $\begin{array}{l}1.17 \\
0.42 \\
1.41 \\
\end{array}$ & $\begin{array}{l}0.83 \\
0.30\end{array}$ & $\begin{array}{l}0.38 \\
0.60\end{array}$ \\
\hline $\begin{array}{l}\mathrm{T} \times \mathrm{P} \\
\mathrm{CM} \times[\mathrm{T} \times \mathrm{P}] \\
\text { Error }\end{array}$ & $\begin{array}{r}1 \\
1 \\
22 \\
\end{array}$ & $\begin{array}{r}0.05 \\
0.26 \\
44.82 \\
\end{array}$ & $\begin{array}{l}0.05 \\
0.26 \\
2.04 \\
\end{array}$ & $\begin{array}{l}0.02 \\
0.13\end{array}$ & $\begin{array}{l}0.89 \\
0.73\end{array}$ \\
\hline $\begin{array}{l}\mathrm{WX} \times \mathrm{P} \\
\mathrm{CM} \times[\mathrm{WX} \times \mathrm{P}] \\
\quad \text { Error }\end{array}$ & $\begin{array}{r}1 \\
1 \\
22 \\
\end{array}$ & $\begin{array}{r}0.42 \\
0.63 \\
36.07 \\
\end{array}$ & $\begin{array}{l}0.42 \\
0.63 \\
1.64 \\
\end{array}$ & $\begin{array}{l}0.26 \\
0.38\end{array}$ & $\begin{array}{l}0.62 \\
0.55\end{array}$ \\
\hline $\begin{array}{l}\mathrm{T} \times \mathrm{WX} \times \mathrm{P} \\
\mathrm{CM} \times[\mathrm{T} \times \mathrm{WX} \times \mathrm{P}] \\
\quad \text { Error }\end{array}$ & $\begin{array}{r}1 \\
1 \\
22 \\
\end{array}$ & $\begin{array}{r}0.26 \\
1.17 \\
35.70 \\
\end{array}$ & $\begin{array}{l}0.26 \\
1.17 \\
1.62 \\
\end{array}$ & $\begin{array}{l}0.16 \\
0.72\end{array}$ & $\begin{array}{l}0.70 \\
0.41\end{array}$ \\
\hline
\end{tabular}

*Bold $F$ value is statistically significant at the $p$ ratio shown in the table. 
Table D9. Validation Category ANOVA Summary Table

\begin{tabular}{|c|c|c|c|c|c|}
\hline Source & $d f$ & SS & MS & $F$ & $p$ \\
\hline \multicolumn{6}{|c|}{ Between subjects } \\
\hline $\begin{array}{l}\text { Crew member }(\mathrm{CM}) \\
\text { Error }\end{array}$ & $\begin{array}{r}1 \\
22 \\
\end{array}$ & $\begin{array}{r}10.08 \\
792.83 \\
\end{array}$ & $\begin{array}{l}10.08 \\
36.04 \\
\end{array}$ & 0.28 & 0.61 \\
\hline \multicolumn{6}{|c|}{ Within subjects } \\
\hline $\begin{array}{l}\text { Precision }(\mathrm{T}) \\
\mathrm{CM} \times \mathrm{T} \\
\quad \text { Error } \\
\end{array}$ & $\begin{array}{r}1 \\
1 \\
22 \\
\end{array}$ & $\begin{array}{r}0.33 \\
0.33 \\
133.58 \\
\end{array}$ & $\begin{array}{l}0.33 \\
0.33 \\
6.07 \\
\end{array}$ & $\begin{array}{l}0.05 \\
0.05\end{array}$ & $\begin{array}{l}0.82 \\
0.82\end{array}$ \\
\hline $\begin{array}{c}\text { Weather (WX) } \\
\mathrm{CM} \times \mathrm{WX} \\
\text { Error }\end{array}$ & $\begin{array}{r}1 \\
1 \\
22\end{array}$ & $\begin{array}{r}3.52 \\
0.52 \\
138.71 \\
\end{array}$ & $\begin{array}{l}3.52 \\
0.52 \\
6.31\end{array}$ & $\begin{array}{l}0.56 \\
0.08\end{array}$ & $\begin{array}{l}0.47 \\
0.78\end{array}$ \\
\hline $\begin{array}{l}\text { Phase }(\mathrm{P}) \\
\mathrm{CM} \times \mathrm{P} \\
\text { Error } \\
\end{array}$ & $\begin{array}{r}1 \\
1 \\
22 \\
\end{array}$ & $\begin{array}{r}3316.69 \\
42.19 \\
685.88 \\
\end{array}$ & $\begin{array}{r}3316.69 \\
42.19 \\
31.18 \\
\end{array}$ & $\begin{array}{r}106.39 \\
1.35\end{array}$ & $\begin{array}{l}0.01 \\
0.26\end{array}$ \\
\hline $\begin{array}{l}\mathrm{T} \times W X \\
\mathrm{CM} \times[\mathrm{T} \times \mathrm{WX}] \\
\quad \text { Error } \\
\end{array}$ & $\begin{array}{r}1 \\
1 \\
22 \\
\end{array}$ & $\begin{array}{r}20.02 \\
0.02 \\
108.71 \\
\end{array}$ & $\begin{array}{r}20.02 \\
0.02 \\
4.94 \\
\end{array}$ & $\begin{array}{l}4.05 \\
0.00\end{array}$ & $\begin{array}{l}0.06 \\
0.95\end{array}$ \\
\hline $\begin{array}{l}\mathrm{T} \times \mathrm{P} \\
\mathrm{CM} \times[\mathrm{T} \times \mathrm{P}] \\
\quad \text { Error } \\
\end{array}$ & $\begin{array}{r}1 \\
1 \\
22 \\
\end{array}$ & $\begin{array}{r}1.69 \\
0.52 \\
136.54 \\
\end{array}$ & $\begin{array}{l}1.69 \\
0.52 \\
6.21 \\
\end{array}$ & $\begin{array}{l}0.27 \\
0.08\end{array}$ & $\begin{array}{l}0.61 \\
0.78\end{array}$ \\
\hline $\begin{array}{l}\mathrm{WX} \times \mathrm{P} \\
\mathrm{CM} \times[\mathrm{WX} \times \mathrm{P}] \\
\quad \text { Error } \\
\end{array}$ & $\begin{array}{r}1 \\
1 \\
22 \\
\end{array}$ & $\begin{array}{r}6.75 \\
0.08 \\
180.42 \\
\end{array}$ & $\begin{array}{l}6.75 \\
0.08 \\
8.20 \\
\end{array}$ & $\begin{array}{l}0.82 \\
0.01\end{array}$ & $\begin{array}{l}0.38 \\
0.93\end{array}$ \\
\hline $\begin{array}{l}\mathrm{T} \times \mathrm{WX} \times \mathrm{P} \\
\mathrm{CM} \times[\mathrm{T} \times \mathrm{WX} \times \mathrm{P}] \\
\quad \text { Error }\end{array}$ & $\begin{array}{r}1 \\
1 \\
22 \\
\end{array}$ & $\begin{array}{r}27.00 \\
0.75 \\
87.50 \\
\end{array}$ & $\begin{array}{r}27.00 \\
0.75 \\
3.98 \\
\end{array}$ & $\begin{array}{l}6.79 \\
0.19\end{array}$ & $\begin{array}{l}0.02 \\
0.67\end{array}$ \\
\hline
\end{tabular}

*Bold $F$ value is statistically significant at the $p$ ratio shown in the table. 
Table D10. Visibility Requirement Category ANOVA Summary Table

\begin{tabular}{|c|c|c|c|c|c|}
\hline Source & df & SS & MS & $F$ & $p$ \\
\hline \multicolumn{6}{|c|}{ Between subjects } \\
\hline $\begin{array}{l}\text { Crew member (CM) } \\
\text { Error }\end{array}$ & $\begin{array}{r}1 \\
22 \\
\end{array}$ & $\begin{array}{r}14.08 \\
170.40 \\
\end{array}$ & $\begin{array}{r}14.08 \\
7.75 \\
\end{array}$ & 1.82 & 0.20 \\
\hline \multicolumn{6}{|c|}{ Within subjects } \\
\hline $\begin{array}{l}\text { Precision }(\mathrm{T}) \\
\mathrm{CM} \times \mathrm{T} \\
\quad \text { Error }\end{array}$ & $\begin{array}{r}1 \\
1 \\
22 \\
\end{array}$ & $\begin{array}{r}11.02 \\
0.00 \\
25.48 \\
\end{array}$ & $\begin{array}{r}11.02 \\
0.00 \\
1.16\end{array}$ & $\begin{array}{l}9.52 \\
0.00\end{array}$ & $\begin{array}{l}0.01 \\
1.00\end{array}$ \\
\hline $\begin{array}{l}\text { Weather }(W X) \\
C M \times W X \\
\text { Error }\end{array}$ & $\begin{array}{r}1 \\
1 \\
22\end{array}$ & $\begin{array}{r}20.02 \\
3.00 \\
71.48 \\
\end{array}$ & $\begin{array}{r}20.02 \\
3.00 \\
3.25\end{array}$ & $\begin{array}{l}6.16 \\
0.92\end{array}$ & $\begin{array}{l}0.03 \\
0.35\end{array}$ \\
\hline $\begin{array}{c}\text { Phase }(\mathrm{P}) \\
\mathrm{CM} \times \mathrm{P} \\
\text { Error } \\
\end{array}$ & $\begin{array}{r}1 \\
1 \\
22\end{array}$ & $\begin{array}{r}168.75 \\
1.69 \\
64.56 \\
\end{array}$ & $\begin{array}{r}168.75 \\
1.69 \\
2.94\end{array}$ & $\begin{array}{r}\mathbf{5 7 . 5 0} \\
0.58\end{array}$ & $\begin{array}{l}0.01 \\
0.46\end{array}$ \\
\hline $\begin{array}{l}\mathrm{T} \times \mathrm{WX} \\
\mathrm{CM} \times[\mathrm{T} \times \mathrm{WX}] \\
\quad \text { Error }\end{array}$ & $\begin{array}{r}1 \\
1 \\
22 \\
\end{array}$ & $\begin{array}{r}6.02 \\
0.75 \\
55.23 \\
\end{array}$ & $\begin{array}{l}6.02 \\
0.75 \\
2.51\end{array}$ & $\begin{array}{l}2.40 \\
0.30\end{array}$ & $\begin{array}{l}0.14 \\
0.60\end{array}$ \\
\hline $\begin{array}{l}\mathrm{T} \times \mathrm{P} \\
\mathrm{CM} \times[\mathrm{T} \times \mathrm{P}] \\
\quad \text { Error } \\
\end{array}$ & $\begin{array}{r}1 \\
1 \\
22 \\
\end{array}$ & $\begin{array}{r}10.08 \\
0.02 \\
24.40 \\
\end{array}$ & $\begin{array}{r}10.08 \\
0.02 \\
1.11 \\
\end{array}$ & $\begin{array}{l}9.09 \\
0.02\end{array}$ & $\begin{array}{l}0.01 \\
0.90\end{array}$ \\
\hline $\begin{array}{l}\mathrm{WX} \times \mathrm{P} \\
\mathrm{CM} \times[\mathrm{WX} \times \mathrm{P}] \\
\quad \text { Error } \\
\end{array}$ & $\begin{array}{r}1 \\
1 \\
22 \\
\end{array}$ & $\begin{array}{r}8.33 \\
0.19 \\
29.98 \\
\end{array}$ & $\begin{array}{l}8.33 \\
0.19 \\
1.36 \\
\end{array}$ & $\begin{array}{l}6.12 \\
0.14\end{array}$ & $\begin{array}{l}0.03 \\
0.72\end{array}$ \\
\hline $\begin{array}{l}\mathrm{T} \times \mathrm{WX} \times \mathrm{P} \\
\mathrm{CM} \times[\mathrm{T} \times \mathrm{WX} \times \mathrm{P}] \\
\text { Error }\end{array}$ & $\begin{array}{r}1 \\
1 \\
22\end{array}$ & $\begin{array}{r}5.33 \\
1.02 \\
24.65\end{array}$ & $\begin{array}{l}5.33 \\
1.02 \\
1.12\end{array}$ & $\begin{array}{l}\mathbf{4 . 7 6} \\
0.91\end{array}$ & $\begin{array}{l}0.05 \\
0.36\end{array}$ \\
\hline
\end{tabular}

*Bold $F$ values are statistically significant at the $p$ ratio shown in the table. 


\section{Appendix E}

\section{Means and Standard Deviations}

Tables E1 through E10 contain the means and standard deviations for the 10 approach chart categories.

Table E1. Means and Standard Deviations for Navigation Category ANOVA

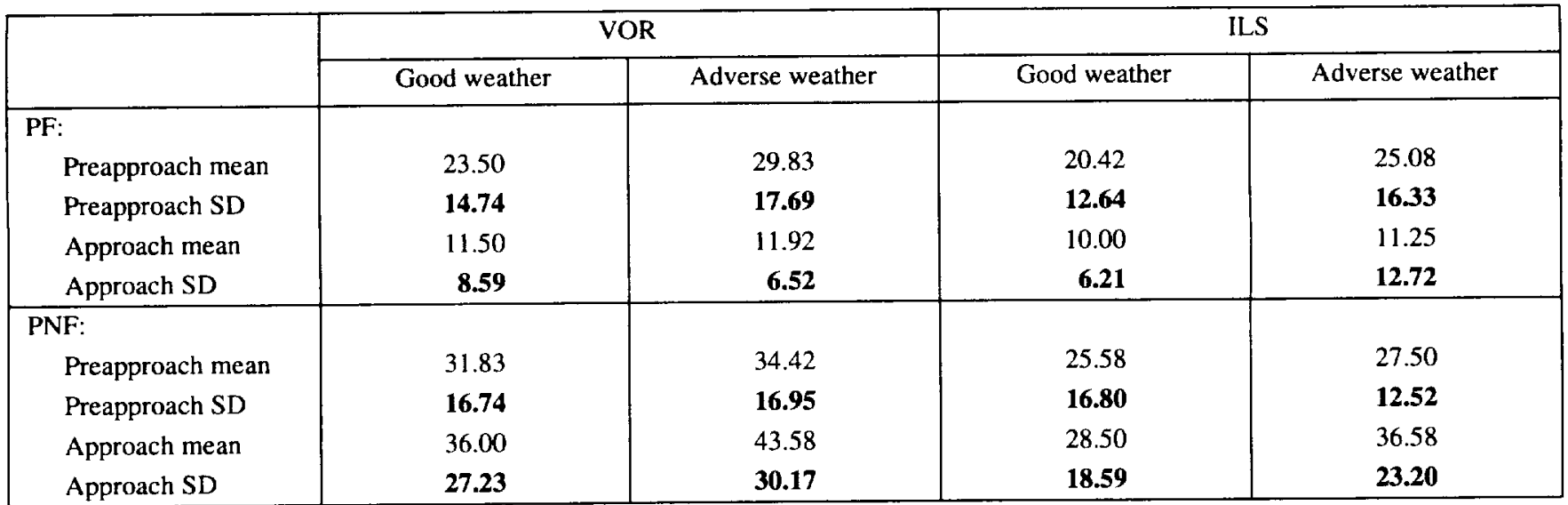

Table E2. Means and Standard Deviations for Missed Approach Category ANOVA

\begin{tabular}{|c|c|c|c|c|}
\hline & \multicolumn{2}{|c|}{ VOR } & \multicolumn{2}{|c|}{ ILS } \\
\hline & Good weather & Adverse weather & Good weather & Adverse weather \\
\hline PF: & & & & \\
\hline Preapproach mean & 3.25 & 6.58 & 3.67 & 1.67 \\
\hline Preapproach SD & 1.60 & 2.78 & 2.54 & 1.16 \\
\hline Approach mean & 0.50 & 0.83 & 0.58 & 0.42 \\
\hline Approach SD & 0.67 & 1.12 & 0.67 & 0.67 \\
\hline PNF: & & & & \\
\hline Preapproach mean & 4.17 & 6.25 & 3.17 & 2.58 \\
\hline Preapproach SD & 2.69 & 3.86 & 1.64 & 1.68 \\
\hline Approach mean & 3.25 & 3.58 & 1.42 & 2.08 \\
\hline Approach SD & 2.93 & 3.87 & 1.51 & 1.93 \\
\hline
\end{tabular}

Table E3. Means and Standard Deviations for Visibility Requirement Category ANOVA

\begin{tabular}{|c|c|c|c|c|}
\hline & \multicolumn{2}{|c|}{ VOR } & \multicolumn{2}{|c|}{ ILS } \\
\hline & Good weather & Adverse weather & Good weather & Adverse weather \\
\hline PF: & & & & \\
\hline Preapproach mean & 1.58 & 2.75 & 1.08 & 1.42 \\
\hline Preapproach SD & 1.73 & 2.14 & 0.67 & 1.08 \\
\hline Approach mean & 0.00 & 0.08 & 0.00 & 0.00 \\
\hline Approach SD & 0.00 & 0.29 & 0.00 & 0.00 \\
\hline PNF: & & & & \\
\hline Preapproach mean & 1.75 & 4.08 & 1.75 & 2.17 \\
\hline Preapproach SD & 1.42 & 4.68 & 1.22 & 1.90 \\
\hline Approach mean & 0.17 & 0.58 & 0.17 & 0.58 \\
\hline Approach SD & 0.58 & 1.51 & 0.58 & 1.08 \\
\hline
\end{tabular}


Table E4. Means and Standard Deviations for Navigation Aids Category ANOVA

\begin{tabular}{|l|c|c|c|c|}
\hline & \multicolumn{2}{|c|}{ VOR } & \multicolumn{2}{c|}{ ILS } \\
\cline { 2 - 5 } & Good weather & Adverse weather & Good weather & Adverse weather \\
\hline PF: & & & & 12.25 \\
Preapproach mean & 12.50 & 12.67 & 9.60 & 10.09 \\
Preapproach SD & $\mathbf{8 . 8 1}$ & 5.16 & 3.58 & 3.08 \\
Approach mean & 3.08 & 2.75 & $\mathbf{2 . 1 9}$ & \\
Approach SD & $\mathbf{3 . 0 0}$ & 2.42 & & \\
\hline PNF: & & & 21.42 & 18.00 \\
Preapproach mean & 17.50 & 21.75 & $\mathbf{8 . 4 8}$ & $\mathbf{9 . 1 4}$ \\
Preapproach SD & 6.86 & $\mathbf{9 . 3 7}$ & $\mathbf{8 . 7 0}$ & 15.33 \\
Approach mean & 12.33 & 15.67 & $\mathbf{1 1 . 1 3}$ & \\
Approach SD & $\mathbf{9 . 4 4}$ & & & 10.42 \\
\hline
\end{tabular}

Table E5. Means and Standard Deviations for Validation Category ANOVA

\begin{tabular}{|l|c|c|c|c|}
\hline & \multicolumn{2}{|c|}{ VOR } & \multicolumn{2}{c|}{ ILS } \\
\cline { 2 - 5 } & Good weather & Adverse weather & Good weather & Adverse weather \\
\hline PF: & & & 10.50 & 8.50 \\
Preapproach mean & 9.33 & 9.92 & 5.84 & 4.44 \\
Preapproach SD & 6.07 & 3.83 & 0.58 & 0.50 \\
Approach mean & 0.08 & 0.08 & 1.00 & 0.80 \\
Approach SD & $\mathbf{0 . 2 9}$ & $\mathbf{0 . 2 9}$ & & \\
\hline PNF: & & & 10.08 & $\mathbf{8 . 0 0}$ \\
Preapproach mean & 8.67 & 9.58 & $\mathbf{5 . 1 1}$ & $\mathbf{4 . 3 9}$ \\
Preapproach SD & $\mathbf{4 . 4 2}$ & $\mathbf{3 . 5 8}$ & 1.50 & 2.00 \\
Approach mean & 1.67 & 1.67 & 1.93 & 2.83 \\
Approach SD & $\mathbf{2 . 7 4}$ & 1.37 & \\
\hline
\end{tabular}

Table E6. Means and Standard Deviations for Obstructions Category ANOVA

\begin{tabular}{|c|c|c|c|c|}
\hline & \multicolumn{2}{|c|}{ VOR } & \multicolumn{2}{|c|}{ ILS } \\
\hline & Good weather & Adverse weather & Good weather & Adverse weather \\
\hline \multicolumn{5}{|l|}{ PF: } \\
\hline Preapproach mean & 6.50 & 5.58 & 5.83 & 4.42 \\
\hline Preapproach SD & 5.02 & 5.09 & 6.69 & 4.34 \\
\hline Approach mean & 4.17 & 2.92 & 5.17 & 3.00 \\
\hline Approach SD & 2.21 & 2.23 & 4.57 & 2.76 \\
\hline \multicolumn{5}{|l|}{ PNF: } \\
\hline Preapproach mean & 12.67 & 6.92 & 5.08 & 3.42 \\
\hline Preapproach SD & $\mathbf{3 . 7 3}$ & 5.05 & 3.58 & 2.71 \\
\hline Approach mean & 9.58 & 12.58 & 7.08 & 9.17 \\
\hline Approach SD & 9.93 & 7.33 & 3.68 & 5.42 \\
\hline
\end{tabular}


Table E7. Means and Standard Deviations for Final Items Category ANOVA

\begin{tabular}{|c|c|c|c|c|}
\hline & \multicolumn{2}{|c|}{ VOR } & \multicolumn{2}{|c|}{ ILS } \\
\hline & Good weather & Adverse weather & Good weather & Adverse weather \\
\hline PF: & & & & \\
\hline Preapproach mean & 0.00 & 0.42 & 0.67 & 0.75 \\
\hline Preapproach SD & 0.00 & 0.67 & 0.99 & 0.87 \\
\hline Approach mean & 0.00 & 0.00 & 0.00 & 0.25 \\
\hline Approach SD & 0.00 & 0.00 & $\mathbf{0 . 0 0}$ & 0.62 \\
\hline PNF: & & & & \\
\hline Preapproach mean & 0.42 & 0.67 & 0.67 & 0.92 \\
\hline Preapproach SD & 1.00 & 0.89 & 0.99 & 1.24 \\
\hline Approach mean & 0.33 & 0.17 & 0.33 & 0.92 \\
\hline Approach SD & 1.16 & 0.58 & 0.89 & 1.73 \\
\hline
\end{tabular}

Table E8. Means and Standard Deviations for Other Runways Category ANOVA

\begin{tabular}{|c|c|c|c|c|}
\hline & \multicolumn{2}{|c|}{ VOR } & \multicolumn{2}{|c|}{ ILS } \\
\hline & Good weather & Adverse weather & Good weather & Adverse weather \\
\hline PF: & & & & \\
\hline Preapproach mean & 1.00 & 1.33 & 1.08 & 0.83 \\
\hline Preapproach SD & 1.48 & 1.72 & 1.56 & 1.75 \\
\hline Approach mean & 0.17 & 0.00 & 0.00 & 0.17 \\
\hline Approach SD & 0.39 & $\mathbf{0 . 0 0}$ & 0.00 & 0.58 \\
\hline PNF: & & & & \\
\hline Preapproach mean & 1.58 & 1.33 & 1.83 & 1.25 \\
\hline Preapproach SD & 2.47 & 1.50 & 2.69 & 1.77 \\
\hline Approach mean & 0.33 & 0.67 & 0.67 & 0.33 \\
\hline Approach SD & 0.65 & 1.07 & 1.30 & 0.78 \\
\hline
\end{tabular}

Table E9. Means and Standard Deviations for Communications Category ANOVA

\begin{tabular}{|c|c|c|c|c|}
\hline & \multicolumn{2}{|c|}{ VOR } & \multicolumn{2}{|c|}{ ILS } \\
\hline & Good weather & Adverse weather & Good weather & Adverse weather \\
\hline \multicolumn{5}{|l|}{ PF: } \\
\hline Preapproach mean & 0.42 & 0.00 & 0.25 & 0.00 \\
\hline Preapproach SD & 1.44 & 0.00 & 0.87 & 0.00 \\
\hline Approach mean & 0.17 & 0.25 & 0.25 & 0.33 \\
\hline Approach SD & 0.58 & 0.62 & 0.62 & 0.89 \\
\hline \multicolumn{5}{|l|}{ PNF: } \\
\hline Preapproach mean & 0.00 & 0.08 & 0.08 & 0.00 \\
\hline Preapproach SD & 0.00 & 0.29 & 0.29 & 0.00 \\
\hline Approach mean & 1.25 & 2.17 & 1.75 & 1.25 \\
\hline Approach SD & 1.60 & 2.76 & 2.49 & 2.56 \\
\hline
\end{tabular}


Table E10. Means and Standard Deviations for Geography Category ANOVA

\begin{tabular}{|l|c|c|c|c|}
\hline & \multicolumn{2}{|c|}{ VOR } & \multicolumn{2}{c|}{ ILS } \\
\cline { 2 - 5 } & Good weather & Adverse weather & Good weather & Adverse weather \\
\hline PF: & & & 0.67 & 0.17 \\
Preapproach mean & 0.00 & 0.00 & $\mathbf{2 . 0 2}$ & 0.58 \\
Preapproach SD & $\mathbf{0 . 0 0}$ & $\mathbf{0 . 0 0}$ & 0.50 & 0.00 \\
Approach mean & 0.00 & 0.00 & $\mathbf{0 . 9 1}$ & $\mathbf{0 . 0 0}$ \\
Approach SD & $\mathbf{0 . 0 0}$ & $\mathbf{0 . 0 0}$ & 0.25 & 0.25 \\
\hline PNF: & 0.00 & 0.17 & $\mathbf{0 . 6 2}$ & $\mathbf{0 . 4 5}$ \\
Preapproach mean & $\mathbf{0 . 0 0}$ & $\mathbf{0 . 3 9}$ & 0.58 & $\mathbf{1 . 5 1}$ \\
Preapproach SD & 0.00 & 0.25 & $\mathbf{0 . 6 2}$ & 0.42 \\
Approach mean & $\mathbf{0 . 0 0}$ & & & $\mathbf{0 . 6 7}$ \\
Approach SD & & & & \\
\hline
\end{tabular}




\section{Appendix F}

\section{Application}

The results of this study could have widespread applications and implications concerning approach information presentation formats. In appendix $F$ the focus is on how the managing approach plate information study (MAPLIST) findings might be applied to the redesign of existing approach charts and to the design of future electronic formats.

The primary finding of this study was that pilots appear to mentally organize and use approach chart information according to 10 primary categories: Communications, Geography, Validation, Obstructions, Navigation, Missed Approach, Final Items, Other Runways, Visibility Requirement, and Navigation Aids. These categories were found to underlie cognitive processes invoked by pilots to accomplish their tasks. The way that pilots acquired approach chart information reflected their use of cognitive processes.

As noted in the main text of this paper, research has shown that presenting information according to the user's mental model improves acquisition efficiency and memory retention while reducing user error and results in overall improvements in performance with the system. Applying the categories that result from MAPLIST to presentation formats might improve pilot performance when approach chart information is being used by not requiring pilots to organize the information to the same extent prior to their using it.

\section{Approach Charts}

One potential application of the MAPLIST findings in the area of approach chart design is to organize the information's presentation by using the similarity categories. Since existing approach chart formats resemble this type of organization already, a simple regrouping of some information may fulfill this design goal. When possible, the location of the chart where the information is currently being presented will be used. In figure $\mathrm{F} 1$ and in the discussion below, a standard (Jeppesen) layout has been used in which the similarity categories and their information element types have been arranged.

Validation items have been placed in the upper right corner of the approach chart where most of this information already exists. Since pilots are accustomed to using the chart starting at the top and progressing to the bottom, and since pilots use the Validation items prior to all others on the approach chart, this section would appear to be in a logical position, given this temporal demand. Airport elevation, airport name, changes, chart date, chart index number, effective date, geographic name, notes, and procedure name are all members of this similarity cluster. Again, most of these items already appear in this area of existing chart formats.

Communications items have been placed in the upper left corner of the approach chart. The position of these items in the upper left quadrant of the chart does not seem to fulfill a temporal requirement and could probably be placed elsewhere if further analysis proved it to be beneficial. This section of the chart was chosen for this discussion since current formats use this area for Communications information. Members of this group are airport departure frequency, approach frequency, Automatic Terminal Information Service (ATIS) arrival frequency, ATIS clearance frequency, ground frequency, and tower frequency. As with the previously discussed category, most of these items are already presented together in current formats. The exceptions (i.e., the additions) are airport departure frequency and ATIS clearance frequency.

The plan view section of current formats gives the map of the area that surrounds and constitutes the airfield. Included in this map is the graphical depiction of Obstructions and Navigation Aids. For this reason, the Geography category's information should be depicted in this section. The Geography category gives additional information concerning these data and consists of the latitude-longitude grid, latitude-longitude airport very high frequency (VHF) omnidirectional range (VOR), magnetic variation, and scaling.

Navigation Aids is the next category listed in the plan view section of the chart. Its members are instrument landing system (ILS) identifier, ILS localizer frequency, ILS Morse code, nondirectional beacon (NDB) frequency, NDB identifier, NDB Morse code, primary facility frequency, primary facility Morse code, VOR frequency, VOR identifier, VOR Morse code, and VOR name. The plan view is a logical place for this information because it can be located next to the graphical depiction of the aid. Experience and current chart formats have shown that some items will need to be duplicated in various places on a chart, and the first such instance in this discussion could be the name of the navigation aid. For example, the distance measuring equipment (DME) distances (in a category to be discussed below) are depicted in various sections of an approach chart and are always measured from certain Navigation Aids. The navigation aid from which distance is measured for a specific instance of a DME distance needs to be shown with the DME depiction. However, the inclusion of the entire Navigation Aids category in the plan view, instead of some kind of distribution, is supported by the way the pilots view this information. Obviously the clustering analysis showed that pilots viewed this information as 


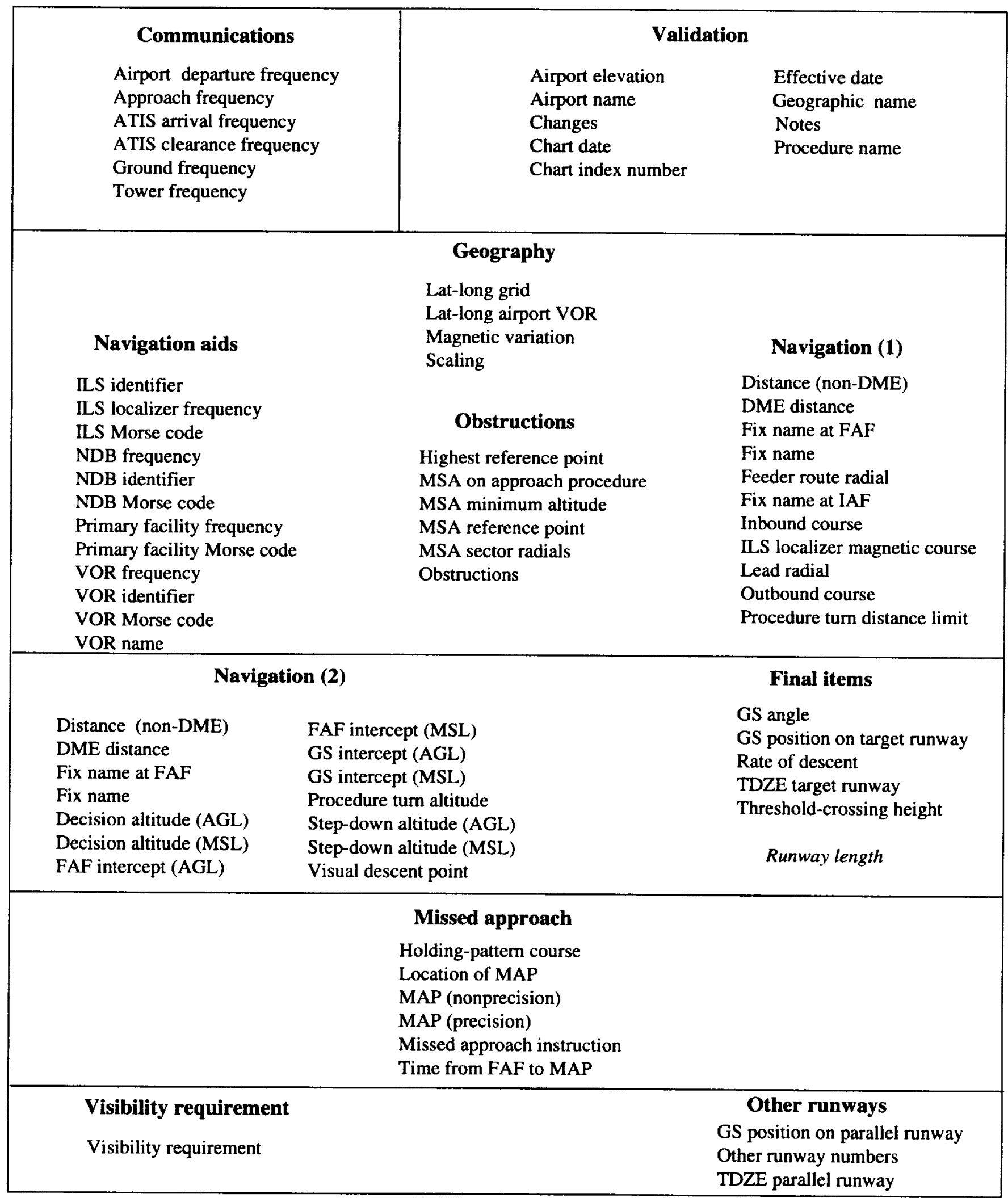

Figure F1. Example use of derived categories for approach chart redesign. 
similar, but they also stated in the debriefing and showed in the acquisition data that a navigation aid, its frequency, the identifier, and its Morse code are viewed as one chunk of information, and should therefore not be separated in its depiction.

All the Obstructions category data have been included in the plan view section. This category consists of the highest reference point, minimum safe altitude (MSA) on approach procedure, MSA minimum altitude, MSA reference point, MSA sector radials, and obstructions. Since this information gives the location (sometimes only abstractly) of the obstruction as well as the altitude to stay above, this information should be next to the geographic information and the graphical depiction of the obstructions.

The Navigation category was the largest and subsequently was further decomposed, as was stated in the text of this paper. When looking at the clustering (fig. 9) at lower levels, one can see that the information is clustered according to whether it was a fix name, distance, altitude, or course (heading). For this discussion, information in this category that pertains to the horizontal navigation (i.e., fix name, distance, and course) will be placed in the plan view section and that which pertains to vertical navigation (i.e., fix name, distance, and altitude) will be depicted in the profile section. Since fix names and distances are needed for both horizontal and vertical navigation (as well as for cross-checking), distance (nondistance measuring equipment (DME)), DME distance, fix name at final approach fix (FAF), and fix name are duplicated in figure F1 (in the plan and profile views). This duplication will not necessarily be the same piece of information, but it sometimes will be (e.g, fix name at FAF). The other information in this category that may be presented in the plan view section exclusively is feeder route radial, fix name at initial approach fix (IAF), inbound course, instrument landing system (ILS) localizer magnetic course, lead radial, outbound course, and the procedure turn distance limit.

Those items in the Navigation category that will also appear in the profile section were discussed above (i.e., distance (non-DME), DME distance, fix name at FAF, and fix name). Those items that pertain exclusively to vertical navigation in this category are decision altitude (AGL), decision altitude (MSL), FAF intercept (AGL), FAF intercept (MSL), glideslope (GS) intercept (AGL), GS intercept (MSL), procedure turn altitude, step-down altitude (AGL), step-down altitude (MSL), and visual descent point. One exception to this breakdown may be that of procedure turn altitude. Most of the items listed in this paragraph refer to the descent profile near the touchdown portion of the approach, and the procedure turn may be out further and therefore treated like the MSA on approach procedure (i.e., in the plan view). The tight clustering of this item with procedure turn distance limit (fig. 9) might also suggest its removal from this section (and its inclusion in the plan view).

The other category that is depicted in the profile view of figure $F 1$ is Final Items. These items are GS angle, GS position on target runway, rate of descent, touchdown zone elevation (TDZE) target runway, and threshold-crossing height. One addition to this category is runway length. This item clustered with the other runways category, but it was felt that it belonged more with the Final Items information (refer to discussion in the main text).

The Missed Approach category information has all been listed in the section traditionally used for the missed approach instruction. Since the pilots view this information as similar, it may be more efficient to present it together in one location, but this does not mean that some of the information could not be duplicated elsewhere. For example, it would probably be useful to depict the holding-pattern course in the plan view section for crosschecking purposes. It might also be useful to present the location of the missed approach point (MAP) in both the plan view and profile view for cross checking. However, when the pilots are dealing with the missed approach, they also may benefit if all of the information is located together.

Visibility Requirement has been placed in figure F1 according to the position of the chart where it is normally presented. However, given the importance pilots placed on this information and its frequent acquisition, it might be beneficial to place it on the chart in an area that is scanned frequently (to promote easy access). Decision altitude is also usually depicted where the visibility requirement is shown in figure $\mathrm{F} 1$. Its inclusion in the profile section makes sense considering that the AGL altitudes are calculated from the TDZE. However, the decision altitude and the visibility requirement are also referenced independently to determine whether the pilots are still legal to fly the approach and to determine if and when to fly a missed approach. For this reason, a separate (and maybe duplicate) depiction of this information might be warranted.

The Other Runways category contains the information that is commonly shown on the airport diagram. This information consists of GS position on parallel runway, other runway numbers, and TDZE on the parallel runway. There was not much activity in this experiment that concerned these data, so their position on the chart might warrant an infrequently scanned location. 


\section{Electronic Formats}

How the categories that were found in this study might influence electronic presentation formats is similar to the ones that were discussed previously for the approach chart. Information that is similar should be presented together. What differs from the above discussion is the integration of approach information with similar information that is presented already on existing displays, instead of in a dedicated display for the electronic chart.

The flight deck used for this discussion will have a primary flight display (PFD), navigation display (NAV), and an electronic library system (ELS) with its corresponding display. In addition, it is assumed that a minimum of two additional displays exist (e.g., engines display and caution and warning-checklist display). No assumptions that concern the location and size of these displays are being made. There is also no attempt here to determine or suggest specific formats for the information that is presented (e.g., font size, icon). Instead, this discussion will be limited to where the information might be placed.

The grouping of information will be the same as that discussed previously (i.e., with two Navigation categories and with runway length being included with Final Items); therefore, only the names of the categories will be used in this discussion.

Presenting this information electronically will automate some of the pilots' current tasks (e.g., getting the correct chart), but the validation information is still needed for pilots to ascertain what the automation is doing and if it is doing it correctly. This type of auxiliary information probably would be most appropriate on the ELS. Also of that nature, and also targeted for the ELS in this discussion is the communications information. ${ }^{10}$

All the information listed above for the plan view section of the approach chart could be presented on the NAV. These categories were Geography, Navigation Aids, Obstructions, and Navigation (1). Many of these items are being depicted on the NAV already and only need minor modifications to include the subtle differ-

\footnotetext{
${ }^{10}$ Items destined for the ELS in this discussion will be those that have no similar items already presented on glass flight decks with which to integrate.
}

ences. Other information in these categories may not be necessary at all for an advanced flight deck. For example, advanced radios could automatically tune and identify themselves, thus removing the need for a visual presentation of Morse code and possibly even the frequency. (Possibly the frequencies could be moved to the ELS for validation purposes.)

The vertical navigation items pose the most difficulty when they are integrated with existing glass cockpit layouts. This information could be added to the NAV display with the use of "altitude arcs" and other similar plan view aids used for vertical navigation. However, given the difference in functions that the Navigation (2) and Final Items information support when compared with that traditionally on the NAV, it would probably be better to dedicate a new display for this purpose. Work has been done in the past for vertical navigation displays, with many formats resembling the profile section of an approach chart with an aircraft icon that indicates the aircraft's current position relative to the path. This display would be needed only during the end of the flight and could possibly share duties with an existing screen on the flight deck.

Missed Approach information could be presented on both the NAV in graphical form and on the ELS in textual form. Another possibility is to present the missed approach information on a third screen in the event of a missed approach execution. In this case, the missed approach courses and MAP information would be presented on the NAV, the textual missed approach information would be presented on the ELS, and in the event that a missed approach is executed, the appropriate information could be treated as caution and warning information and displayed on the appropriate caution and warning screen. Of course with these types of advanced display technologies, the possibilities are numerous. For example, in the event of a missed approach, the missed approach courses and MAP information could also be highlighted on the NAV.

The Visibility Requirement and Other Runways categories, probably would be most appropriate on the ELS. This information is not often integrated with the other information functionally and should probably be treated as auxiliary information, even though it is important and in the case of Visibility Requirement information often accessed. 


\section{References}

Ashby, F. Gregory 1992: Multidimensional Models of Perception and Cognition. Lawrence Erlbaum Assoc., Publ.

Boeing Commercial Airplane Group 1991a: Flight Deck Information Management, Phase 1. D6-56305, Flight Deck Research.

Boeing Commercial Airplane Group 1991b: Flight Deck Information Management, Phase 2. D6-56305-1, Flight Deck Research.

Cannon-Bowers, Janis A.; Tannenbaum, Scott I.; and Salas, Eduardo 1991: Toward an Integration of Training Theory and Technique. Human Factors, vol. 33, no. 3, pp. 281-292.

Carroll, J. Douglas 1972: Individual Differences and Multidimensional Scaling. MultiDimensional Scaling-Theory and Applications in the Behavioral Sciences, Roger N. Shepard, A. Kimball Romney, and Sara Beth Nerlove, eds., Seminar Press, pp. 105-155.

Clay, Melanie C. 1993: Key Cognitive Issues in the Design of Electronic Displays of Instrument Approach Procedure Charts. DOT-VNTSC-FAA-93-18, Federal Aviation Administration. (Available from DTIC as AD-A275647.)

Hansman, R. John, Jr.; and Mykityshyn, Mark 1990: Current Issues in the Design and Information Content of Instrument Approach Charts. ASL-90-1-1.

Jeppesen Sanderson, Inc. 1993: Instrument Rating Manual, Seventh ed., Chapt. 3, Sec. A, Instrument Approach Charts, pp. 3-2-3-28.

Jonsson, J. E.; and Ricks, W. R. 1995: Cognitive Models of Pilot Categorization and Prioritization of Flight-Deck Information. NASA TP-3528.
Kruskal, Joseph B.; and Wish, Myron 1978: Multidimensional Scaling. Series No. 07-011, Sage Publ.

Mykityshyn, Mark G.; and Hansman, R. John, Jr, 1990: An Exploratory Survey of Information Requirements for Instrument Approach Charts. ASL-90-1-2.

Mykityshyn, Mark G.; and Hansman, R. John, Jr. 1991: Design and Evaluation of Advanced Electronic Cockpit Displays for Instrument Approach Information. ASL-91-5.

Nosofsky, R. M. 1984: Choice, Similarity, and the Context Theory of Classification. J. Exp. Psychol-Learning Memory \& Cogn., vol. 10, no. 1, pp. 104-114.

Nosofsky, R. M. 1986: Attention, Similarity, and the Identification-Categorization. J. Exp. Psychol.-General, vol. 115, no. 1, pp. $39-57$.

Nosofsky, Robert M. 1992: Similarity Scaling and Cognitive Process Models. Annu. Rev. Psychol., vol. 43, pp. $25-53$.

Romesburg, H. Charles 1984: Cluster Analysis for Researchers. Lifetime Learning Publ.

Shepard, R. N. 1980: Multidimensional-Scaling, Tree-Fitting, and Clustering. Science, vol. 210, no. 4468, pp. 390-398.

Wilkinson, Leland; Hill, MaryAnn; and Vang, Erin 1992: SYSTAT: Statistics, Version 5.2 ed. SYSTAT, Inc., Evanston, IL.

Woods, D. D. 1985: Knowledge Based Development of Graphic Display Systems. Proceedings of the Human Factors Society 29th Annual Meeting, Human Factors Soc. 


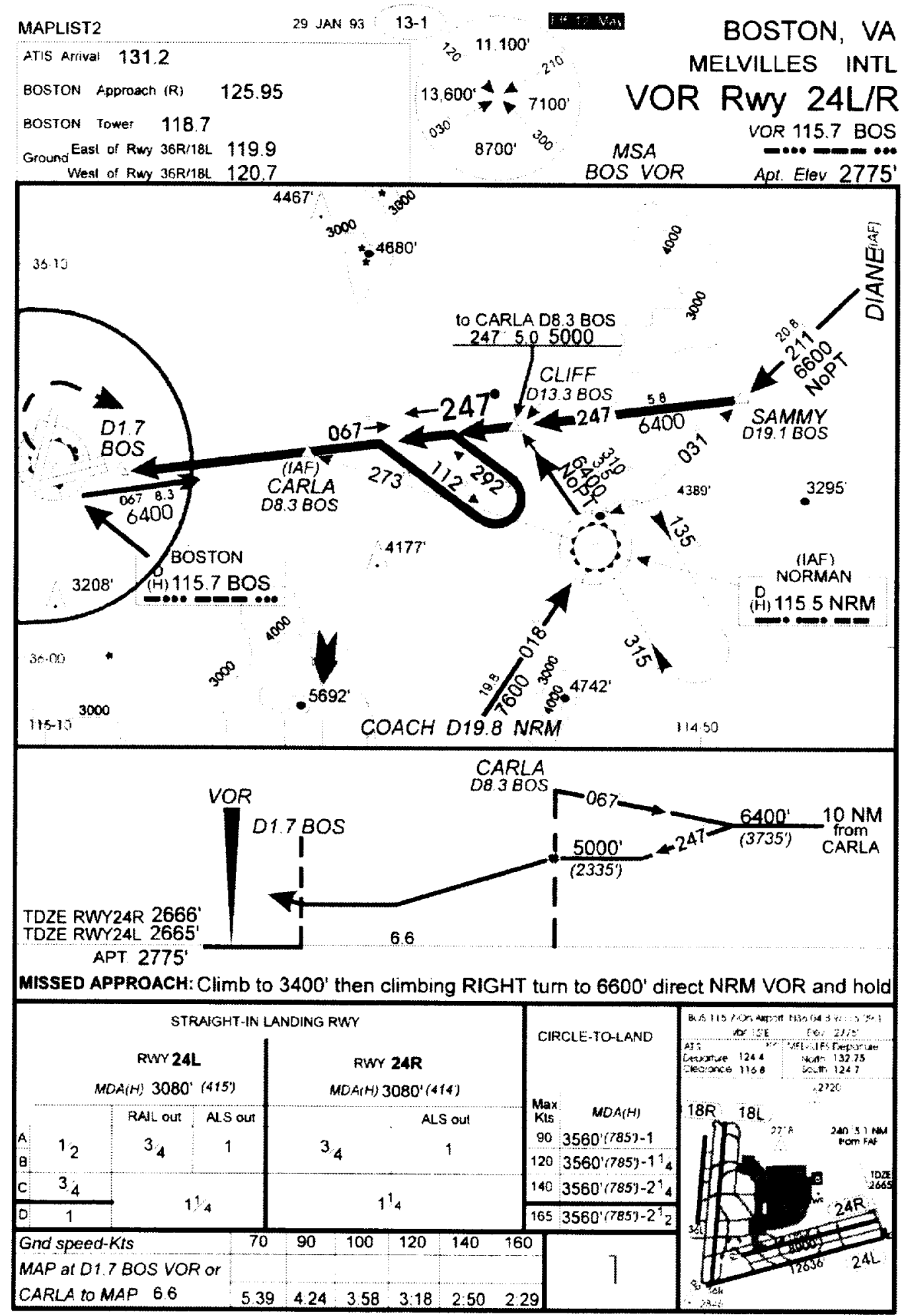

Figure 1. Approach chart 1. 


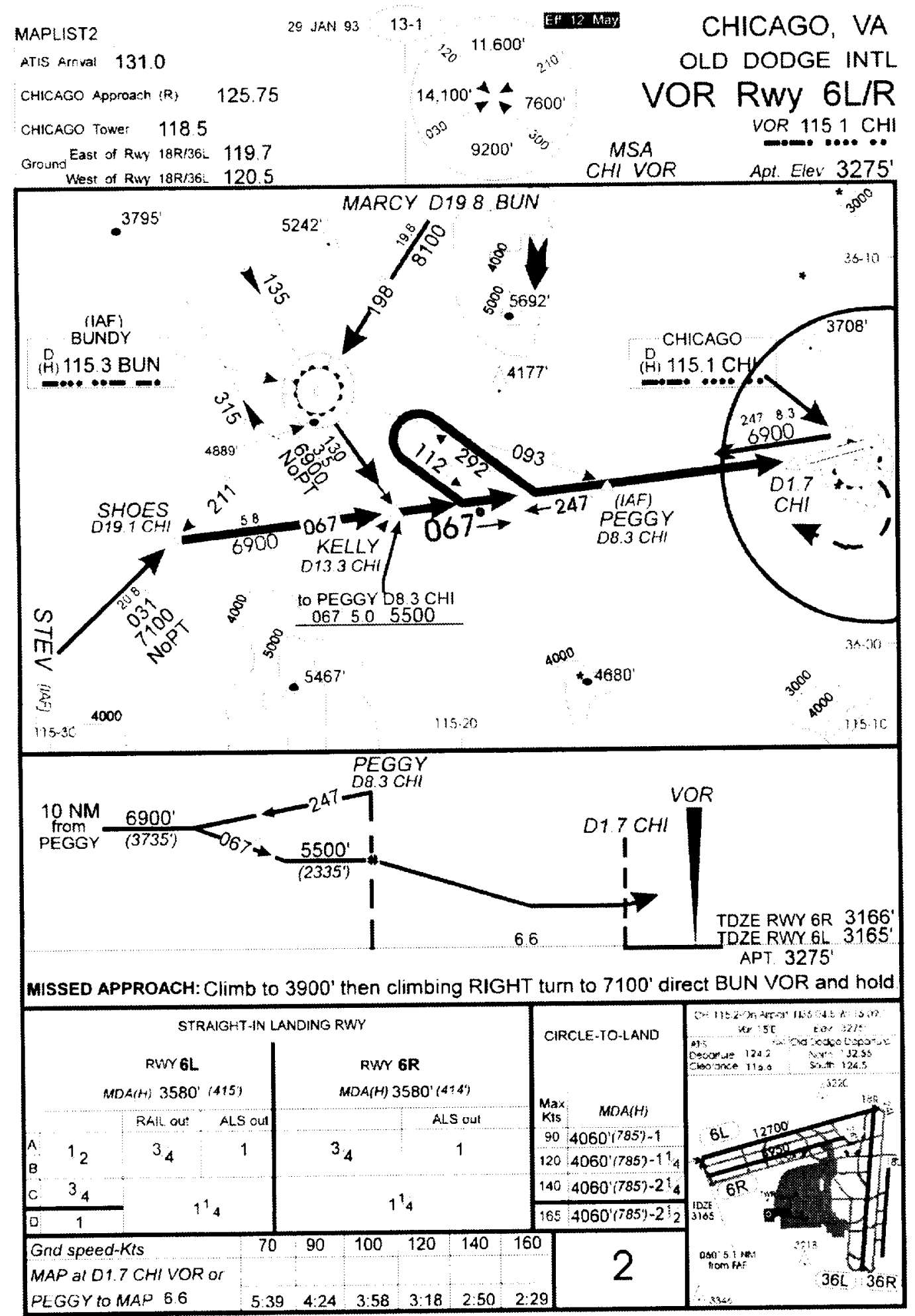

Figure 2. Approach chart 2. 


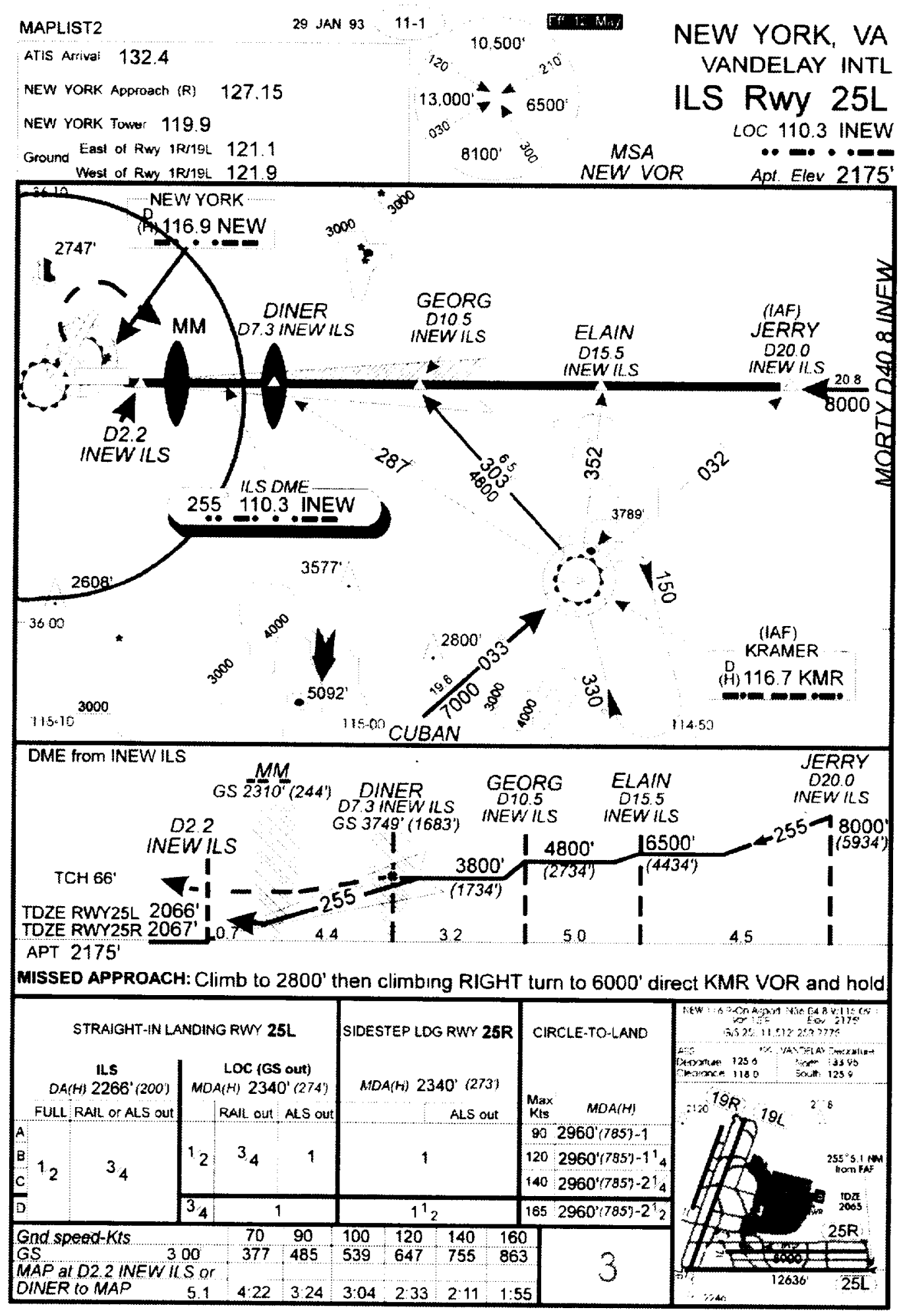

Figure 3. Approach chart 3. 


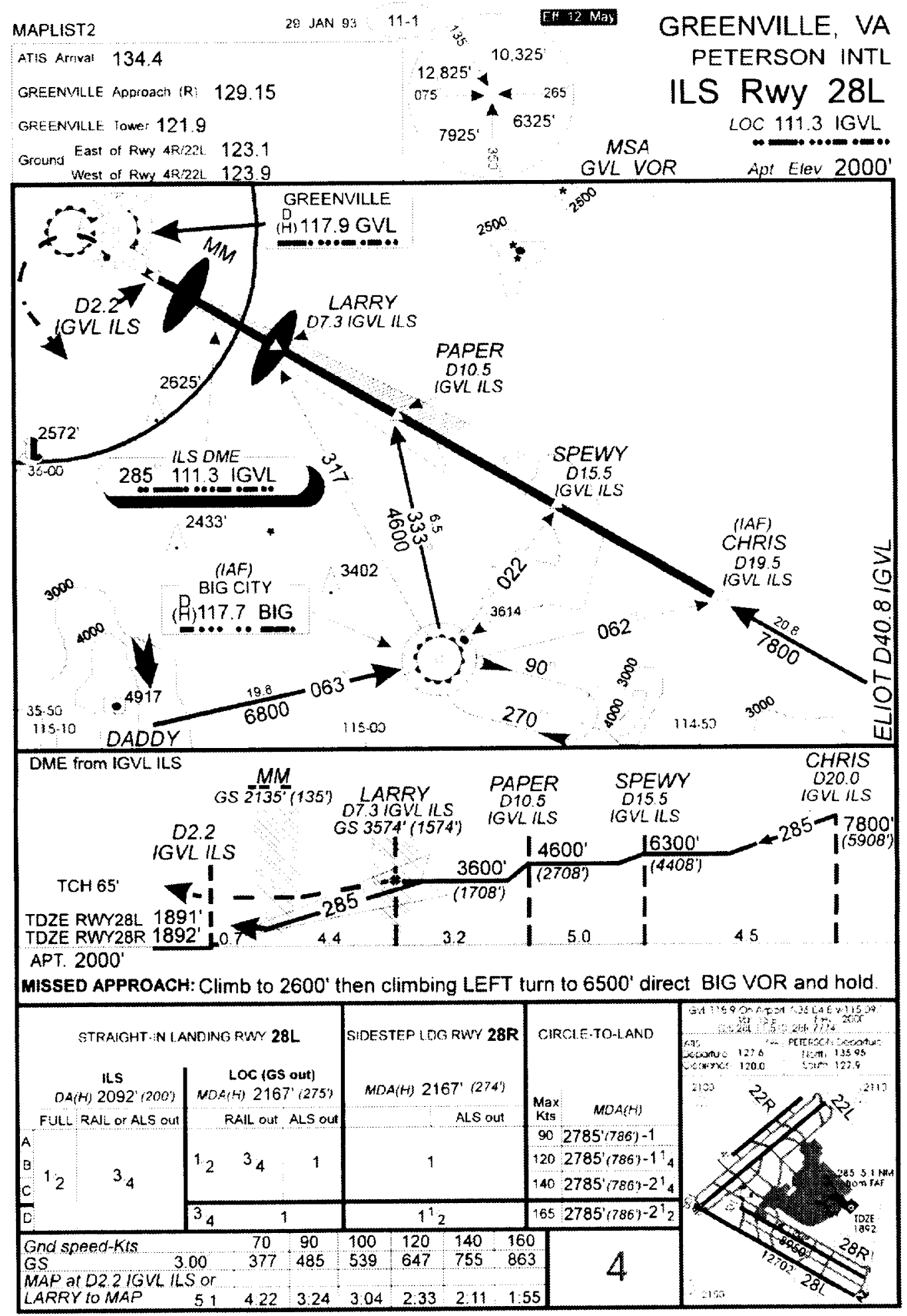

Figure 4. Approach chart 4. 


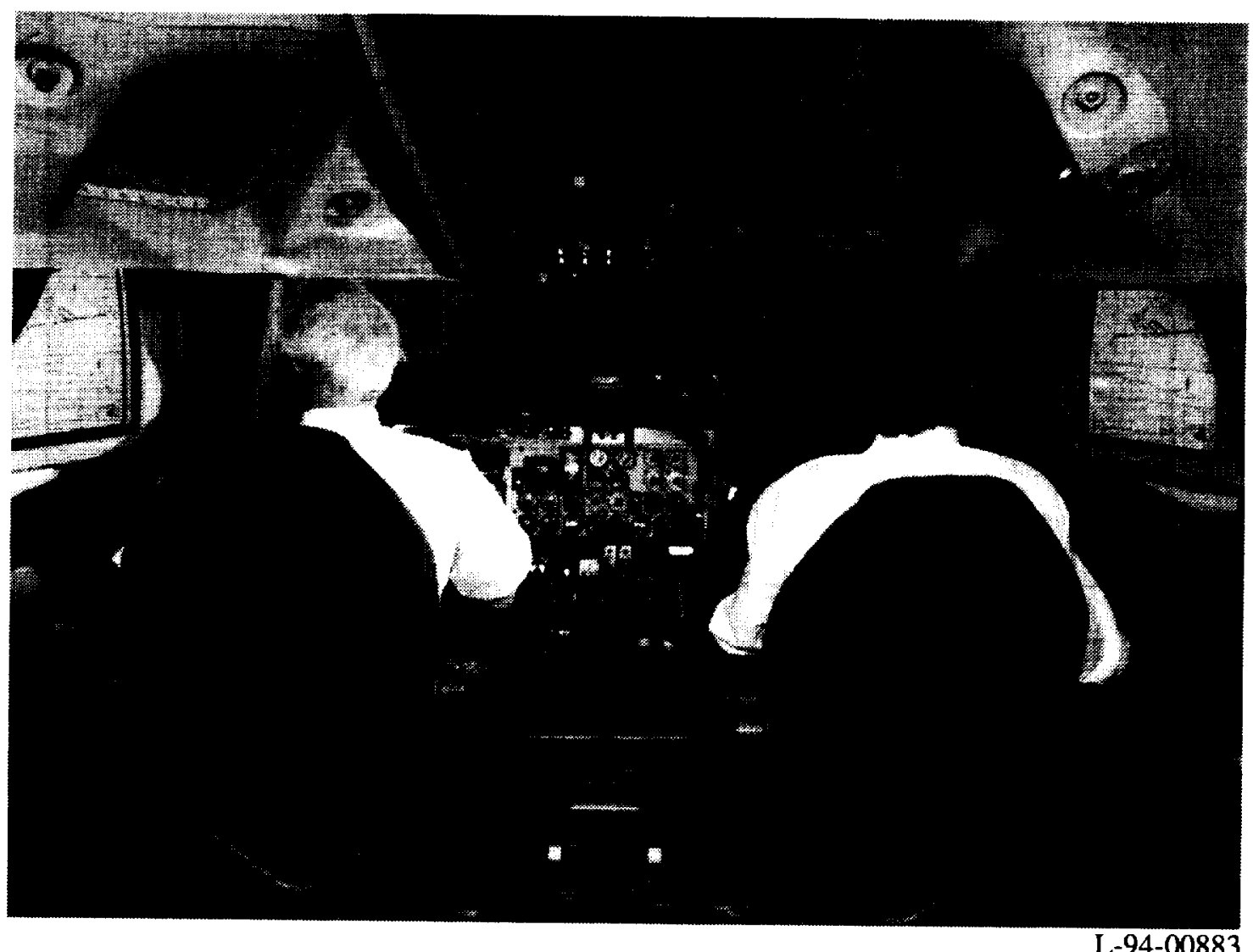

Figure 5. DC-9 simulator and MAPLIST configuration. 


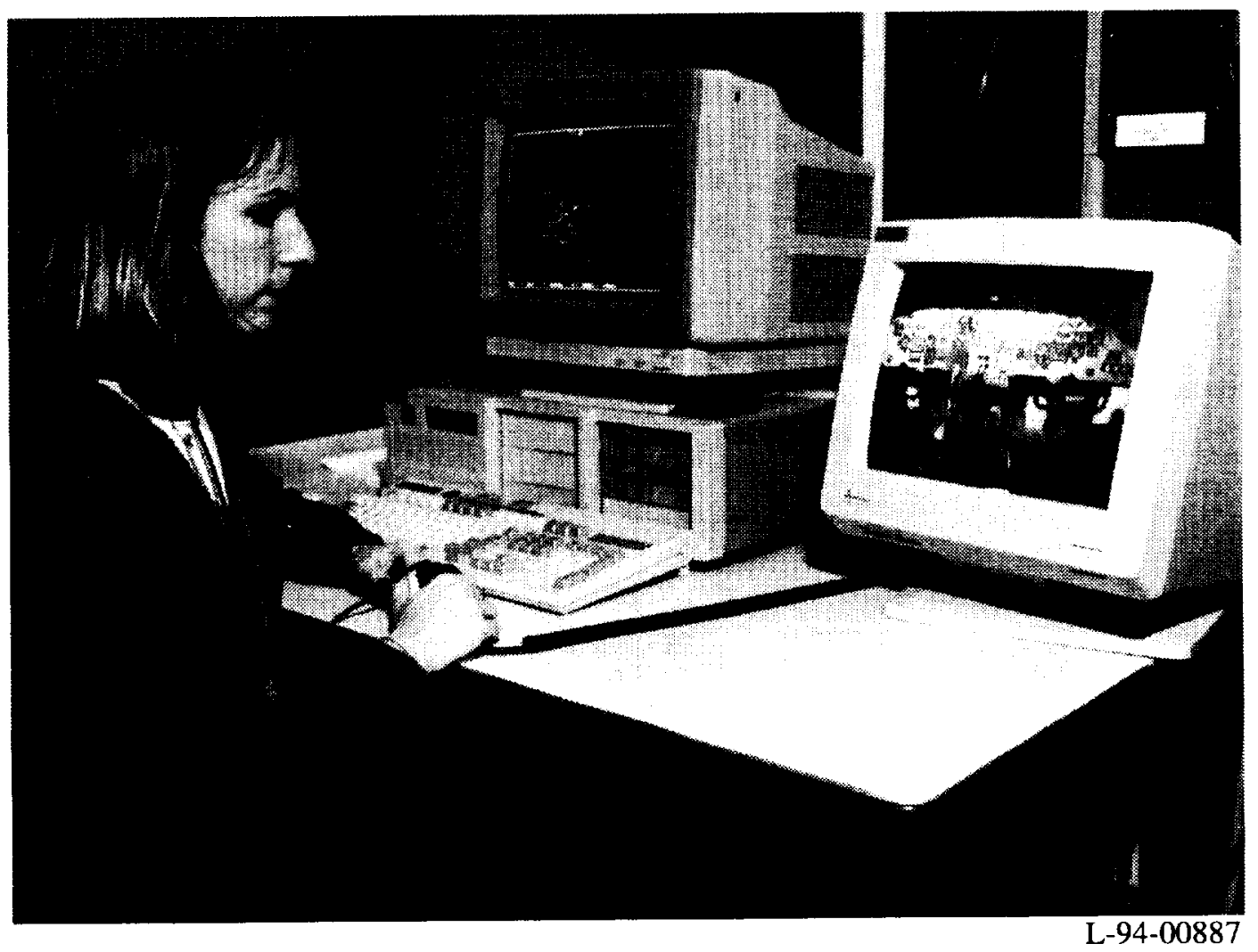

Figure 6. MAPLIST air traffic control station. 


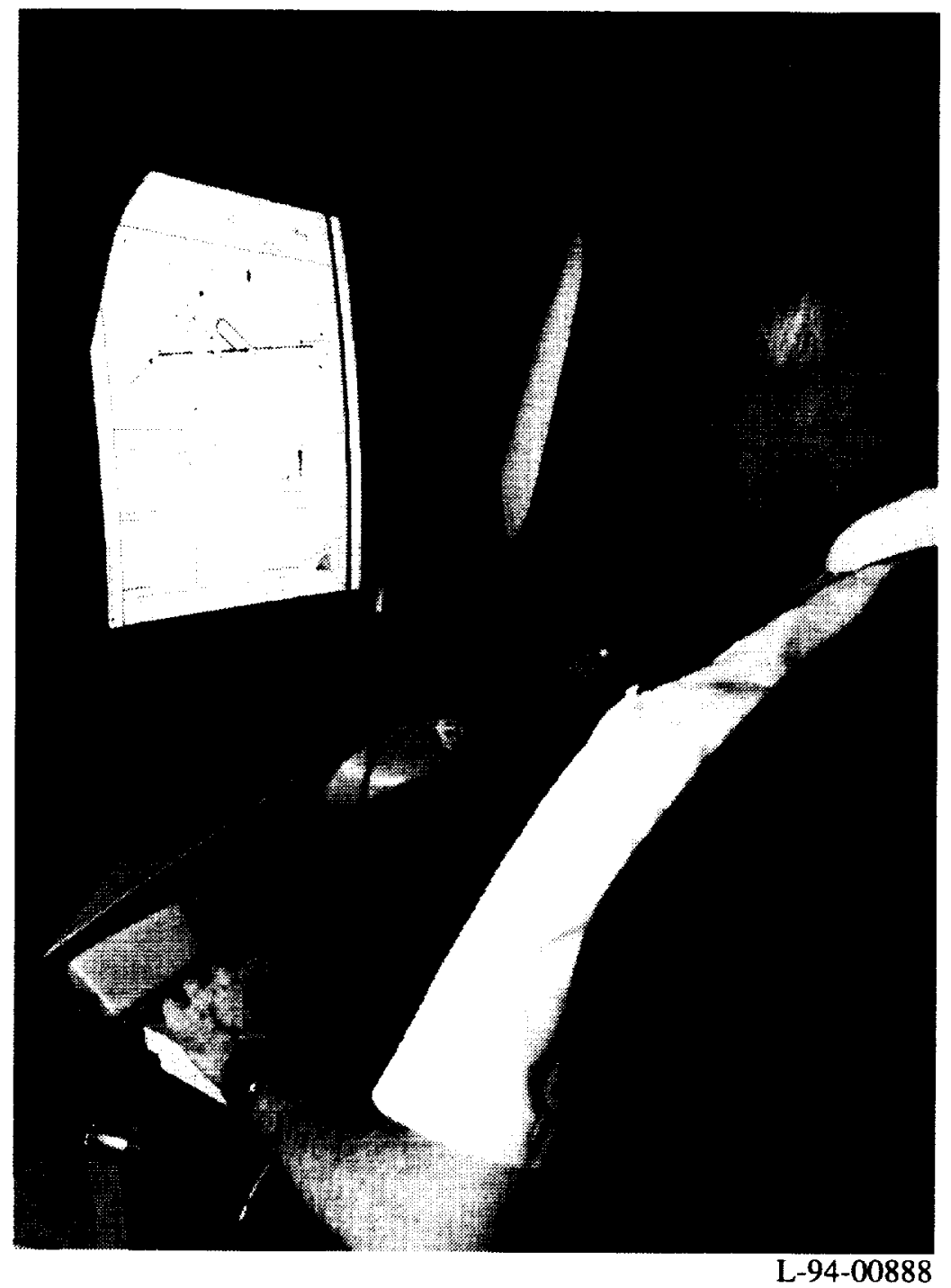

Figure 7. Pilot with MAPLIST approach chart interface. 


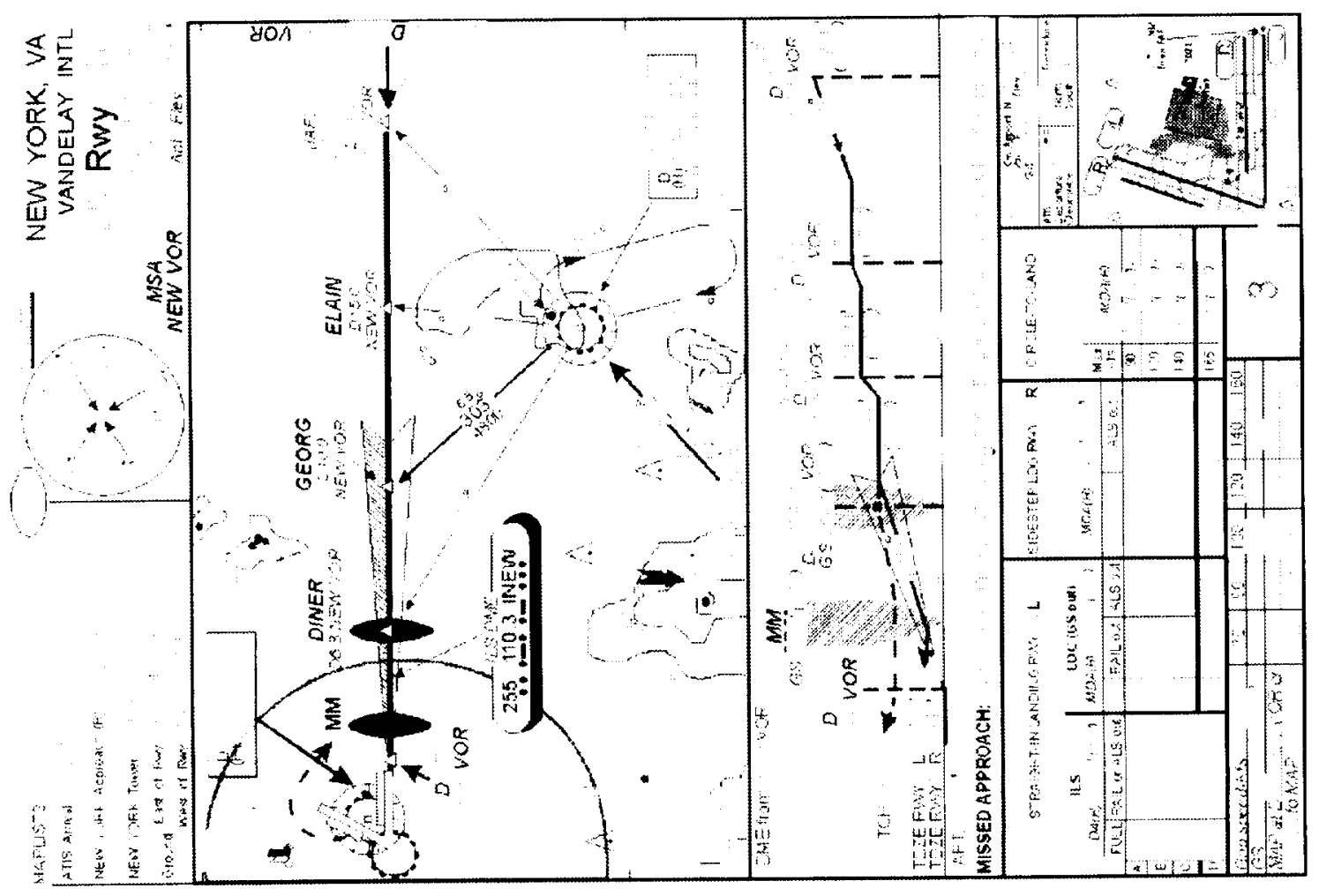

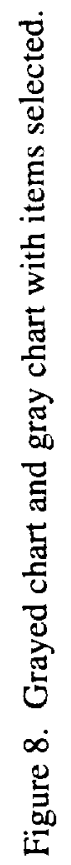

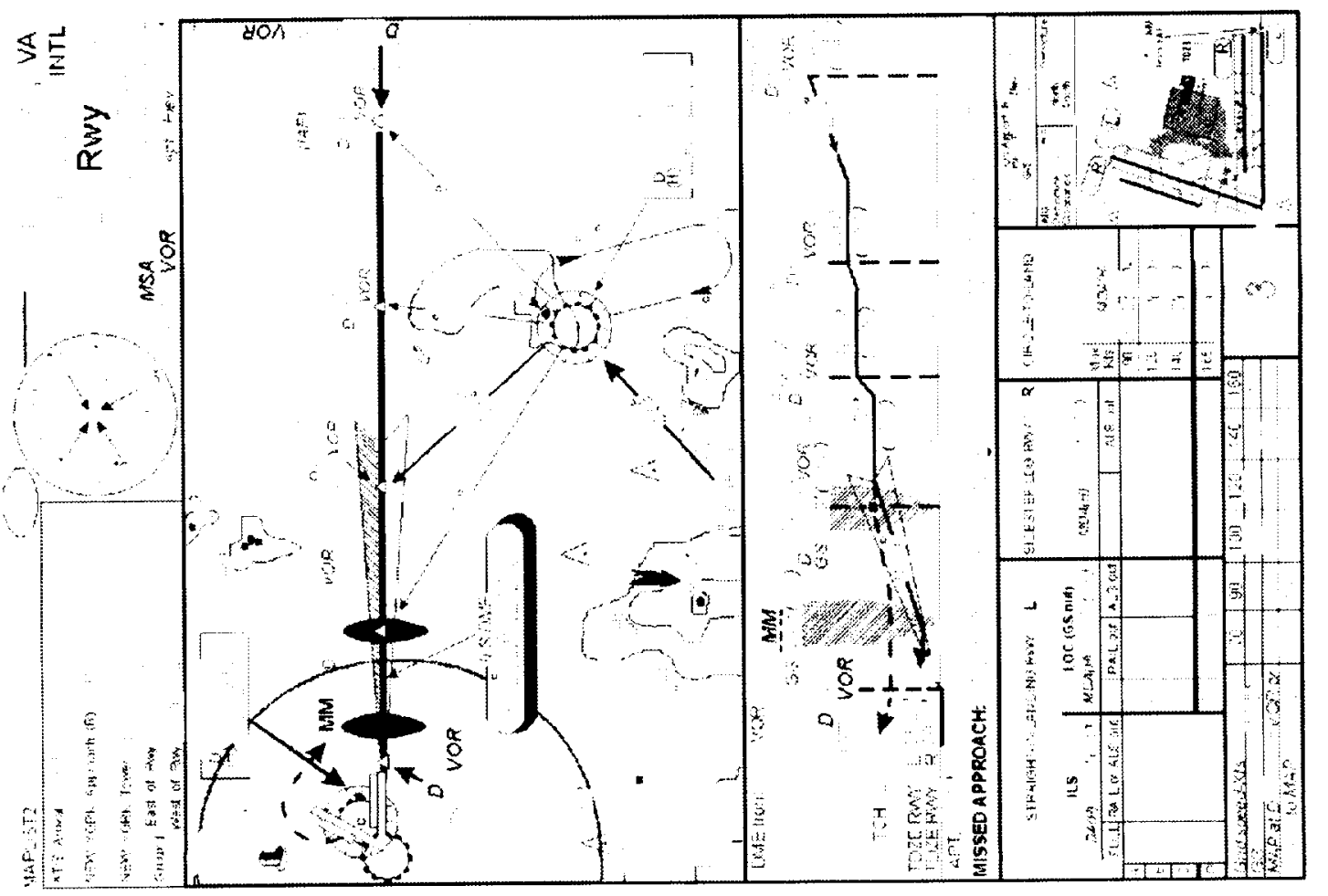


Airport departure frequency

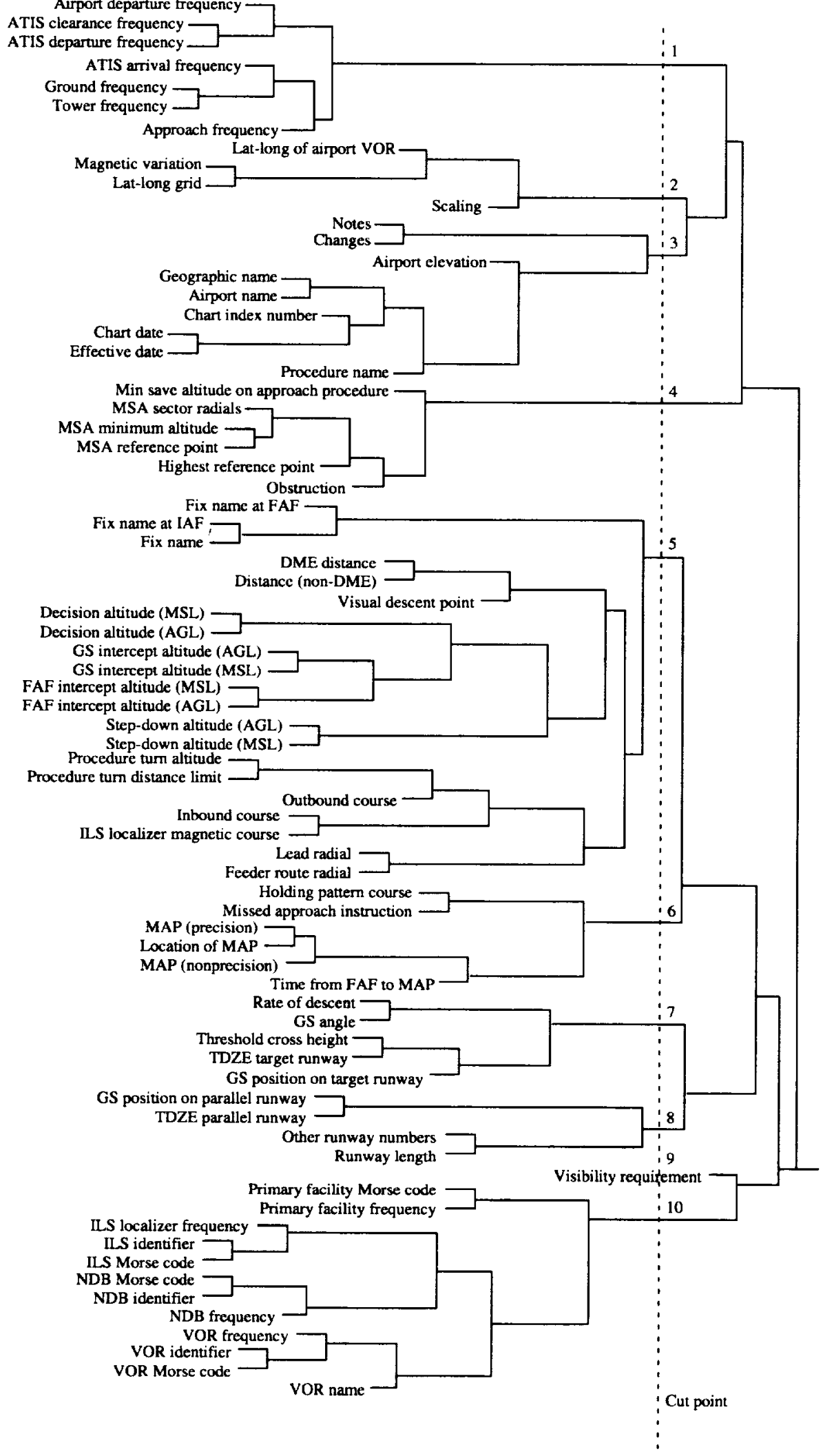

Figure 9. Dendogram of similarity ratings. 
1

\begin{tabular}{|l|}
\hline Communications \\
Airport departure freq. \\
Approach freq. \\
ATIS arrival freq. \\
ATIS clearance freq. \\
ATIS departure freq. \\
Ground freq. \\
Tower freq.
\end{tabular}

6

Missed approach

Holding pattern course Location of MAP

MAP (nonprecision) MAP (precision)

Missed approach instr.

Time from FAF to MAP
2 Geography Lat-long grid Lat-long airport VOR Magnetic variation Scaling

7

Final items

GS angle

GS pos target runway Rate of descent

TDZE target runway Threshold cross height
3

\begin{tabular}{|c|c|}
\hline $\begin{array}{c}\text { Validation } \\
\text { Airport elevation } \\
\text { Airport name } \\
\text { Changes } \\
\text { Chart date } \\
\text { Chart index number } \\
\text { Effective date } \\
\text { Geographic name } \\
\text { Notes } \\
\text { Procedure name }\end{array}$ \\
\begin{tabular}{|c|} 
Obstruction \\
Highest ref. point \\
MSA on approach proc. \\
MSA minimum alt. \\
MSA reference point \\
MSA sector radials \\
Obstructions
\end{tabular} \\
\begin{tabular}{|c|} 
Other runways \\
GS pos. parallel rwy \\
Other rwy numbers \\
Runway length \\
TDZE parallel runway
\end{tabular} \\
\hline
\end{tabular}

5 Navigation

Decision alt. (AGL)

Decision alt. (MSL)

Distance (non-DME) DME distance

FAF intercept (AGL)

FAF intercept (MSL)

Feeder route radial Fix name

Fix name at FAF

Fix name at IAF

GS intercept (AGL)

GS intercept (MSL)

ILS loc mag course

Inbound course

Lead radial

Outbound course

Procedure turn alt.

Proc turn dist limit

Step-down alt. (AGL)

Step-down alt. (MSL)

Visual descent point

10

Navigation aids
ILS identifier
ILS localizer freq.
ILS Morse code
NDB frequency
NDB identifier
NDB Morse code
Prim. fac. freq.
Prim. fac. Morse code
VOR frequency
VOR identifier
VOR Morse code
VOR name

Figure 10. Element clusters with interpretation. 
- TDZE parallel R/W

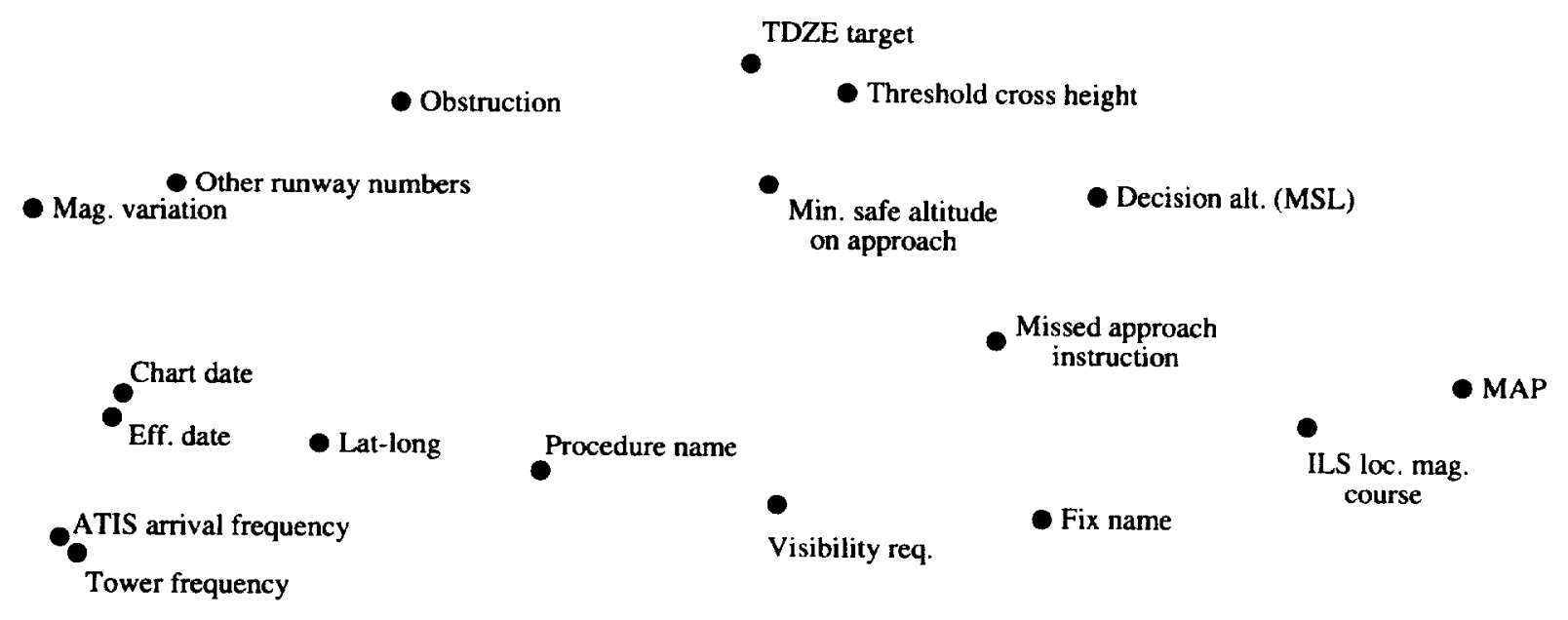

- Primary fac. frequency

- ILS loc. frequency

Figure 11. Two-dimensional MDS solution of similarity ratings. 


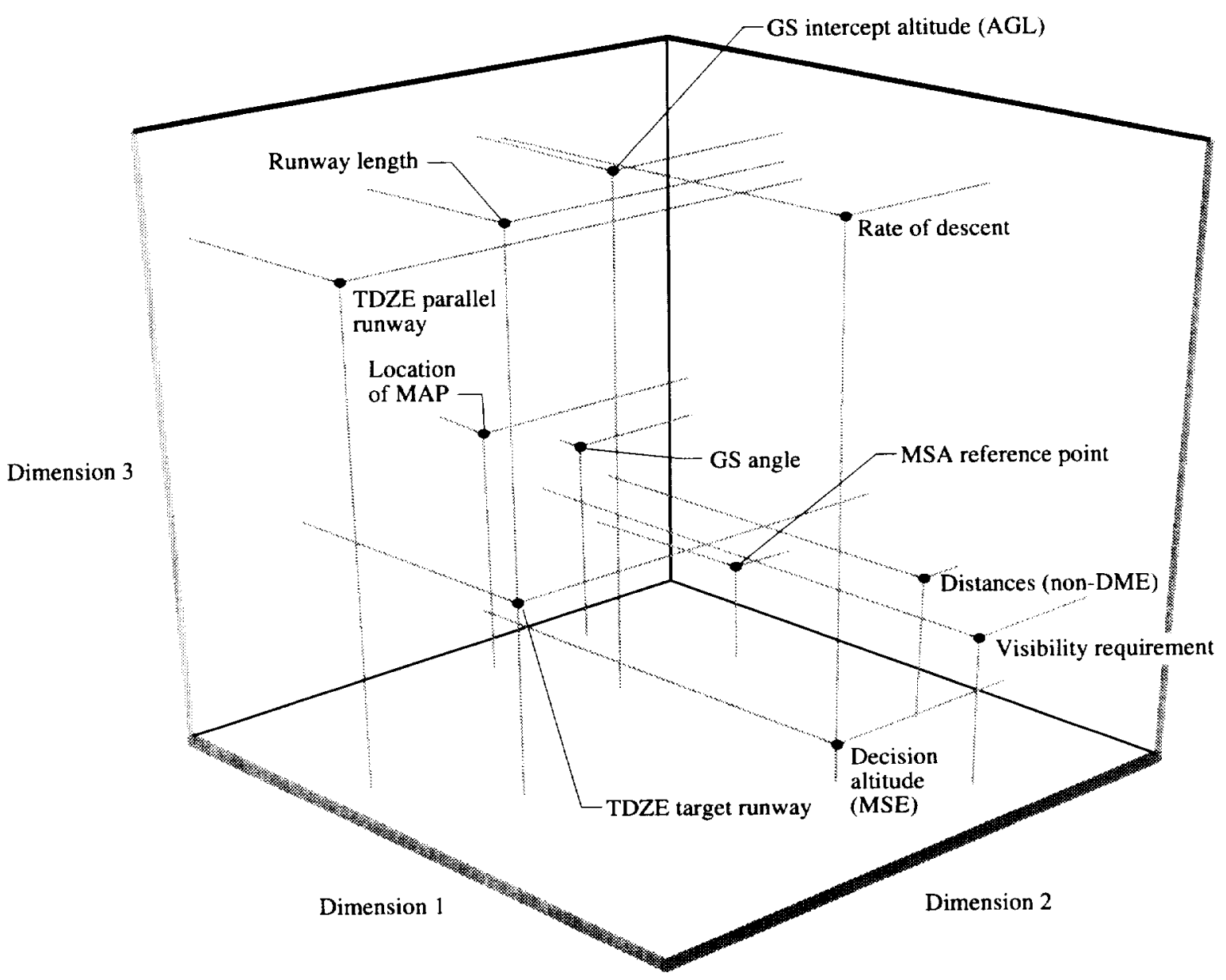

Figure 12. Three-dimensional PCPREF solution of ranking data. 

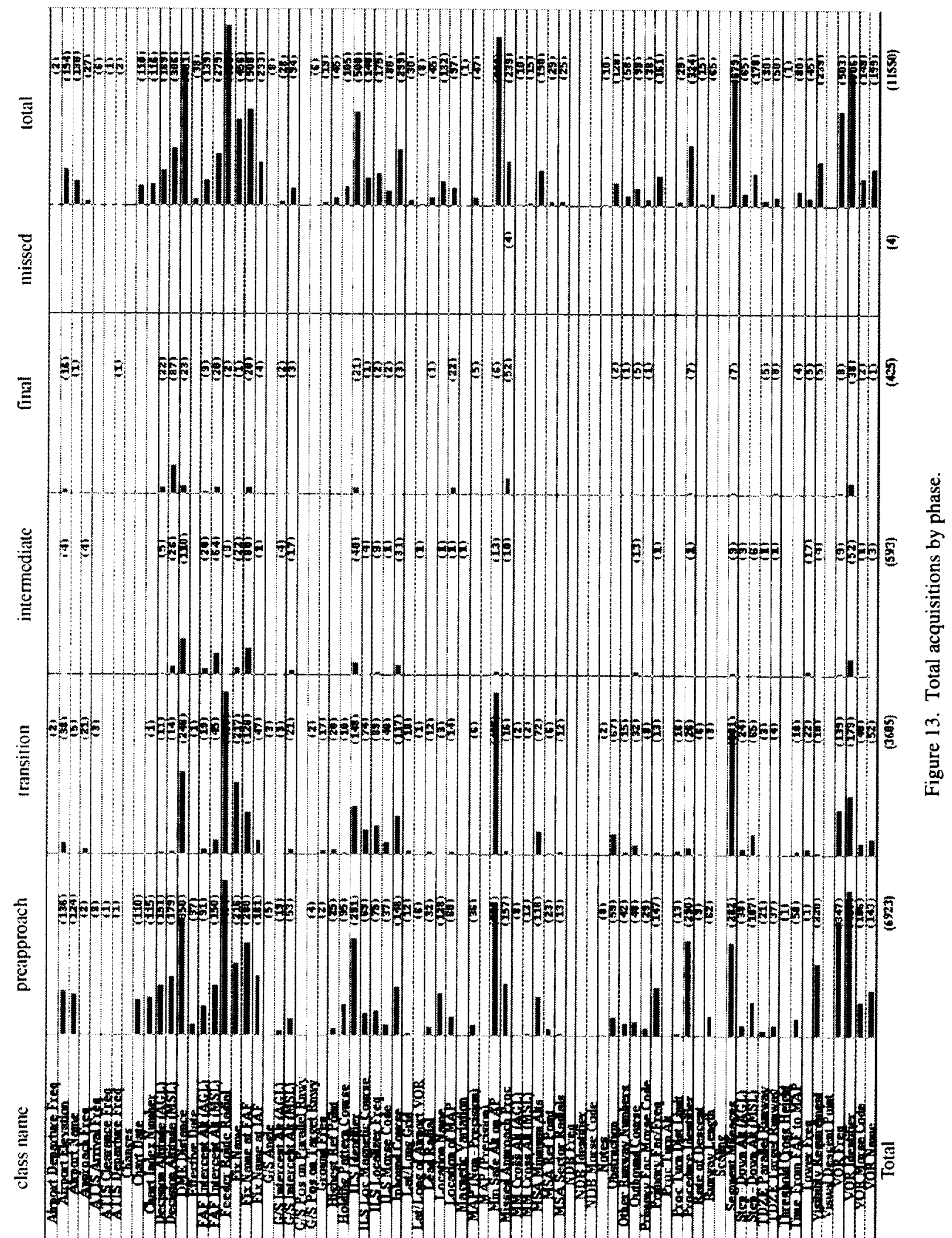


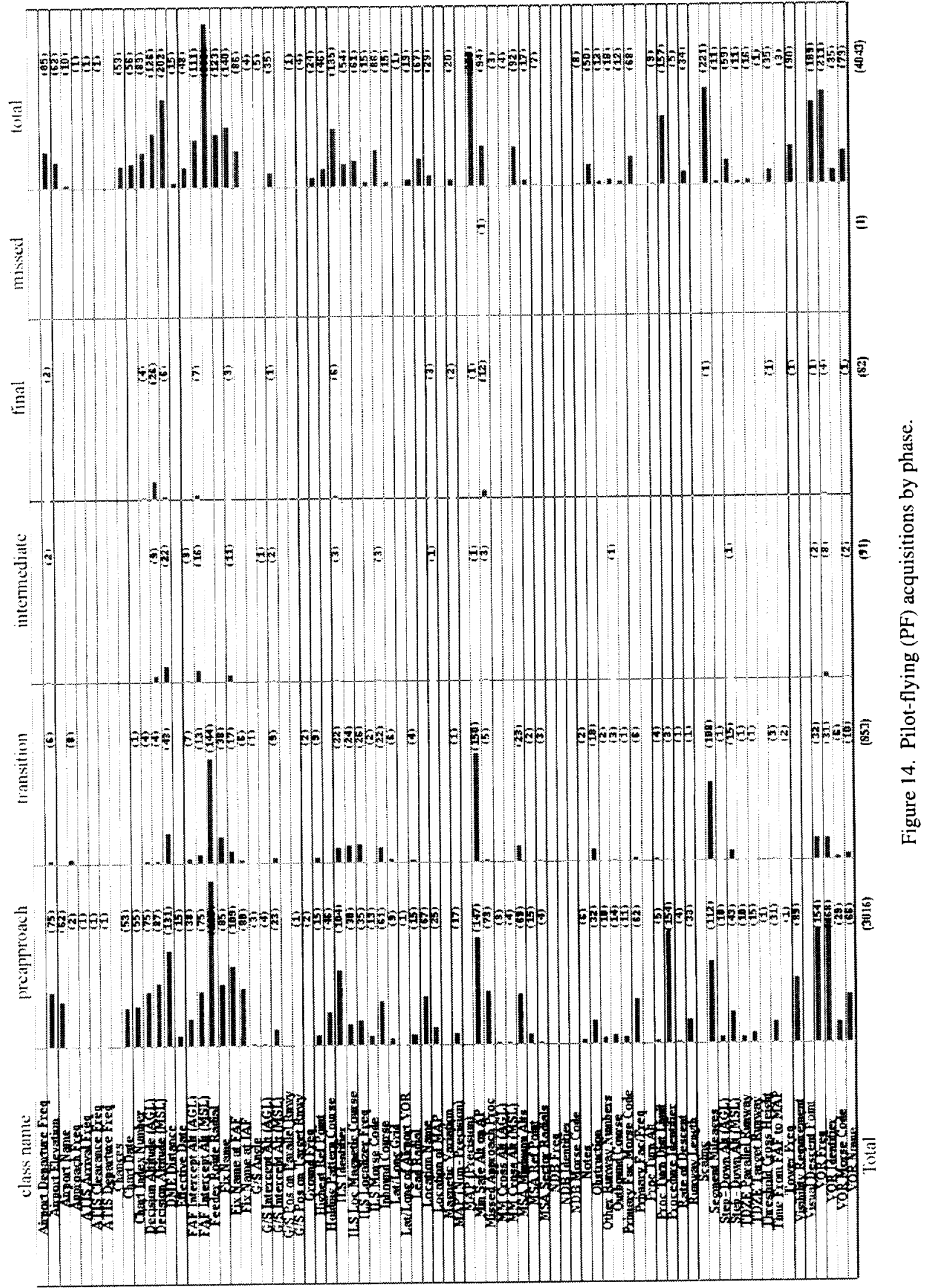




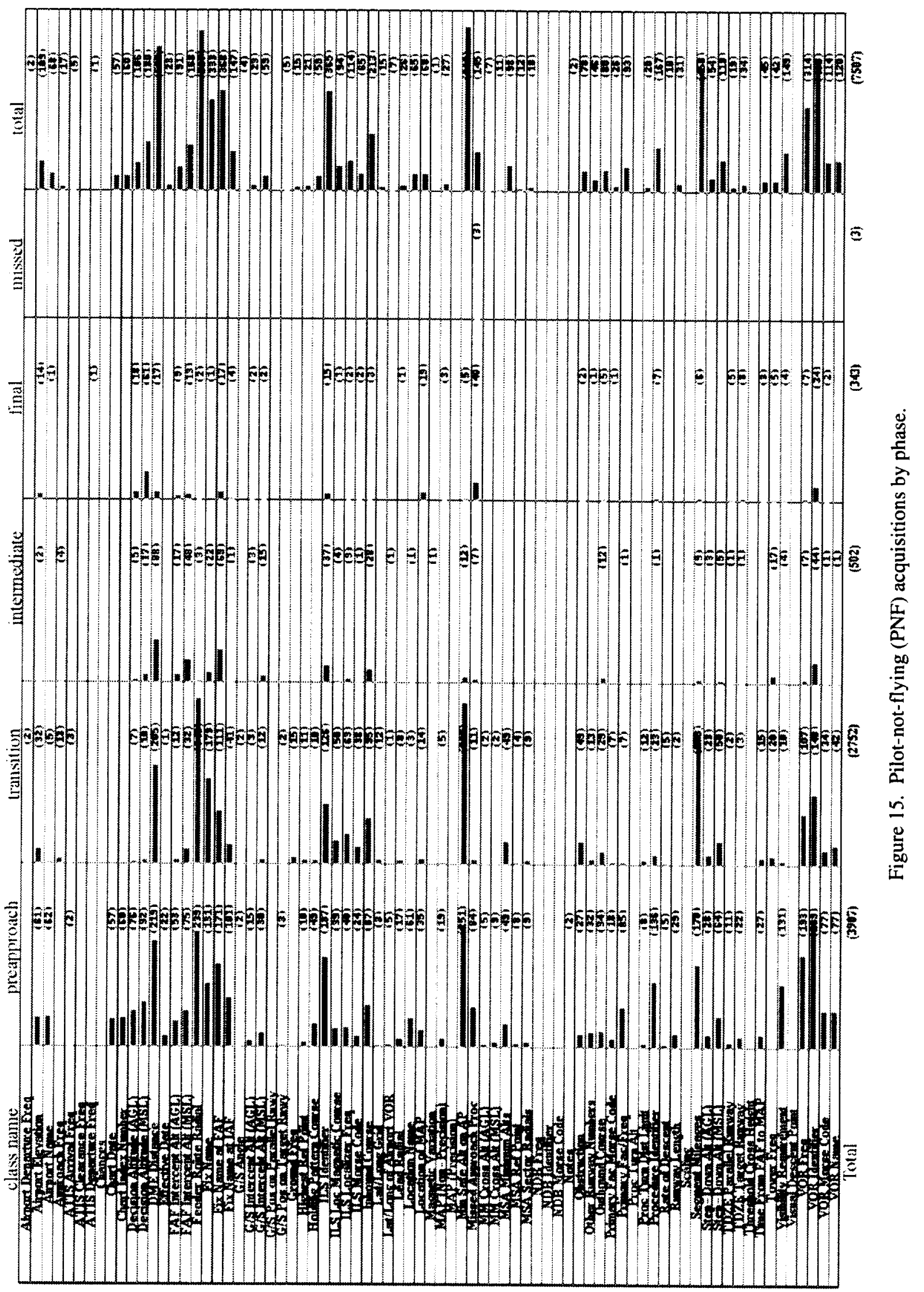




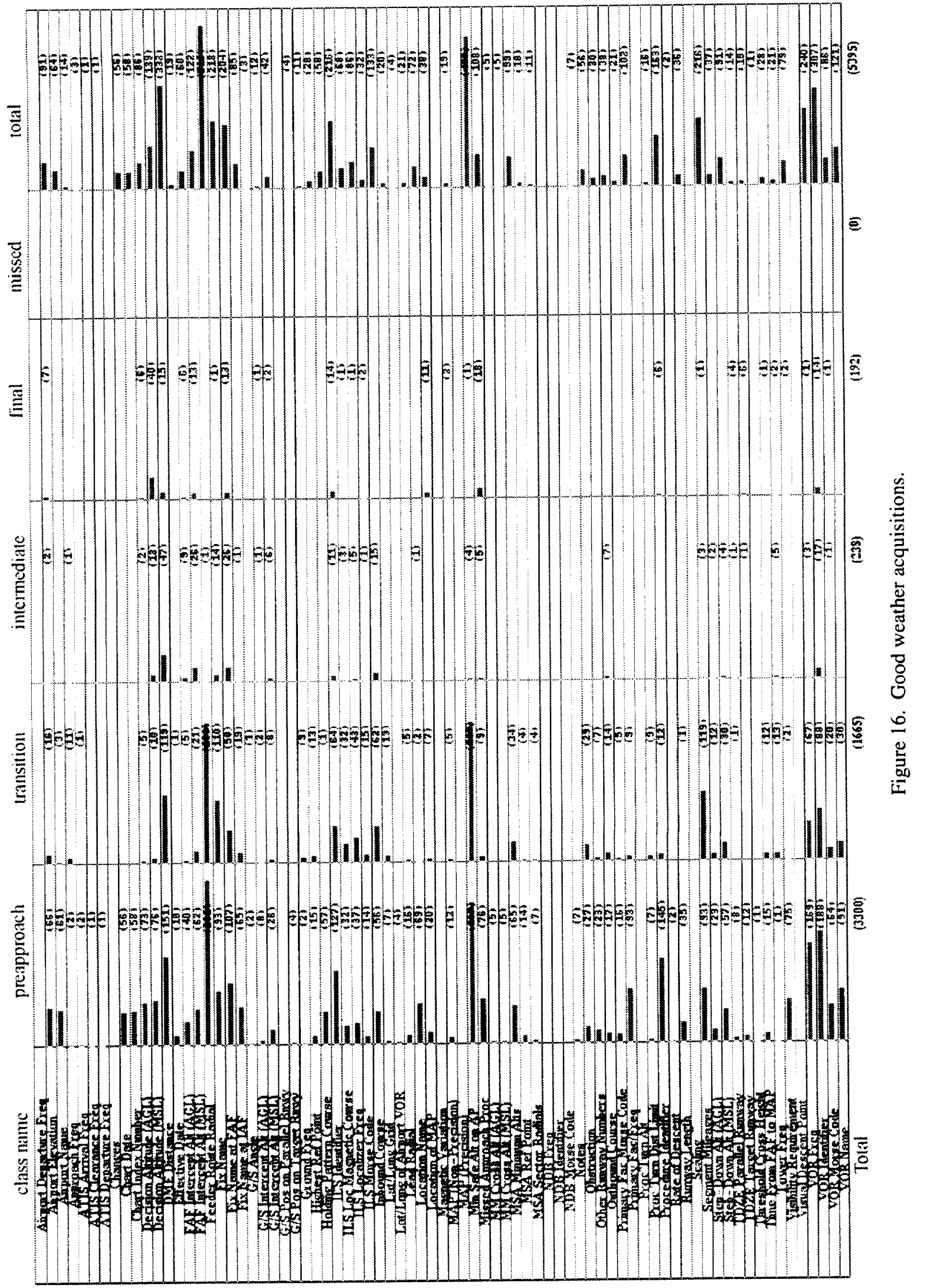



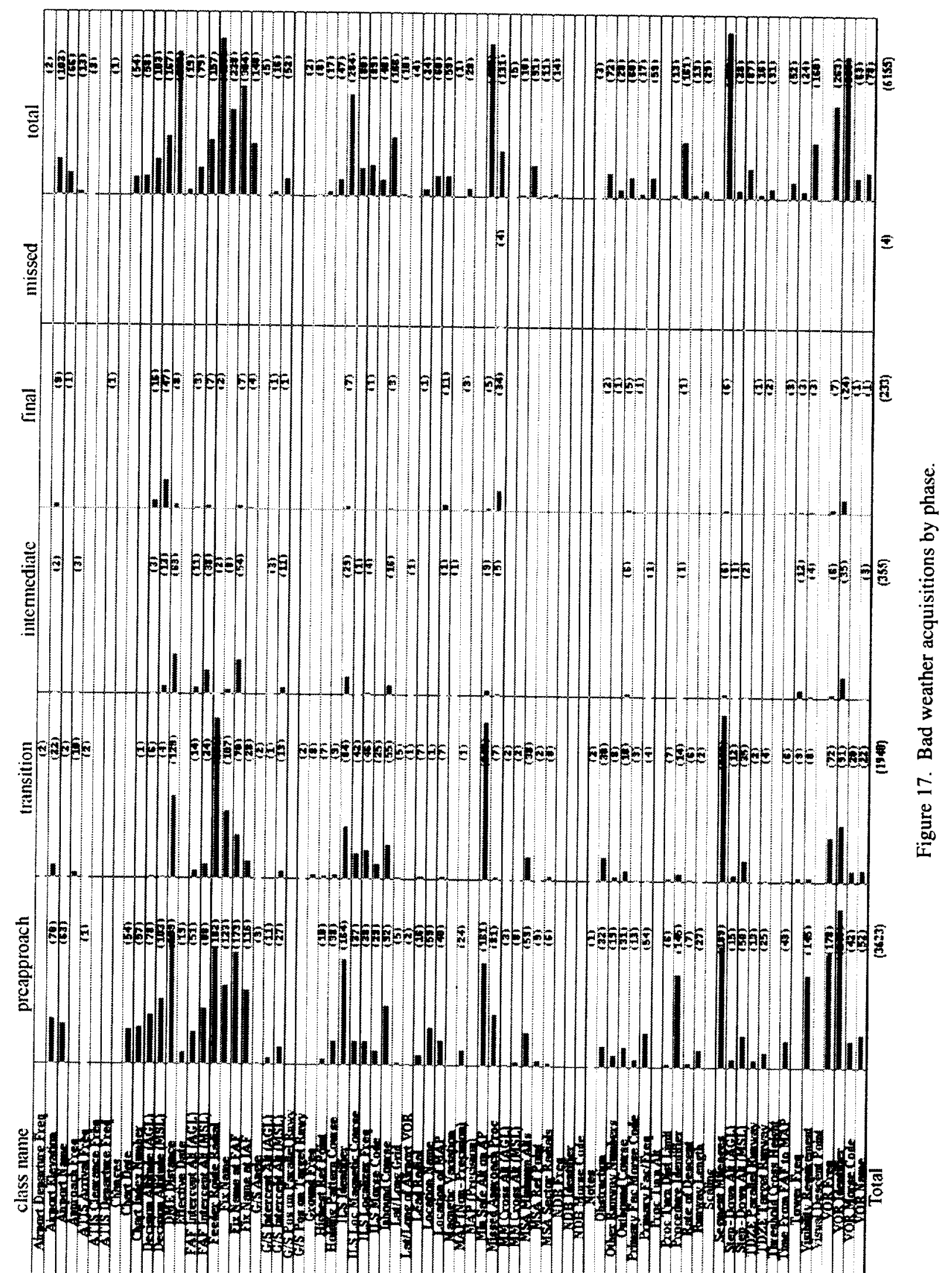


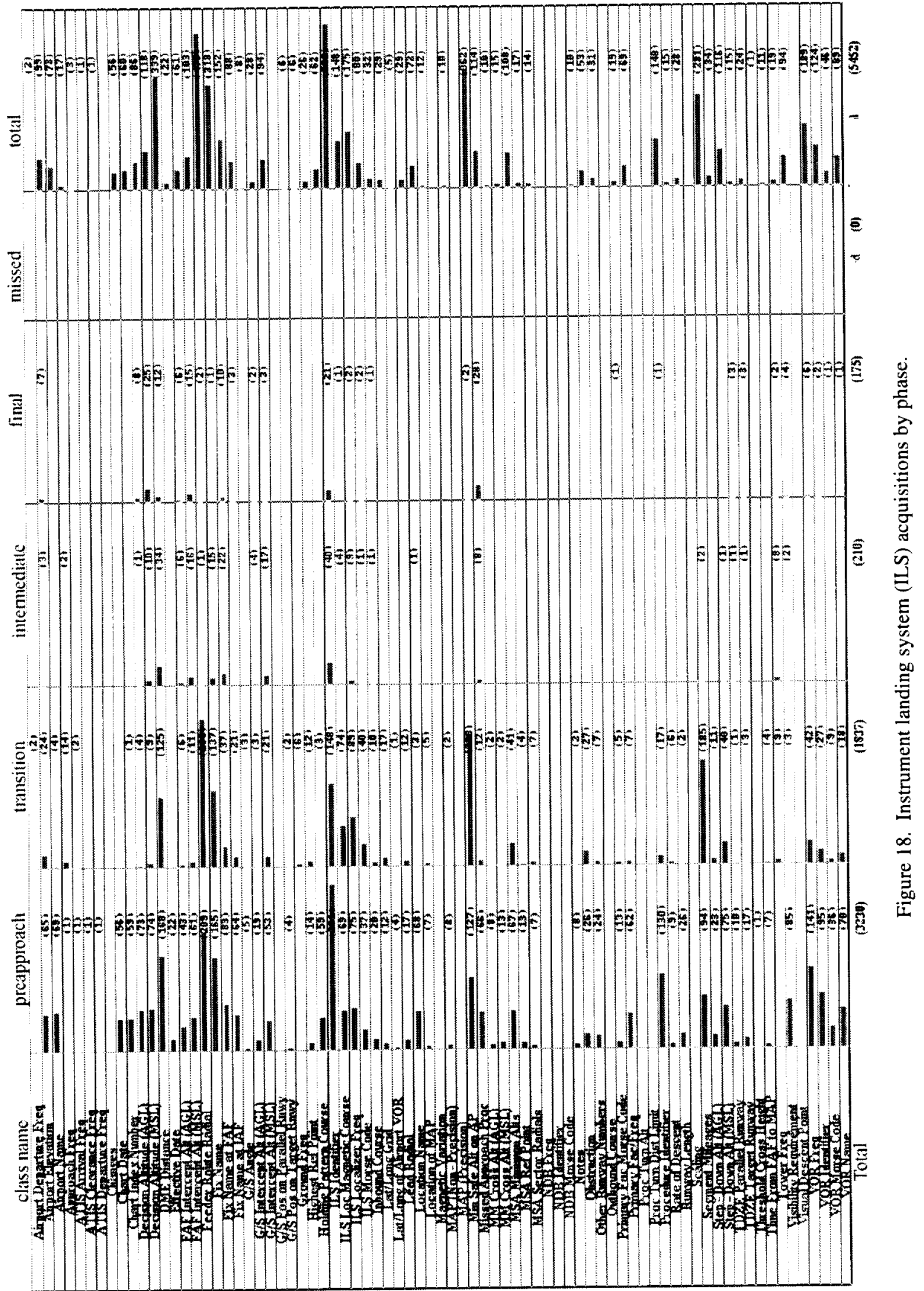




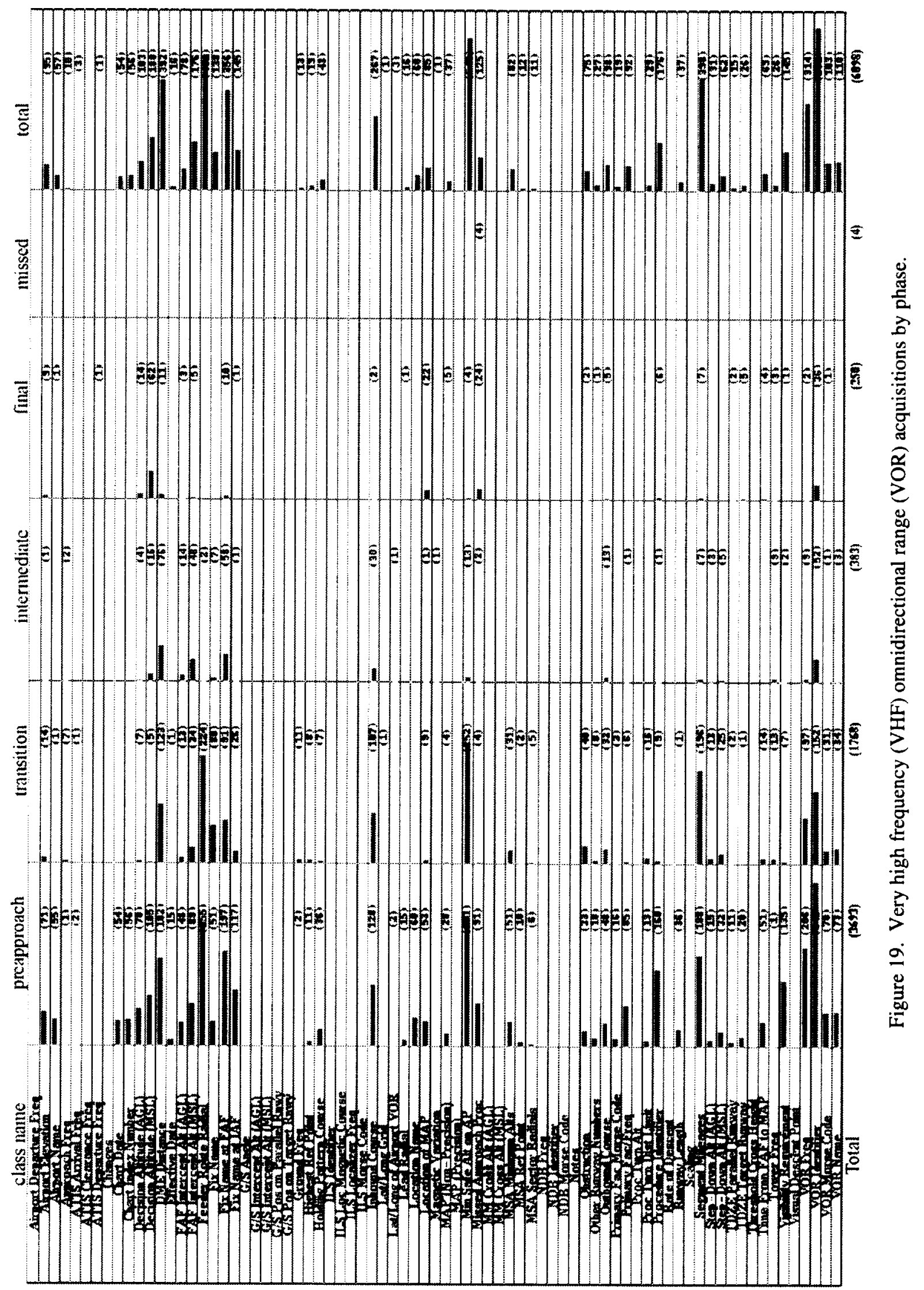




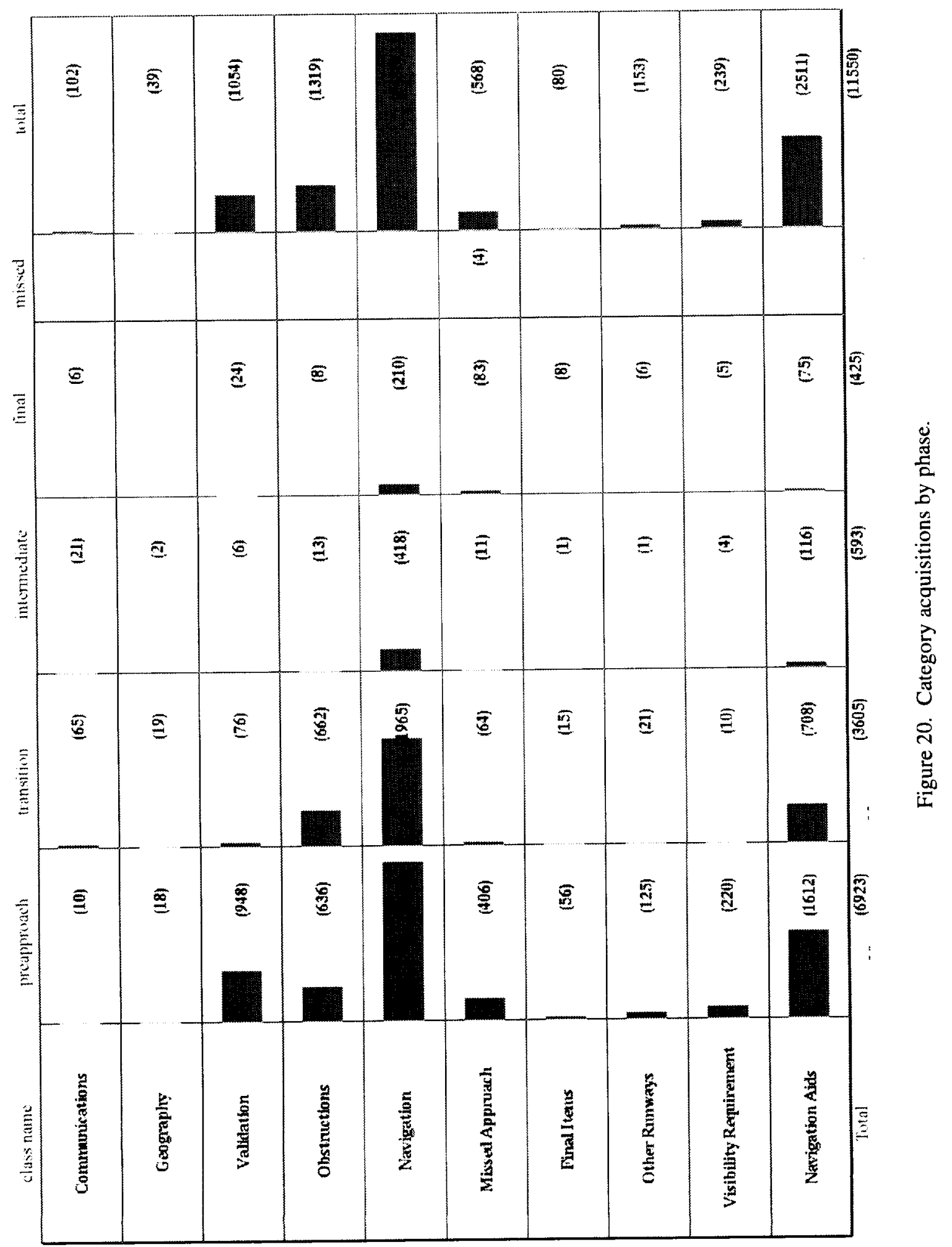




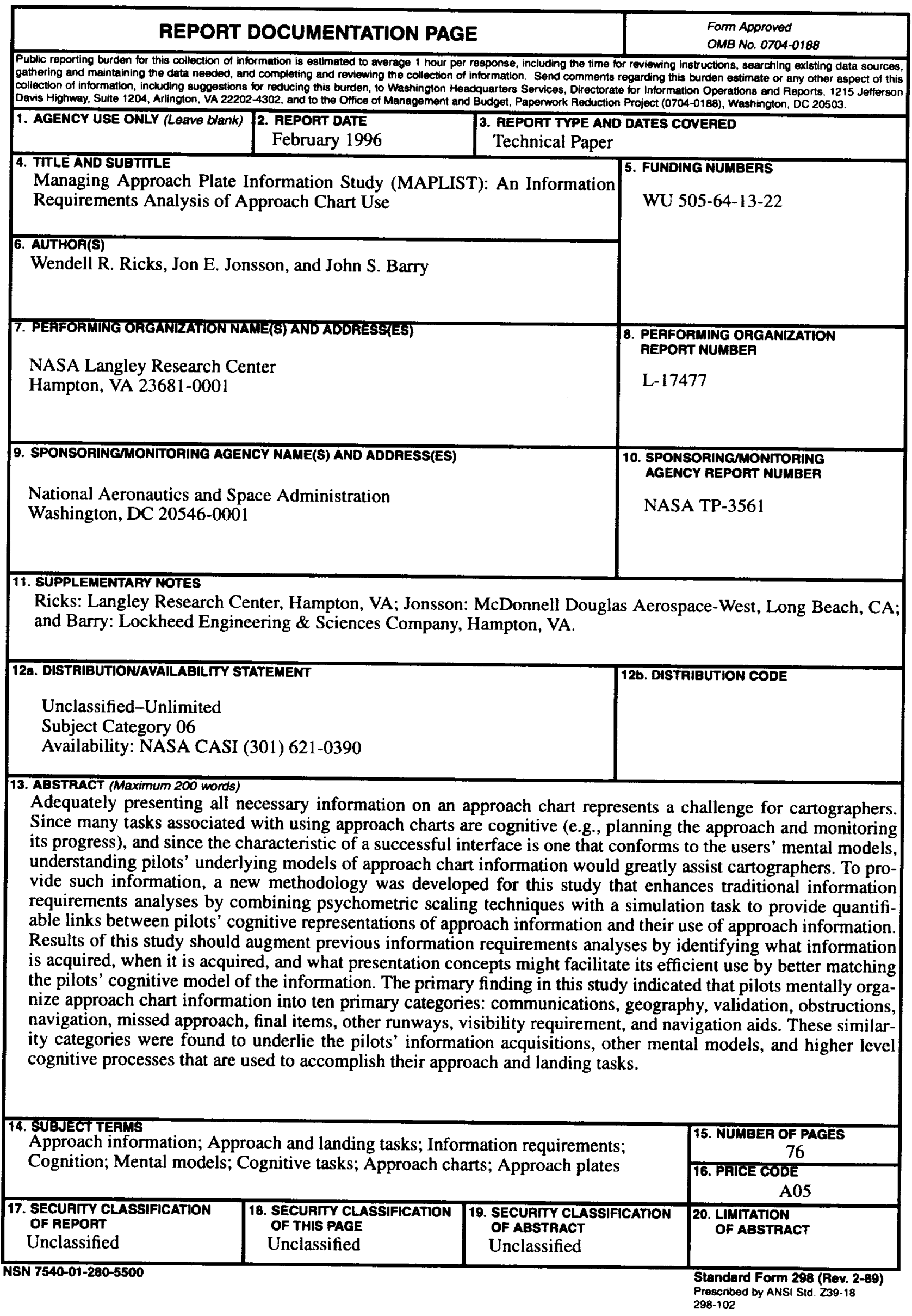





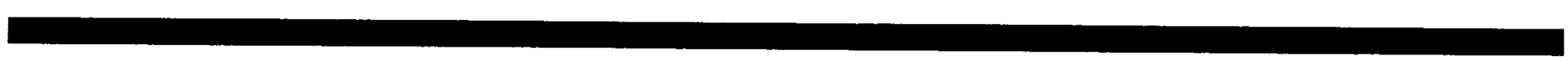

